Portland State University

PDXScholar

Spring 6-10-2014

\title{
Implications of Local and Regional Food Systems: Toward a New Food Economy in Portland, Oregon
}

Michael Mercer Mertens

Portland State University

Follow this and additional works at: https://pdxscholar.library.pdx.edu/open_access_etds

Part of the Agricultural and Resource Economics Commons, Regional Economics Commons, and the Urban Studies and Planning Commons

Let us know how access to this document benefits you.

\section{Recommended Citation}

Mertens, Michael Mercer, "Implications of Local and Regional Food Systems: Toward a New Food Economy in Portland, Oregon" (2014). Dissertations and Theses. Paper 1892.

https://doi.org/10.15760/etd.1891

This Dissertation is brought to you for free and open access. It has been accepted for inclusion in Dissertations and Theses by an authorized administrator of PDXScholar. Please contact us if we can make this document more accessible: pdxscholar@pdx.edu. 
Implications of Local and Regional Food Systems:

Toward a New Food Economy in Portland, Oregon

by

Michael Mercer Mertens

A dissertation submitted in partial fulfillment of the requirements for the degree of

Doctor of Philosophy

in

Urban Studies: Regional Science

Dissertation Committee:
James Strathman, Chair
Sheila Martin
Nathan McClintock
Madeleine Pullman
Jennifer Allen

Portland State University

2014 
(C) 2014 Michael Mercer Mertens 


\begin{abstract}
The local food movement in the Portland Metro Region of Oregon is as prevalent as anywhere in the Country. To a large degree this is driven by the Portland Metro area food culture and the diverse agricultural landscape present in the Willamette Valley and throughout the State. Portlanders demand local food and thus far the rural periphery has been able to provide it; driving a new food economy that has economic implications throughout the region. As this regional food economy emerges much attention has been focused on harnessing its power for economic development perpetuated by the belief that there exists an opportunity to foster a cluster of economic activity pertaining to the production, processing, distribution and sale of regional foods that might generate economic opportunities throughout the value chain.
\end{abstract}

The research presented here constitutes an attempt to characterize the local and regional food system that currently exists in the Portland Metro Region and to bring to light the opportunities present at the regional scale that link the agricultural periphery to the urban core. I present two different definitions of local and regional food systems and show how these different conceptions have very different implications for economic development. Once defined, I test for differences between local and regional food systems and the export-oriented, agro-food sector by analyzing aspects of geographic space and processes of knowledge accumulation and innovation in the context of aspects of regional economic 
development such as agglomeration economies, knowledge spillovers, business life cycle and industrial location.

My analysis showed that there are significant differences between local and regional food systems and the export-oriented agro-food industry specific to supply chains, actors and products of the different systems. Furthermore, through spatial analysis, I found that there are differences in terms of the spatial structure and distribution between producers who participate in the different systems. Local and regional producers tend to cluster closer together at smaller scales, are smaller in size and are found to be closer to the urban core. Through a qualitative inquiry I found that this clustering facilitates forces of agglomeration economies specific to food producers who participate in local and regional supply chains, particularly non-pecuniary effects of knowledge accumulation. This underlying structure has significant effects on economic outcomes and as such has implications in terms of regional economic development when local and regional food systems are considered in terms of the city-region. 


\section{Acknowledgements}

I would like to express my gratitude to my colleagues at Ecotrust who throughout my career have inspired me to push the envelope in developing innovative solutions to complex problems and to investigate alternative economies that benefit people and place. It is through their inspiration that I had the energy to accomplish this feat. In particular, I would like to thank Dr. Astrid Scholz, President, and Dr. Kristen Sheeran, Vice President of Knowledge Systems, for encouraging me as well as ensuring the flexibility in my work schedule to pursue and complete my Ph.D. I would also like to thank Dr. Noah Enelow for providing feedback on my quantitative analysis and my former colleague at Ecotrust, Howard Silverman, for hours of insightful and thought provoking conversations specific to this subject matter.

I am also grateful to my Dissertation Committee for their time and commitment. Specifically: Dr. James Strathman for providing encouragement and invaluable guidance throughout my entire academic process and; Drs. Sheila Martin and Nathan McClintock for their critical and insightful review of my dissertation.

Finally, I'd like to thank my wife for her patience and her meticulous (and sometimes painstaking) review of this work when she had better things to be doing. 


\section{TABLE OF CONTENTS}

ABSTRACT i

ACKNOWLEDGEMENTS ................................................................................ii

LIST OF TABLES ................................................................................................................ ix

LIST OF FIGURES

CHAPTER I: INTRODUCTION ........................................................................................1

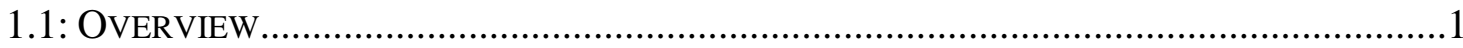

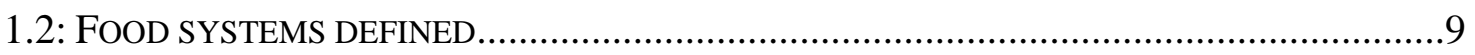

1.2.1: Evolution of local and regional food systems discourse ................................... 9

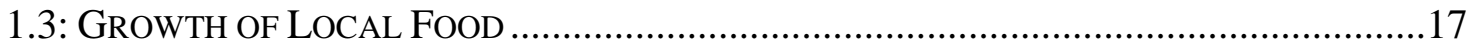

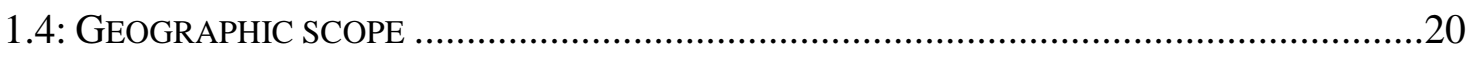

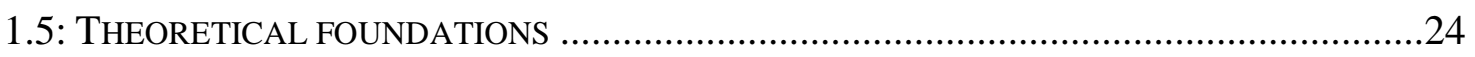

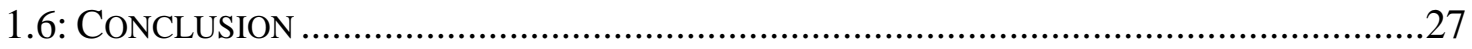

CHAPTER II: LITERATURE REVIEW ..............................................................29

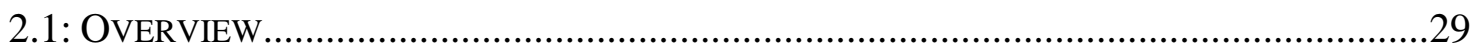

2.2: LOCAL AND REGIONAL FOOD SYSTEMS AND AGRO-FOOD RESEARCH ........................29

2.3: INSTITUTIONAL STRUCTURES AND THE GLOBALIZED AGRO-FOOD SYSTEM .................32

2.3.1: Distribution and information technology ...................................................... 33

2.3.2: Processed and manufactured foods............................................................. 35

2.3.3: Consolidation and vertical and horizontal integration ................................... 35

2.4: CONSEQUENCES OF GLOBALIZED FOOD SYSTEMS ……………...............................40

2.5: LOCAL AND REGIONAL FOOD SYSTEM STRUCTURES AND SUPPLY CHAINS .................42

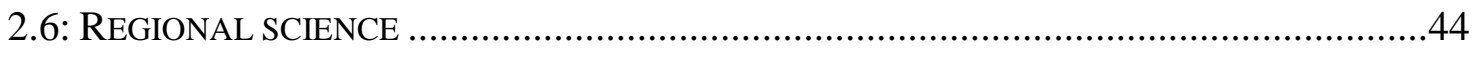

2.7: New GRowth THEORY AND AgGLOMERATION ....................................................48 
2.8: AGRO-FOOD STUDIES AND ECONOMIC DEVELOPMENT .

2.8.1: Import substitution 53

2.8.2: Multiplier effects 55

2.8.3: Benefiting regional economies by attracting outside dollars. 58

2.8.4: Local food as an amenity 59

2.9: MEASURING IMPACTS .60

2.10: CONCLUSION .64

\section{CHAPTER III: HISTORY AND PRESENT DAY STRUCTURE OF FOOD SYSTEMS IN THE PORTLAND METRO REGION} .66

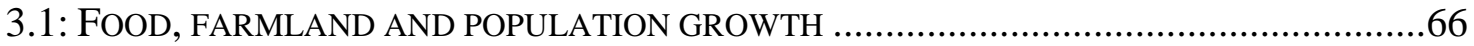

3.2: EFFECTS OF URBANIZATION ON FARMLAND STRUCTURE.....................................70

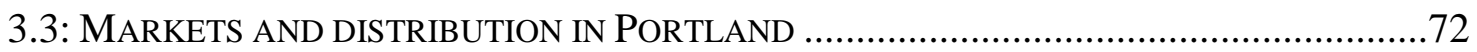

3.4: OREGON'S LAND USE PLANNING LAWS AND EFFECTS ON FOOD SYSTEMS.................75

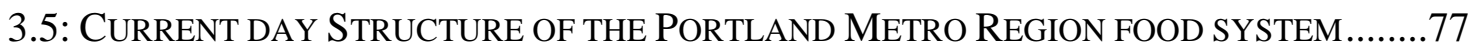

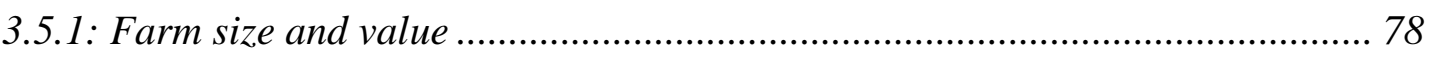

3.5.2: Value of farms, direct sales and revenue ................................................... 80

3.6: DIFFERENCES BETWEEN LOCAL AND NON-LOCAL FOOD PRODUCERS IN CLACKAMAS

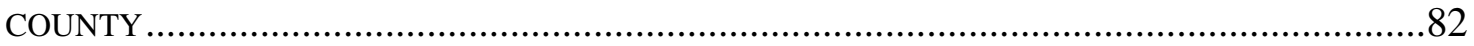

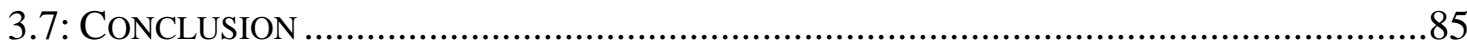

CHAPTER IV: DATA AND METHODS USED IN DESCRIPTIVE, QUANTITATIVE AND QUALITATIVE ANALYSES.........................................86

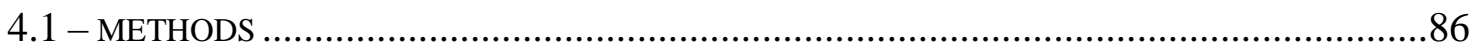

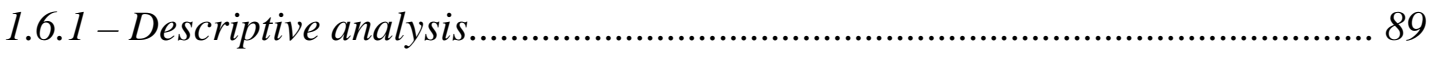

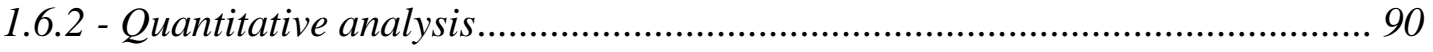


4.2: Testing the RePresentativeness of the Clackamas County Producers'

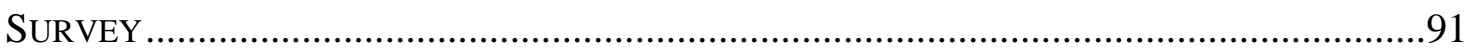

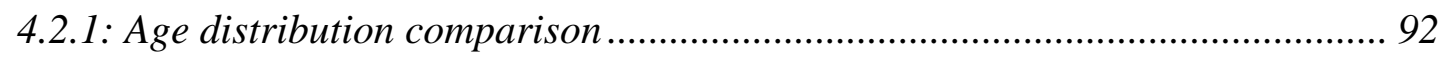

4.2.2: Comparison of the share of direct sales...................................................... 95

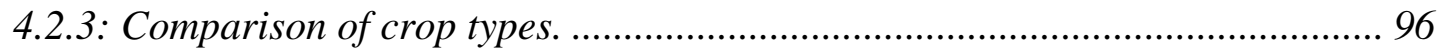

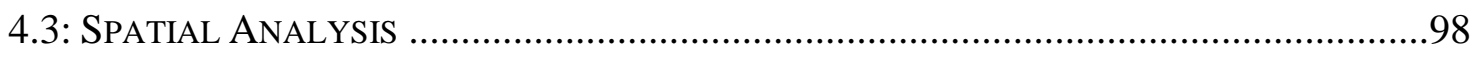

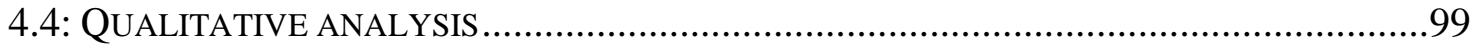

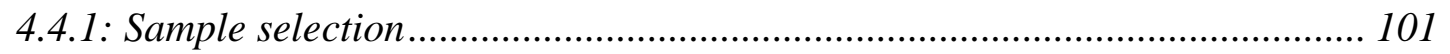

4.5: PARTICIPANT OBSERVATION ......................................................................... 102

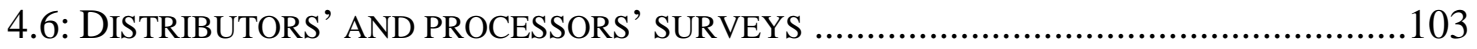

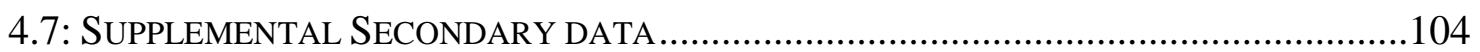

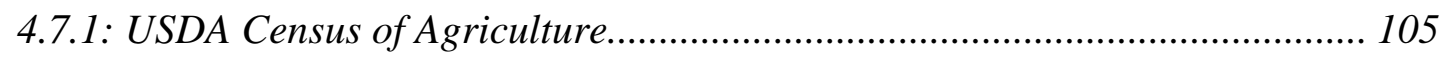

CHAPTER V: ANALYSIS OF SPATIAL DISTRIBUTION AND STRUCTURE OF

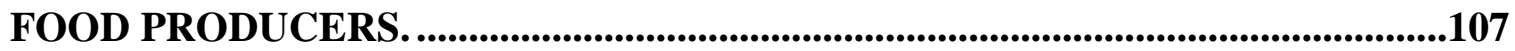

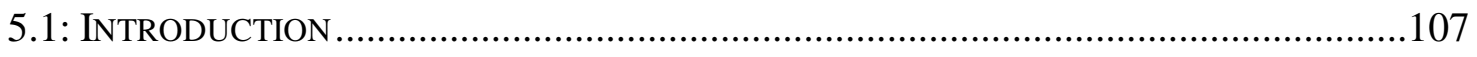

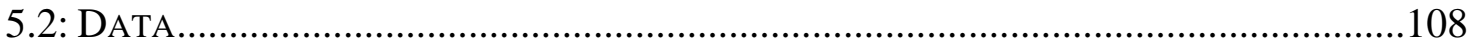

5.3: ANALYSIS OF SPATIAL CLUSTERS TO TEST FOR THE PRESENCE OF AGGLOMERATION111

5.3.1: Stage I: Using Moran's I to test spatial bias in the sample ......................... 119

5.3.2: Stage II: Measuring intra-sample spatial autocorrelation using Moran's I 122

5.3.3: Stage III: Evaluating clustering of local and non-local producers ............. 124

5.3.4: Testing for erroneous cluster effects .................................................... 128

5.4: SPATIAL DISTRIBUTION............................................................................. 132

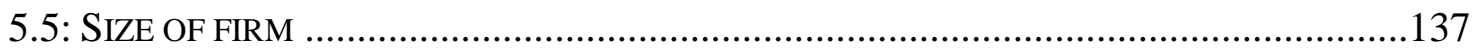

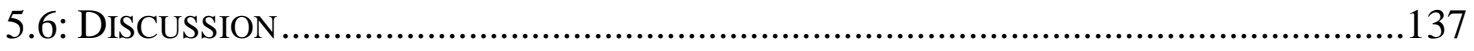




\section{CHAPTER VI: INNOVATION DIFFUSION AND KNOWLEDGE \\ ACCUMULATION OF FOOD PRODUCERS IN THE PORTLAND METRO}

REGION

6.1: INTRODUCTION 142

6.2: FORCES OF AGGLOMERATION 143

6.3: SELECTED PRODUCERS IN THE PORTLAND METRO REGION. 145

6.3: AGGLOMERATION EFFECTS 147

6.3.1: Pecuniary effects . 147

6.3.2: Non-pecuniary effects. 149

6.4: SOURCES OF AGGLOMERATION EXTERNALITIES .150

6.4.1: Connection to the urban core. 150

6.4.2: The concept of "neighbor" 151

6.4.3: Clusters 153

6.5: PROFITABILITY AND OFF-FARM EMPLOYMENT. 154

6.6: CONCLUSION .156

CHAPTER VII: POTENTIAL CONTRIBUTIONS OF LOCAL AND REGIONAL FOOD SYSTEMS TO REGIONAL ECONOMIC DEVELOPMENT. .158

7.1: INTRODUCTION .158

7.2: LOCAL AND REGIONAL FOODS AND THE CITY-REGION 162

7.3: THE NEW FOOD ECONOMY 166

7.4: FUTURE RESEARCH. 167

7.5: CONCLUSION .170

REFERENCES .176 
APPENDIX A: CLACKAMAS COUNTY AGRICULTURAL OPPORTUNITIES

ASSESSMENT: PRODUCER SURVEY QUESTIONS ................................................196

APPENDIX B: CLACKAMAS COUNTY AGRICULTURAL OPPORTUNITIES

ASSESSMENT: PROCESSOR / DISTRIBUTOR SURVEY QUESTIONS .197

APPENDIX C: SAMPLE QUESTIONS FOR OPEN ENDED INTERVIEWS WITH FOOD SYSTEM ACTORS .198

APPENDIX D: SUPPLEMENTAL ANALYSES TO SUPPORT DISSERTATION200

D.1: TESTING FOR VIOLATIONS OF REGRESSION ASSUMPTIONS IN THE TIME SERIES ANALYSIS. 200

D.2: CORRELATION BETWEEN PARCEL SIZE AND DISTANCE TO THE URBAN CORE .201

APPENDIX E: EMPLOYMENT IN FOOD RELATED ESTABLISHMENTS IN

THE THREE COUNTY REGION.....................................................................................203

APPENDIX F: AGRICULTURAL PRODUCER CHARACTERISTICS IN

CLACKAMAS COUNTY .207

F.1: FOOD GROWERS AND NON-FOOD GROWERS .208 


\section{LIST OF TABLES}

Table 1.1 Differences between global and local supply chains, actors and products

Table 2.1 Top retail establishments sales 2004-2012 (\$1,000)

Table 3.1 Parameter estimates for predictors of proportion of small farms

Table 3.2 Number of farms by size class

Table 3.3 Acres by farm size class

Table 3.4 Farm value by value class

Table 3.5 Sales by crop and proportion of direct sale for the Three County Region.

Table 3.6 NAICS codes used to determine food system employment

Table 3.7 Regional food system employment by sector

Table 4.1 Methods for testing research hypotheses

Table 4.2 Share of number of farms that market directly

Table 4.3 Proportion of farms of different crop types under production (Census v. Survey comparison)

Table 4.4 Proportion of acres of different crop types under production (Census v. Survey comparison)

Table 5.1 Sample size for spatial variables considered

Table 5.2 Moran's I at different distance thresholds for Stage I analysis

Table 5.3 Proportion of variables within significant local sample clusters

Table 5.4 Spatial autocorrelation of food producers at different distance

Table 5.5 Clustering differences of local and non-local food producers at 128 different distance thresholds 
Table 5.6 Impedance values assigned to road types

Table 5.7 Urban core neighborhoods

Table 6.1 Interviewee characteristics

147

Table 6.2 Parameter estimates for the relationship between off farm

155 employment and urbanization

Table 6.3 Agglomeration externalities realized by different producer types 


\section{LIST OF FIGURES}

Figure 1.1 Conceptual model of the food system 11

Figure 1.2 Map of Portland Metro Area and the Three County Region 21

Figure 1.3 Map of Clackamas County Agricultural and Food Production 24 Lands

Figure 3.1 1884 plat map showing Downtown Portland and close in $\quad 68$ agricultural lands

Figure 3.2 Portland population growth, 1850 to 1910

$\begin{array}{lll}\text { Figure 3.3 Yamhill Street Market (circa 1919) } & 73\end{array}$

$\begin{array}{lll}\text { Figure } 3.4 & \text { Portland Public Market (circa 1933) } & 75\end{array}$

$\begin{array}{lll}\text { Figure 4.1 Graphical representation of the four phase approach } & 87\end{array}$

Figure 4.2 2002, 2007 and predicted 2007 census age distribution 93

Figure $4.3 \quad 2002,2007$ and predicted 2011 census age distribution $\quad 94$

Figure 4.4 Proportional age class comparison between the 2011 predicted 95 Census of Agriculture and Survey respondents

Figure 5.1 Differences between conceptualization methods for testing 118 spatial autocorrelation

Figure 5.2 Map of locally significant clusters within the spatial sample 121

Figure 5.3 Map of locally significant clusters using a $1 / 2$ mile distance 126 threshold

Figure 5.4 Map of locally significant clusters using a three mile distance 127 threshold

Figure 5.5 Influence of sample size on the stability of distance thresholds

Figure 5.6 Map of travel times to the urban core 136

$\begin{array}{lll}\text { Figure } 6.1 \quad \text { Causes of agglomeration } & 144\end{array}$ 


\section{CHAPTER I: INTRODUCTION}

\section{1: OVERVIEW}

There has been a recent explosion of interest in the concept of local and regional food systems as an alternative to the globalized agro-food sector both here in the Pacific Northwest as well as throughout North America and Europe. Evidence of this emerging popularity of more local forms of food production and consumption can be seen by both the increase in alternative outlets such as farmers markets, CSAs and restaurants touting local ingredients as well as institutional support such as farm to school programs and other public sector procurement policies. So too has there been an explosion in research pertaining to alternative food structures because, to a large degree, the many problems associated with the industrialization of food chains are becoming apparent (Watts et al. 2005).

This recent rise in the prevalence of local and regional foods has been presented by many as a means to resist the globalized agro-food structures (Hendrickson et al. 2001; Hendrickson and Heffernan 2002; Allen et al. 2003; Hinrichs 2003; Selfa and Qazi 2005). Primary themes highlighted in the literature of alternative food systems include embeddedness, authenticity, quality and shortened supply chains. Localization therefore has been a natural extension of these themes in that "local" represents spaces for resistance to the global system (Hendrickson and Heffernan 2002). And while the social and environmental benefits are not explicit outcomes of localizing food supply chains, the concept of localization often is seen as a panacea for all of the consequences of the 
globalized system (Morris, Buller 2003). In addition, as an alternative to the social and environmental failures of the globalized system, some scholars attest localized food systems offer economic development opportunities that can be attributed to defensive localism and import substitution (Bellows and Hamm 2001; Winter 2003; Swenson 2009). Yet, while the idea of local foods as an economic driver is clearly capturing the imagination of a wide range of actors, much of the activity surrounding the issue exists at the level of advocacy rather than in relation to empirical research that evaluates the extent and impact of the sector on regional economies (Morris, Buller 2003).

In a 2013 special edition of "Journal of Agriculture, Food Systems, and Community Development" that focused on research priorities, Boys and Hughes identify the need for a better understanding of the regional economic benefits resulting from local food systems particularly in terms of inter-firm networks that are formed through agglomeration, firm clustering, and ultimately regional competitiveness and a means of benefit generation through backward and forward supply-chain linkages. Highlighting these research priorities, the authors point out that to date, little research or evidence has been produced that draw from these analytical frames to support the thesis that local and regional food systems actually do offer an opportunity for economic development. The lack of evidence about the existing structures within the local and regional food sector in terms of their impact on regional economies is a primary motivation behind the research presented here. 
The research pertaining to economic development opportunities associated with localized food systems that does exist stems primarily from the rural development / re-structuring paradigm. For example Marsden et al., (1999), Ross et al. (1999), Marsden et al. (2000), Hinrichs (2003), Winter (2003), and Ikerd (2005) have all suggested that expansion of local foods may be a development strategy for rural areas, particularly those areas that have experienced negative effects of globalization. And while many scholars have highlighted the importance of local food systems to regional economies (Feenstra 1997; Trobe 2001; Renting et al. 2003; Star et al. 2003; Bhatia and Jones 2011), few have sought to exploit recent theoretical frames advanced by researchers from the fields of economic geography and regional science; the fields most concerned with regional economic development. The concept of local and regional foods as a regional development strategy and, by extension, the analysis of regional food systems in the context of the city-region, present a unique theoretical lens of which new insights into the factors that influence the emergence of such systems can be examined. Disciplines that evaluate the influence of location and distance on economic activity are uniquely suited to assess local food systems and the policies that affect them (Boys and Hughes 2013). When contextualized at the regional scale, economic development takes on a different meaning. Here, aspects of agglomeration economies become important in terms of the clusters of economic activities that exist, and the diversity of industries within the region.

The research presented here draws from the disciplines of Economic Geography and Regional Science to explore how knowledge accumulation and innovation diffusion 
affect local and regional food system actors in terms of aspects of economic development. I do so as an extension of, not an alternative to, the social theory and rural development constructs outlined above. That is, the themes of embeddedness, authenticity, quality and nature when coupled with and emerging from innovative cityregions enable the emergence of the new food economy at the regional scale. In this sense I have situated my analysis in terms of the city-region economy, and investigated how a regional food system, including all of its components, distinct from that of the export oriented, agro-food industry, might contribute to that economy.

Throughout this dissertation, I use the term "the new food economy"1 rather than terms such as community food systems, sustainable agriculture, or alternative food networks as often cited in the literature. The "new food economy" conjures aspects of economic development that are not implicit in these other expressions and hence frames the epistemological approach I have applied in my analysis. That is, I use the regional economy as my unit of analysis, and while I do address other aspects of local and regional food systems such as food justice, quality and embeddedness, resistance to existing global food structures and commodity chains, concerns of environmental degradation and health implications, my primary focus is on aspects pertaining to regional economic development. Given this narrow scope, the work presented here contributes evidence upon which additional research can be built so that economic

\footnotetext{
${ }^{1}$ The "new food economy" was first coined by Winter (2001) and expanded upon by Blay-Palmer and Donald (2006) in their attempt to situate alternative food systems from a city-region and innovations perspective.
} 
development professionals, urban and regional planners and concerned stakeholders can make informed decisions specific to fostering these new food economies. Specifically, the research presented here addresses the following research questions:

Research Questions:

- How does the new food economy differ from the traditional, globalized agro-food industry?

- What are the implications of geographic space on how the new food economy emerges?

- What are the implications for regional economic development stemming from the new food economy?

In the following chapters I explore these questions through descriptive, qualitative and quantitative analyses, focusing on a key set of hypotheses grounded in the literature. Specifically I test three distinct hypotheses that together represent a dissertation of the research questions. These hypotheses are as follows:

Hypothesis 1: Local and regional food systems in the Portland region and other regions around North America and Europe can be differentiated from the export-oriented, global agro-food sector;

Hypothesis 1b: As a sector, local and regional food systems are indeed new relative to the export-oriented agro-food sector and;

Hypothesis 1c: The new food economy is growing. 
Hypothesis 2: The new food economy is subject to effects of agglomeration different than that of the global agro-food sector because it is a nascent industry.

Hypothesis 2b: We would expect this new food sector to be active in product innovations that are fostered by both "Jacobian" and "Porter" externalities (relative to the global food system that is vertically integrated, seeks out process innovations, cheap land and cheap labor) and hence;

Hypothesis 2c: We would expect this new food sector to be dominated by smaller actors clustered close together and close to the urban core.

Hypothesis 3: Based on the new economic geography and the geography of knowledge literatures, urban and regional form matter because the distribution of producers, processors, distributors and consumers will affect the benefits realized from agglomeration economies.

The above set of hypotheses stem from a unique theoretical perspective; when contextualized in terms of the city-region, perhaps these food systems can be perceived as endogenous products of the innovative output of the city-region itself. In her book The Economy of Cities (1969) Jane Jacobs posited an alternative perspective of how regions develop. She envisioned rural economies spawning from work that naturally evolved in cities rather than cities developing on the back of surplus generated by rural agriculture: 
Just as no real separation exists in the actual world between city-created work and rural work, so there is no real separation between 'city consumption' and 'rural production.' Rural production is literally the creation of city consumption. That is to say, city economies invent the things that are to become city imports from the rural world, and then they reinvent the rural world so it can supply those imports. This, as far as I can see, is the only way in which rural economies develop at all, . . . (pp 38)

This passage, while admittedly city-centric, represents a unique but critical perspective on how regions develop as well as how the growth of new systems - even agricultural systems - emerge from urban areas. It highlights the importance of linkages between the rural and urban components of a region. And when coupled with theories and methods stemming from Regional Science and Economic Geography, it becomes a unique perspective through which to analyze emergent aspects of the new food economy.

The research presented here constitutes an attempt to characterize the local and regional food system that currently exists in the Portland Metro Region and to bring to light the opportunities present at the regional scale that link the agricultural periphery to the urban core. I present two different definitions of local and regional food systems and show how these different conceptions have very different implications for economic development. Once defined, I test for differences between local and regional food systems and the 
export-oriented, agro-food sector by analyzing aspects of geographic space and processes of knowledge accumulation and innovation in the context of aspects of regional economic development such as agglomeration economies, knowledge spillovers, business life cycle and industrial location. My analysis shows that there are significant differences between local and regional food systems and the export-oriented agro-food industry in terms of supply chains, actors and products of the different systems. However, these differences are highly dependent on the very definition of local and regional food systems. And depending on this definition, there can be a significant amount of overlap between the local and regional and export-oriented systems, making quantifying effects challenging.

Furthermore, through spatial analysis, I find that there are differences in terms of the spatial structure and distribution between producers who participate in local and regional food systems relative to those that focus exclusively on exporting their products. Local and regional producers tend to cluster closer together at smaller scales, are smaller in size and are found to be closer to the urban core. Through my qualitative analysis I find that this clustering facilitates forces of agglomeration economies, particularly non-pecuniary effects of knowledge accumulation. Information flows were critical for local and regional producers and depending on the supply chain in which they participated, they accumulated knowledge in very different ways.

Finally, the contribution of local and regional food systems to regional economies is highly dependent on the definition of the systems themselves. I present two distinct 
definitions; one geographic, the other qualitative, and define theoretical rationales for understanding how the contributions of the systems as described by these two different definitions may or may not contribute to economic development at the regional scale. While I do not specifically measure the contribution of local and regional food systems to economic development here in the Portland Metro Region, I do provide the theoretical basis for why such a contribution could in fact exist.

\section{2: FOOD SYSTEMS DEFINED}

Undeniably, all of my hypotheses presented above hinge on the one underlying assumption that a local food economy is indeed different than and can be differentiated from the export-oriented, global agro-food sector at a scale of which differences in terms of economic development can be analyzed. That is, because I draw from the industry lifecycle literature, and test whether agglomeration forces affect the systems differently, it is important to understand differences in terms of the components that comprise distinct sectors of the economy that each system represents.

\subsection{1: Evolution of local and regional food systems discourse}

Much of the recent research into the agro-food system has focused on how processes of globalization contribute to the reshaping of food production processes according to patterns of capital accumulation (Murdoch, 2003). While the term "food system" is used extensively, the concept of a system is often loosely defined and not always linked with systems theory (Sobal et al., 1998). Systems theory takes a holistic perspective in 
examining system boundaries, delineating subsystems and their relationships, emphasizing process and considering relationships between systems. Systems are viewed as sets of elements that function together as collective units. The most useful conceptualizations are those that describe a food system as a chain or web of activities from production to consumption, with particular emphasis on processing and marketing and the multiple transformations of food that these entail (Ericksen, 2008)

In fact, the modern day food system is a highly complex web of services and activities that has gone through dramatic transformation over the last century, with different products experiencing dramatically different flows through the system. Figure 1.1 represents the core food system components and product flows of the present day food system. The blue arrows represent some form of distribution. Many components actually may function on multiple tiers of the model depending on supply chains and integration of participating firms (e.g., many vertically integrated food retailers have systems in place that capture the procurement mechanisms within the system such as distribution, aggregation and in some cases even processing). Omitted from this model are aspects of food management, safety and waste management. 


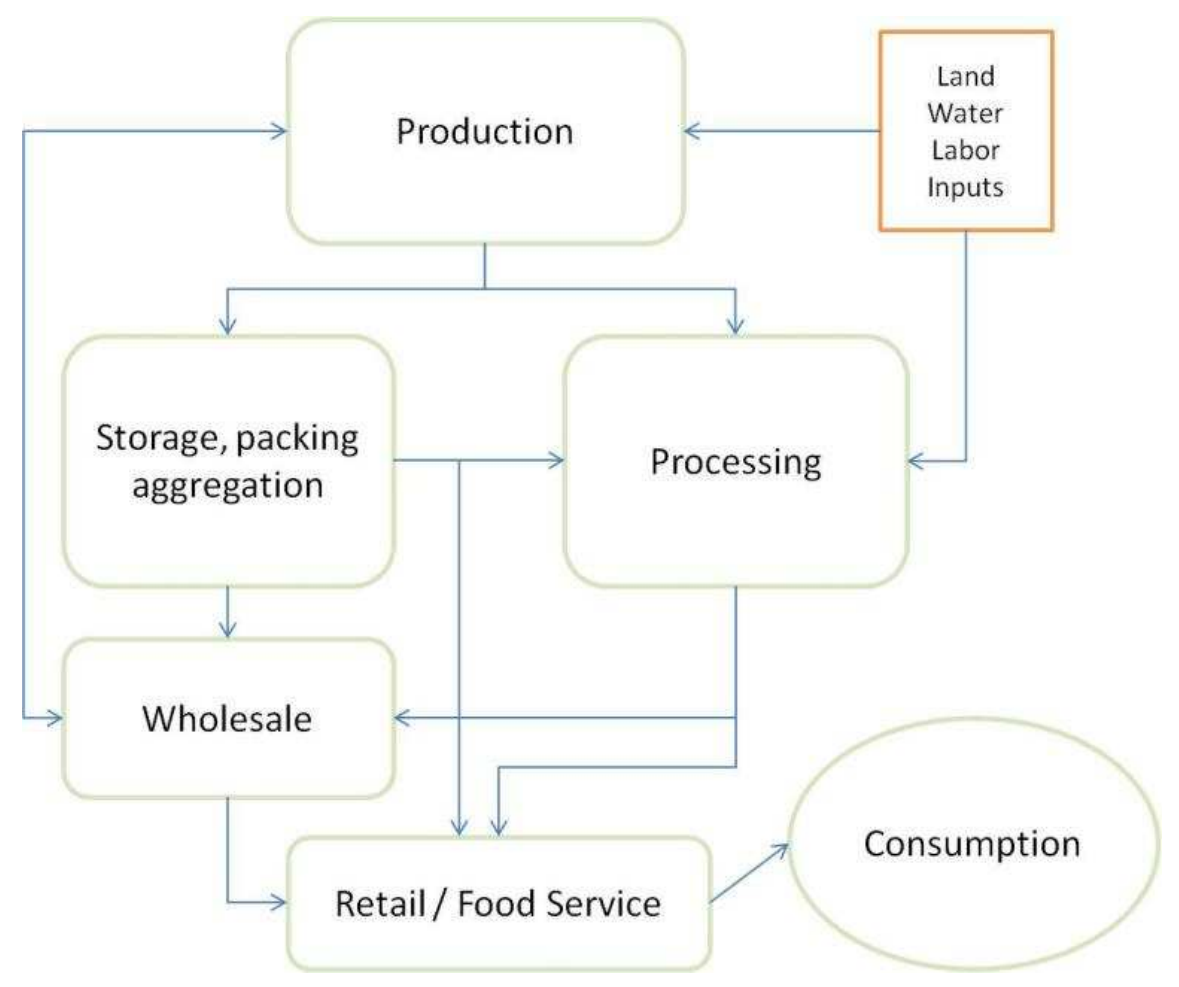

Figure 1.1: Conceptual model of the food system

While this figure represents the system that has emerged over the last 50 years that is closely associated with flows in the globalized agro-food sector, local and regional food systems are often inter-related and interconnected with the same supply chains that are represented in this model. For example, many local and regional channels include the production, procurement and sale of goods through "traditional" processing, storage, distribution, wholesale and retail channels. This to some degree is because vertically integrated "globalized" companies are responding to market pressure to procure more local and regional foods but in some cases is also a result of localized competitive advantages in production and distribution of products (usually associated with more perishable goods). But these supply chains also represent the only way in which many 
local producers can get their product to local markets. Not all local and regional foods however go through these more traditional supply chains and many local and regional products are often associated with shorter supply chains or even sold directly to consumers. So what exactly are local and regional foods and how do we know a local and regional food system when we see it?

A multitude of actors participate in the food system in the Portland Metro Region, many of whom are agnostic about both the geographic origin and location of final sale of their products. Food system firms include producers, processors, aggregators and packers, distributors, institutions, food service and retailers. The majority of these firms cannot be conveniently partitioned into the distinct categories of local and non-local and disaggregating the local products from the aggregated supply chains is challenging. Traditionally, the smaller, locally based firms were more likely to handle products that were produced and sold locally however in recent years, because of the growth in popularity of local and regional foods, even the larger, vertically integrated multi-national conglomerates are sourcing (and selling) local and regional products. For example, during the summer season, locally sourced produce accounts for $20 \%$ of produce available at WalMart and 30\% of produce available at Safeway (Martinez, 2010). Presumably, these products pass through these companies' regional distribution centers.

The conflation of local and non-local products among firms occurs primarily within the intermediaries in the supply chain. For example, according to a survey conducted by 
Ecotrust (2013) of local and regionally focused distributors in the Portland Metro Area (see Chapter IV for more detail), all were dedicated to local and regional sourcing of products; however, none were able to exclusively source locally. The proportion of local and regional produce ranged from $25 \%$ to $80 \%$ (during the growing season). These firms relied on imported products for the success of their businesses, particularly during the winter months. Likewise, processing facilities have been unable to source exclusively from local producers because the supply of product is too inconsistent. ${ }^{2}$

While extensive literature has emerged that has attempted to define local and regional food systems, no single agreed-upon definition currently exists. The concept of local and regional food systems emerged for the most part in the late 1990's, largely presented as an alternative to the undesirable effects of the globalized food system. These early scholars articulated alternative food systems as being distinct from the global food system but much of this work was focused on describing specific case studies or systems that represented niche markets or supply chains. Murdoch (2002) questioned the degree to which these alternatives described by many researchers actually created a new structural configuration.

Furthermore, a primary distinction of these alternative systems included aspects of shortened supply chains. Inherent in this is the concept of re-spatialization of food supply chains by which local food became a poster child for the alternative movement.

\footnotetext{
${ }^{2}$ Information derived through my participant observation (see Chapter IV for more detail)
} 
However, the perceived social and environmental outcomes associated with sustainable agriculture (and by extension alternative food systems) should not necessarily be confused with outcomes of a more local and regional food system. This is what Born and Purcell (2008) refer to as the "local trap". The local trap refers to the tendency of food activists and researchers to assume something inherent about the local scale. However, local food system advocates as well as researchers and economic development professionals continue to tout potential benefits that can stem from re-localizing food systems. I argue, the terms "local" and "alternative" are often used interchangeably however care must be taken not to confuse the two. The term alternative refers to an alternative to something. Sonnino and Marsden (2006) point out that such alternative definitions are variously and loosely defined in terms of "quality", "transparency", and "locality", and that such newly emerging networks are signaling a shift away from the industrialized and conventional food sector, towards a re-localized food and farming regime. While there are elements of this definition that are inherently local, "local" food systems as defined by many do not necessarily always exhibit the characteristics of "alternative" systems identified by the social theorists who have juxtaposed alternative systems as a form of resistance to the global agro-food industry. Here in lies a fundamental distinction between definitions of local and regional foods. On the one hand, a purely geographic definition describes local and regional foods as being produced within some specified distance (or other geographic measure) of where the food is ultimately consumed. The geographic definition of local and regional foods is subject to the "local trap" described above. Food may be produced and consumed within the same 
geography or region with the consumer knowing nothing about the food's source or practices used to produce it. It may very well be that these local foods are being produced by large-scale, export-oriented operations held by multinational corporations that do little to support local economies, the environment or community well-being.

A qualitative definition of local and regional foods however incorporates the alternative system into a spatial framework. That is, the qualitative definition of local and regional foods is a subset of the geographic definition in which products consumed are produced locally AND are embedded with information pertaining to the source and production practices. The consumer is consuming not only food but aspects specific to the quality, nature and authenticity of the food itself. They do so by interacting with the producers themselves (through directly marketed channels) or through some "trusted" source that preserves some transparency specific to the supply chain of the product (intermediated channels). Table 1.1 shows some of the primary differences between local and regional food systems and the global, export-oriented, agro-food industry. In some cases, the distinctions apply to the differences between the qualitative definition of local and regional food systems and the export-oriented food systems and in some cases, the distinctions may apply to both the geographic and qualitative definitions. 
Table 1.1: Differences between global and local supply chains, actors and products

\begin{tabular}{|c|c|c|}
\hline & Local and regional & Global / export-oriented \\
\hline \multicolumn{3}{|l|}{ Supply chains } \\
\hline & $\begin{array}{l}\text { Short / localized / direct. Intermediated / } \\
\text { traditional }\end{array}$ & Spatially extended (Murdoch, 2003) \\
\hline & $\begin{array}{l}\text { Spot markets which transmit price signals } \\
\text { to buyers and sellers (Brown et al., 2014) }\end{array}$ & $\begin{array}{l}\text { Vertically integrated or } \\
\text { preproduction contracts } \\
\text { (Hendrickson and Heffernan, 2007) }\end{array}$ \\
\hline & $\begin{array}{l}\text { 'embedded' with value-laden information } \\
\text { concerning the mode of production, } \\
\text { provenance and distinctive quality assets } \\
\text { of the product (Renting et al., 2003). }\end{array}$ & $\begin{array}{l}\text { Dissembeded information used for } \\
\text { food safety (Low \& Vogel, 2009) }\end{array}$ \\
\hline & $\begin{array}{l}\text { product oriented (Feenstra et al, 2003; } \\
\text { Ibery \& Maye, 2005) }\end{array}$ & $\begin{array}{l}\text { Retail influenced (Fearne \& Hughes, } \\
\text { 1999) }\end{array}$ \\
\hline & Low tech, inefficient distribution systems & $\begin{array}{l}\text { Highly specialized technologies and } \\
\text { supply chain management (Handfield } \\
\text { and Nichols, 1999) }\end{array}$ \\
\hline \multicolumn{3}{|c|}{ 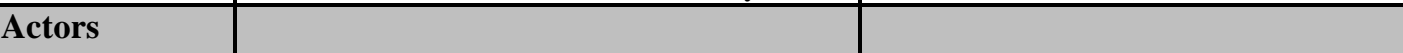 } \\
\hline & $\begin{array}{l}\text { Producers tend to be smaller, more likely } \\
\text { to grow produce, are younger, and more } \\
\text { likely to use social media }\end{array}$ & $\begin{array}{l}\text { More likely to be older, larger firm } \\
\text { size, use traditional means for } \\
\text { marketing }\end{array}$ \\
\hline & Independent growers & Contract growers \\
\hline & $\begin{array}{l}\text { Retailers of multiple types (direct and } \\
\text { intermediated outlets) }\end{array}$ & Consolidated retail sector \\
\hline & $\begin{array}{l}\text { Producers have a diverse portfolio of } \\
\text { products }\end{array}$ & $\begin{array}{l}\text { Producers are more likely to produce } \\
\text { one single crop }\end{array}$ \\
\hline & $\begin{array}{l}\text { Labor intensive (Own observation from } \\
\text { interviews) }\end{array}$ & $\begin{array}{l}\text { Mechanized / industrialized (Gibbon, } \\
\text { 2003) }\end{array}$ \\
\hline \multicolumn{3}{|l|}{ Products } \\
\hline & $\begin{array}{l}\text { Quality, nature and embeddedness } \\
\text { (Murdoch et al., 2000;) }\end{array}$ & Dissembedded \\
\hline & Local and regional (own definition) & non-local \\
\hline & $\begin{array}{l}\text { Tend to be more expensive, specialty } \\
\text { niche products or fresh meat or produce }\end{array}$ & $\begin{array}{l}\text { inexpensive, processed or } \\
\text { standardized products (Regmi \& } \\
\text { Gehlhar, 2005). }\end{array}$ \\
\hline
\end{tabular}


My quantitative and spatial analysis for the Portland area focuses on producers who sell locally through any channel. That is, in the analysis I am interested in actors producing local food rather than actors participating in local food supply chains. I conducted this analysis by drawing on a dataset derived from a survey that explicitly asks a series of questions of producers specific to the geographic distribution of their product in addition to marketing channels. In this sense, the analysis uses the geographic definition of local and regional food systems described above. My qualitative analysis on the other hand focuses on producers who marketed their products through specific supply chains. I therefore am able to explore aspects of agglomeration forces specific to the qualitative definition of local and regional food systems.

\section{3: GROWTH OF LOCAL FOOD}

Growth of both the popularity in the concept of local and regional food as well as the actual sales of local and regional food products that are directly marketed has been on the rise. Furthermore this growth has been a recent phenomenon. While historic data pertaining to local and regional food supply chains is limited to case studies, data does exist that describes the growth at the firm level. Perhaps the best indicator of growth of the local and regional food sector can be accounted for in the final sale of local and regional products through direct markets.

Data on direct-to-consumer food sales were first collected in the 1978 Census of Agriculture, after the Farmer-to-Consumer Direct Marketing Act was passed (Low and 
Vogel, 2011). Multiple other sources exist that collect data specific to the number of outlets by marketing channel as well. Direct-to-consumer marketing amounted to $\$ 1.2$ billion in sales in 2007, compared with \$551 million in 1997 (USDA, 2007). In the Portland Metro Region of Oregon, there was also a sharp increase from 2002 to 2007 in the proportion of sales through direct channels. The USDA Census of Agriculture reported a total of 1,245 farms or $19.29 \%$ of all food farms in the Three County Region (i.e., excluding products such as hay, Christmas trees, or ornamentals) reported direct to market sales. Furthermore, total direct to consumer sales increased by $87.1 \%$ from 2002 to 2007 in the Three County Region.

The number of direct to consumer outlets has been on the rise as well. Farmers' Markets voluntarily listed in USDA National Farmers Market Directory are up more than 400\% from $1994(1,755)$ to $2013(8,144)$. CSAs were first established in the U.S. in mid-1980s with 2 operations. In the 2007 Census of Agriculture, 12,549 farms reported they had marketed products through CSAs or some form of subscription agriculture arrangement.

There has been an increase in sales and the number of outlets in the intermediated channels of local and regional food as well. The number of farm to school programs, which use local farms as food suppliers for school meals programs, increased to 2,095 in 2009, up from 400 in 2004 (Low and Vogel, 2011). The growth can be seen in the popularity of locally sourced products in major retail establishments as well. For 
example, several leading retailers have recently announced local food initiatives including WalMart, Safeway, Kroger and Ahold (Martinez, 2010).

In the Portland Metro Area, all of Portland's farmers' markets (14 in all) with the exception of Portland Farmers' Market now located at Portland State University, have opened since 1994. In 2007, there were 37 farmers' markets in the Three County Region, compared to just four in 1994 (Oregon Farmers Market Association, 2013). CSA's have also increased dramatically in the last 20 years. The first CSA's were started in the Portland Metro Region in the 1990's (Portland Area Community Supported Agriculture Coalition). The City of Portland's Bureau of Planning and Sustainability maintains a list of self-reported CSA's. Currently there are over 50 CSA's listed in the region.

Considering a substantial amount of local and regional products pass through intermediated channels (Low and Vogel, 2011), and that tracking trends in these channels is difficult, there is insufficient evidence to point to the growth of local and regional foods in terms of its geographic definition. It may very well be that recent introduction of local produce in major retail establishments is merely a function of daylighting preexisting supply chains to take advantage of the perceived benefits of local foods. It may also be that the amount of local and regional products passing through intermediated channels is in decline as more local and regional producers forego these channels to take advantage of direct to consumer supply chains. In this sense, the above trends indicate that there has been substantial growth specific only to the qualitative definition of local 
and regional foods and that it is the practice of selling food embedded with information and economic and social relations that constitutes a new and growing sector.

\section{4: GEOGRAPHIC SCOPE}

The geographic scope of the research presented here is conceptualized at the regional scale. The growth of cities is directly related to, affect, and are affected by their periurban and rural counterparts. Economic activity plays out at the regional scale. When considered as a system, the new food economy unfolds at the regional scale as well. For example, given concepts of localization, embeddedness, and food geographies, both the supply of food products and the demand for those products are regional in scale. ${ }^{3}$

Furthermore, agglomeration economies are regional and benefits of both localization externalities and urbanization externalities can affect how systems organize. My unit of analysis therefore is the Portland Metro Region of Oregon. And while I will draw on descriptions of the new food economy in regions throughout North America and Europe, I have defined my region of interest for this analysis as the three counties in Oregon that have strong connections in terms of food product flows to the core metro area of Portland. These include Washington, Multnomah and Clackamas counties (Map 1.1). While together these counties represent a significant proportion of the state's agricultural production, they also are the three most urbanized counties in the state (U.S. Bureau of Census 2010). Combined, the three counties represent nearly $43 \%$ of the state's total

\footnotetext{
${ }^{3}$ While there is no clear definition of exactly what constitutes local in term of food production, given the unit of analysis presented here is the region, the definition stems from that unit. That is, I only consider food that is produced sold within the region to be local and regional and while food from outside the region, under many definitions, may be considered local and regional, it is not considered in this analysis.
} 
population and are home to three of the State's five largest cities (U.S. Bureau of Census 2010).

In terms of agricultural output, Oregon is the 28th largest producer of agricultural products in the United States and nearly $45 \%$ of all agricultural revenues originate from the Willamette Valley. Furthermore, of the top five counties in terms of revenue associated with agricultural products, Clackamas, Washington and Multnomah are 2nd, 4th and 5th respectively (USDA NASS 2007).

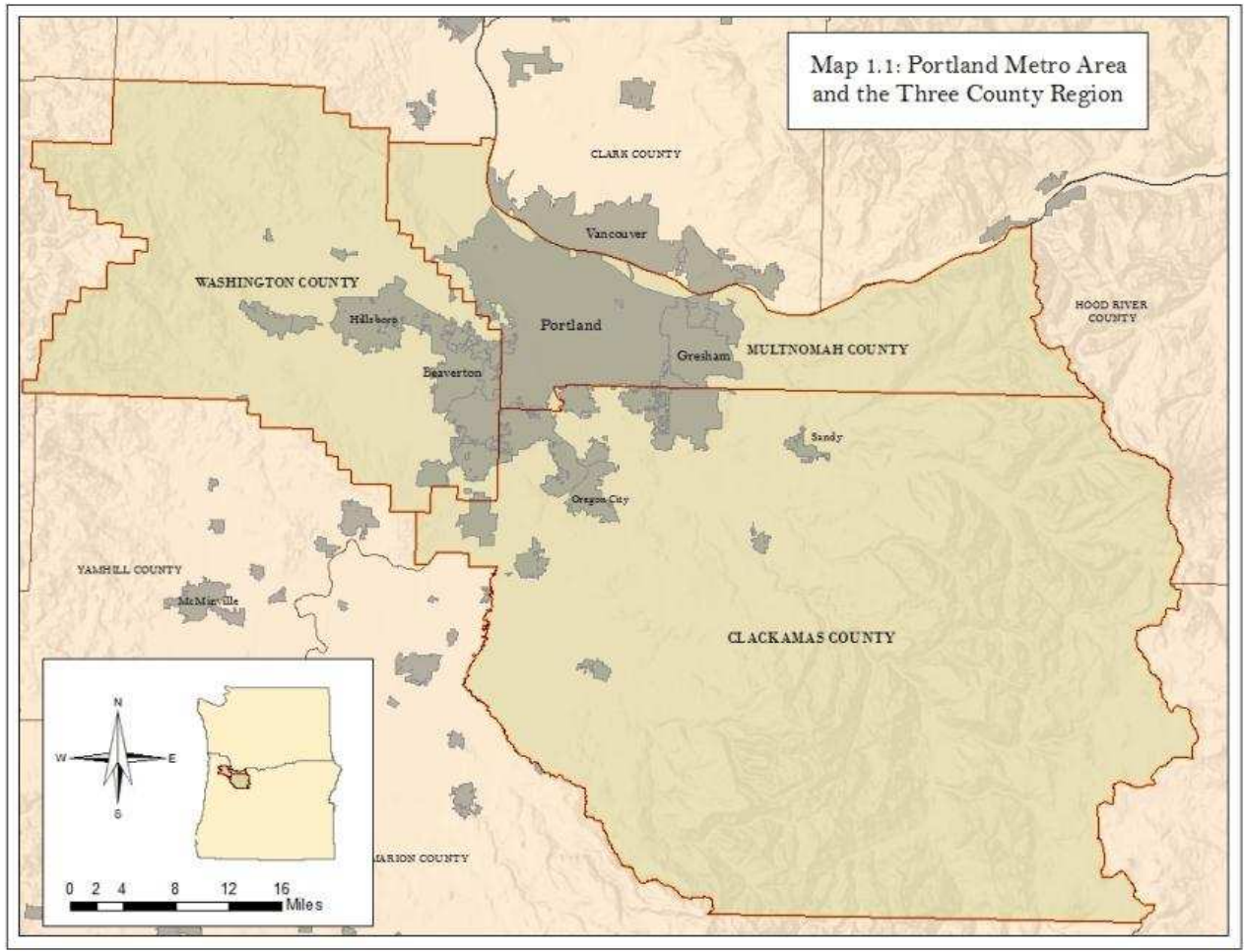

Figure 1.2: Map of Portland Metro Area and the Three County Region 
Agriculture products are among Oregon's major industries accounting for 9\% of Oregon's gross state product and 8\% of all Oregon jobs (US Bureau of Labor and Statics 2008). In 2010, Oregon produced $\$ 3.75$ billion in total agricultural output, and the Three County Region accounted for roughly $20 \%$ of this total $(\$ 793,244,000)$ (USDA NASS 2008). Oregon exports roughly $35 \%$ of its total agricultural output in value ( $\$ 1.32$ billion) and represents 100\% of the nation's output for blackberries, hazelnuts and two different types of grass seed (ryegrass and fescue) all of which originate in the Willamette Valley (USDA ERS 2010).

While the Three County Region is a major exporter of many agricultural products (for example nursery stock and Christmas trees as well as many types of berries), it also grows a significant amount of food products that are sold locally relative to other regions in the Country ${ }^{4}$. In Portland, a dedicated focus on building rural-urban connections emerged among food system activists in the 1990s, with organizational leaders that included Portland Farmers Market, Food Alliance, Portland Chapter of the Chefs Collaborative, New Seasons Market, Burgerville, Kaiser Permanente, Ecotrust, and many others (Halweil 2004). The success of these establishments and the social and environmental values of which they embody, have led regional leaders to take a close look at concepts around local food as a regional economic development strategy. For example, both Multnomah County and Clackamas County have begun to investigate how fostering a regional and local food system "cluster" could contribute to economic

\footnotetext{
${ }^{4}$ USDA NASS 2007 Census of Agriculture reported that nearly 4\% of food products grown in the Three County Region were directly marketed to consumers relative to $<1 \%$ nationally.
} 
development. ${ }^{5}$ Given the unique agricultural landscape in the Three County Region, and the dense urban population, coupled with the region's history of land use planning laws that allow for the persistence of farmland close to the urban core, ${ }^{6}$ the study area is an ideal setting to understand potential implications of the new food economy in the context of the city-region.

While my descriptive and qualitative analyses both focus on the broader Three County Region, my quantitative and spatial analyses focus on Clackamas County alone.

Clackamas County represents a significant proportion of agricultural output in the region (\$397,318,000 relative to Multnomah County: \$84,546,000 and Washington County: $\$ 311,380,000)$ and produces the majority of all vegetables $(\$ 19,212,000$ relative to Multnomah County: \$11,774,000 and Washington County: \$6,874,000) (USDA NASS 2007). Map 1.2 shows Clackamas County agricultural lands and parcels that produce food products on at least a proportion of their land. Furthermore the County is actively pursuing a variety of strategies to try and foster local and regional food supply chains. As part of the County's strategy, it developed the Clacakamas County producers survey, of which I have drawn from extensively to both differentiate local and regional food producers from export oriented producers and conduct my spatial analysis presented in chapter V.

\footnotetext{
${ }^{5}$ The Multnomah food initiative and the Clackamas County Agricultural Opportunities Assessment are both recent programs that exemplify this focus.

6 Oregon adopted growth management legislation in 1973 and Portland's UGB was proposed in 1977 and approved by the state in 1980
} 


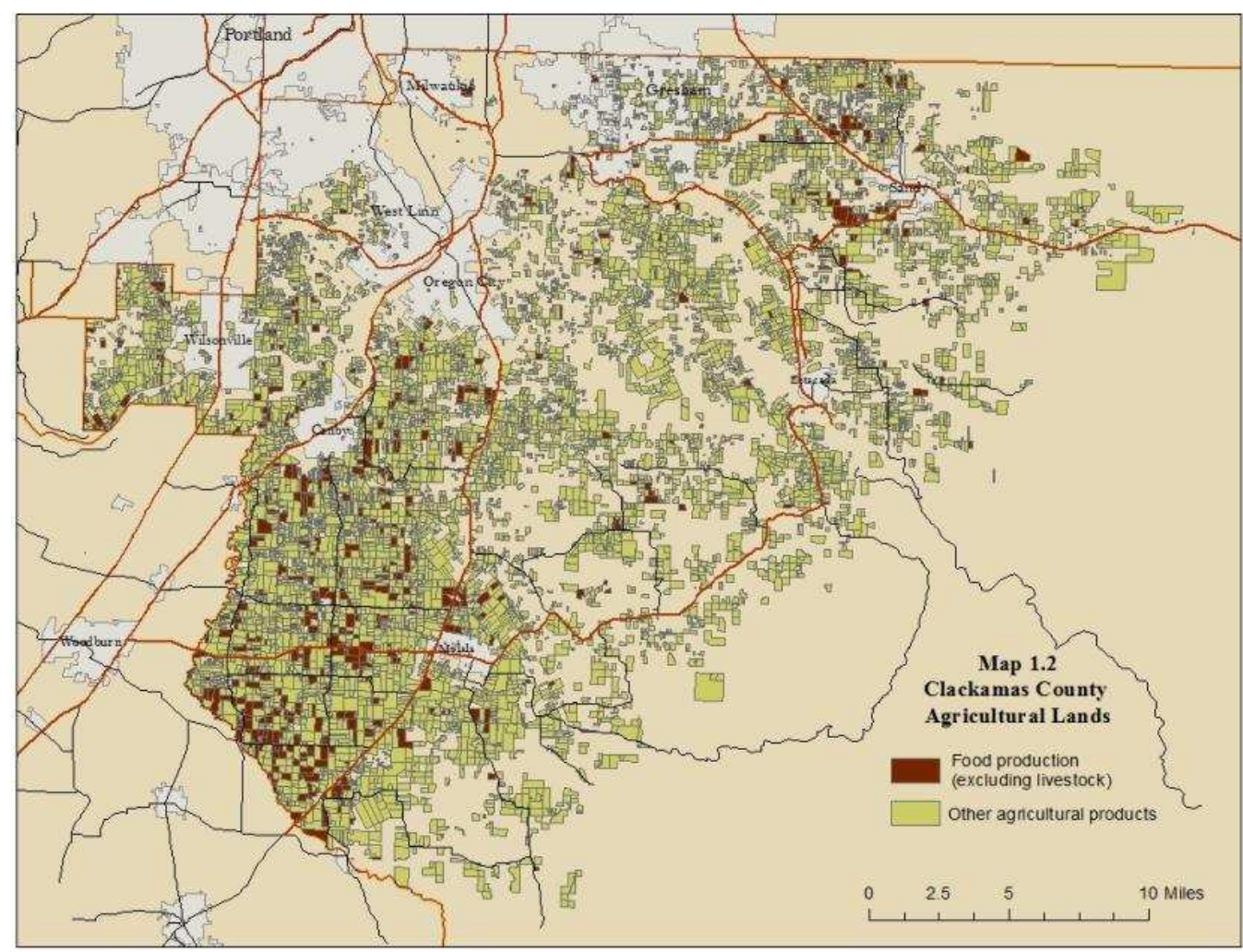

Figure 1.3: Map of Clackamas County Agricultural and Food Production Lands

\section{5: THEORETICAL FOUNDATIONS}

Although the research presented here does not attempt to expand on any specific body of theory, it is not without its theoretical foundations. On the contrary, I have drawn upon the theoretical foundations of industry life cycle, political economy, endogenous growth theory, and theories stemming from the knowledge geography literature to formulate my hypotheses and construct a sound methodology for data analysis. 
To help differentiate the local regional food system from the export oriented food system I have drawn extensively from the theoretical underpinnings originating from the agrofood literature. These stem from three dominant theories: political economy which situates the food regime as partly about international relations of food, and partly about the world food economy and regulation of the food regime underpins and reflects changing balances of power among states, organized national lobbies, classes-farmers, workers, peasants and capital (Friedmann, 2005); rural sociology which contextualizes alternative systems as a form of resistance against the globally connected, agro-food industry and the failures of that system and; actor network theory (e.g. Murdoch et al. 2000; Goodman 2003; Selfa amd Qazi 2005) in which localized forms of food systems are defined by the value of the networks and the relative importance of how actors in the system construct notions of local. I draw on each of these theories to characterize differences between the global and local food systems. However, while the theories of political economy, rural sociology, and actor network theory all play a key role in formulating the hypotheses and contextualizing the concept and motivations behind the emergence of the new food economy, as well as highlighting key differences between the systems, my motivation behind this specific line of inquiry stems from the fields most concerned with economic interactions that are constrained by geographic space and unfold at the regional scale.

Ultimately, the theoretical lens for this research draws from theories that have arisen from the fields of Economic Geography and Regional Science. Within Economic Geography, 
I situate my analysis by drawing from those theories concerned with economic growth at the regional scale including endogenous growth theory and theories of agglomeration externalities. Endogenous growth theory - postulated by Paul Romer (1994) and Robert Lucas (1988) - is concerned with the development of regions through endogenous forces such as human capital, knowledge spillovers and innovation rather than exogenously through demand for exports. Agglomeration theories attempt to explain the clustering of activity as a result of positive externalities associated with labor pooling, specialized services, urbanization externalities and knowledge spillovers.

Closely related although more focused on methods rather than theoretical constructs is the field of Regional Science. Walter Isard in his book Location and Space Economy (1956), details historic lines of thought pertaining to general theories applicable to what would ultimately become the field of Regional Science. Central to Isard's theories are the works of three German economists who between them describe the foundational spatialeconomic interactions pertaining to regions: Von Thünen's isolated state theory builds on work by Adam Smith to conceptualize how a farmer is expected to maximize his profit from his farmland; Walter Christaller's, central place theory builds on Von Thunen's work to describe how regions grow and are arranged in a spatial context, specifically how goods and services flow within regions and; Alfred Weber's theory of industrial location tries to explain and predict the location patterns of industry at a macro-scale. Together these three theories provide explanations for where a firm will locate, what the value of land will be, and how regions grow. All three are drawn from (and prove to be 
interrelated) by Isard in his formulation of his general theory relating to industrial location, market areas, land use, trade and urban structure. And all are pertinent to the concept of how the new food economy emerges at the regional scale.

Each of these disparate bodies of theory provides the foundation for my analysis. And I draw from the broad set of methodological tools offered by these fields. In the next section I turn to a general overview of my approach, saving the detail of exact methodologies for subsequent chapters in which the associated analyses are presented.

\section{6: CONCLUSION}

Economic development professionals, city and regional planners, decision makers and food policy advocates are all grappling with ways in which to foster local and regional food systems for a multitude of reasons. Many of these efforts are focused on expanding existing clusters of economic activity for the purpose of regional and or rural economic development. However, research pertaining to the benefits of local and regional food systems specific to economic development is largely lacking and currently little evidence exists to support rational investment and intervention strategies to foster the new food economy. Building on the wide body of literature pertaining to alternative food systems, and bridging it with the literature specific to Regional Science and Economic Geography, the research presented here aims to construct a theoretical framework that situates the new food economy within the context of the city-region. This framework can be used to support future research for identifying whether new food economies represent an 
opportunity for regional economic development and will result in evidence that can serve as a key foundational building block on which to begin to understand strategies for fostering these new food economies.

The structure of this dissertation is as follows: In the next chapter (chapter II) I present a literature review of the foundational and substantive works pertaining to the disciplines of agro-food systems research, Regional Science and Economic Geography - focusing on aspects of economic development and agglomeration economies and works stemming from the knowledge geography literature. In chapter III, I provide an historical overview of the evolution of food systems and agriculture in the Portland Metro Region and detail the present day structure, paying close attention to the economic, policy and land use drivers that have set the stage for the emergence of the new food economy in its present state. In chapter IV, I give a detailed overview of my methods and the data used in my analyses and then in chapters V and VI, I present my spatial and qualitative analyses in which I test hypotheses specific to the spatial structure of local and regional food systems and the processes of knowledge accumulation. Finally in chapter VII, I consider the implications of the new food economy in terms of regional economic development and discuss existing barriers and constraints to the emergence of such a system specific to the two definition presented above before concluding with thoughts on possible future directions of the system and future research needs. 


\section{CHAPTER II: LITERATURE REVIEW}

\section{1: OVERVIEW}

I focus my literature review on three distinct bodies of research: the agro-food systems literature, Regional Science and New Growth Theory. My review of the agro-food literature provides a theoretical background for describing the existing agro-food structures both in terms of the characteristics of the dominant regime of the exportoriented, globally linked agro-food sector as well as the reasons for the emergence of the new food economy; the New Growth Theory literature helps me frame my hypotheses and provides a theoretical foundation for contextualizing the emergence of the new food economy in terms of the city-region and; the Regional Science literature both supports the theoretical foundations presented by the New Growth Theorists as well as provides a framework for both my quantitative and spatial analyses. In this chapter, I provide an overview of each of these distinct bodies of literature and then discuss some of the theoretical applications of economic development for local and regional food systems before concluding with an overview of some recent works that have attempted to measure the impacts of local and regional food systems at the regional scale.

\section{2: LOCAL AND REGIONAL FOOD SYSTEMS AND AGRO-FOOD RESEARCH}

The research stemming from the agro-food literature draws on a wide array of theoretical frames including social theory and economic sociology (Kloppenberg et al. 1996; 
Murdoch et al. 2000; Hendrickson and Heffernan 2002; Hinrichs 2003; Jaroz 2008), actor network theory (Goodman 1999; Murdoch et al. 2000; Selfa amd Qazi 2005) and political economy (Murdoch et al. 2000; Allen et al. 2003; Winter 2003) among others. Some of the themes that have emerged in recent research elucidate concepts presented by social theorists such as David Harvey (1996) pertaining to consequences of modernity and post-modernity and situate alternative systems as a form of resistance to the modern globally connected agro-food industry. This resistance involves the emergence of alternative systems defined by themes such as embeddedness, quality, stronger social connections and connections with nature.

Political economy is often used to describe the existing structure that has emerged as the dominant regime. The food sector has gone through a broad shift to transnationalization and globalization and has been integrated into a set of transnational and transectoral production process (Murdoch et al.2000). Political economy has been used to both describe this process (Hendrickson et al. 2001) as well as contextualize some of the consequences of this integration (Mardsen 1988; Friednalnd et al. 1991; McMichael 1994).

Social theory and economic sociology is used extensively throughout the agro-food literature as a way to situate alternative food structures as a form of resistance to the globalized systems. For example Hendrickson and Heffernan (2002) argue that food system alternatives challenge the time space distantiation that characterizes the 
continuing development of the dominant agro-food system. Local food has recently emerged as a banner under which people attempt to counteract trends of economic concentration, social disempowerment and environmental degradation resulting from the globalized agro-food regime (Hinrichs, 2002). At the center of this discourse is the local as a place for connections and resistance. For example, Allen et al. (2003) attest that people are working to construct new initiatives that challenge the existing food system. Localizing food seems to manifest both oppositional and alternative desires, providing an opportunity for directly personal relationships between producers and consumers. They apply concepts articulated by Harvey (1989) such as alternative, oppositional, militant particularism and global ambition to examine the local as a site of resistance.

However, the local as a site of resistance has been conflated with local as a geographic specifier and the assumption that local alone can solve the problems resulting from the failures of the globalized system should be questioned. Recent research interrogates whether and to what degree this new food paradigm addresses the objectives of social justice and inclusion, ecological sustainability and economic viability (Jarosz 2008). Born and Purcell (2008) argue that local food systems are no more likely to be sustainable or just than systems at other scales. They use scale theory to frame their argument that scale is socially produced: scales (and their interrelations) are not independent entities with inherent qualities but strategies pursued by social actors with a particular agenda. Goodman (2004) argues that the spatial content of local contexts needs to be more critically examined both to take account of how scale is socially constructed and to 
understand how social and environmental relations are themselves spatialized. In this sense, much work is still required to better understand and evaluate the roles that regional food systems might play in providing for social and natural wellbeing (Martinez et al. 2010).

What have emerged in the literature are two distinct concepts of local food. On the one hand there exists a geographic definition articulated by the proximity of production and consumption. On the other hand is a more qualitative definition articulated by themes such as embeddedness, quality, stronger social connections and connections with nature. The qualitative definition may also encompass aspects of defensive localism. For example Winter (2003) found considerable evidence of an ideology of localism based on sympathy for farmers. That is, the turn to local food may cover many different forms of agriculture, encompassing a variety of consumer motivations and giving rise to a wide range of politics (Winter, 2003).

\section{3: INSTITUTIONAL STRUCTURES AND THE GLOBALIZED AGRO-FOOD SYSTEM}

In this section I highlight literature that has attempted to characterize some of the more dominant trends in food systems more broadly. Food systems have gone through tremendous transformation in the last 50 years. And through this transformation the

global system has emerged. Depending on the frame of reference, this transformation has been called a variety of terms such as processes of agricultural industrialization (Parrottet 
al., 2002), or productivism (Ilbery and Bowler, 1998). Regardless of the nomenclature used, the transformation has been marked by three major trends: 1) rapid advances in transport and communication technologies; 2) increase in processed and manufactured products and; 3) substantial consolidation and vertical integration of food system conglomerates particularly within both the production and retail sub-systems.

\subsection{1: Distribution and information technology}

The growing flows of freight have been a fundamental component of contemporary changes in most economic systems at the global scale (Hesse \& Rodrigue, 2004) and food systems are no exception. Advances in transport and communication technologies have created new opportunities for the development and growth of multinational firms within the food industry and now represents a significant sub-system within the globalized agro-food sector.

Logistics consider the wide set of activities dedicated to the transformation and circulation of goods, such as the material supply of production, the core distribution and transport function, wholesale and retail as well as the related information flows (Handfield and Nichols, 1999). The core component of materials management is the supply chain, the time- and space-related arrangement of the whole goods flow between supply, manufacturing, distribution and consumption. (Hesse \& Rodrigue, 2004). With the coupling of information technology, marketing and strategic planning with distribution and materials management, logistics has evolved into supply chain 
management. The flow-oriented mode of corporate management and organization currently affects almost every single activity within the entire process of value creation in the globalized agro-food system (Lummus and Vokurka, 1999).

Management of supply chains that carry food products, particularly perishable products, have had to respond to the growing demand for year around products. There is now a considerable supply variation due to seasonality of agricultural production, weather conditions, and the biological nature of agricultural products, which results in input variation and unpredictability (Henson and Reardon, 2005). Vertical alliances have emerged that often aim to smooth supply variation and guarantee the planned delivery of supplies (Mangina \& Vlachos, 2005). Coupled with increased competition these logistics alliances have resulted in considerable structural changes in food supply chains (Clark \& Hammond, 1997; Fearne \& Hughes, 2000). For example, automatic stock replenishment and deliveries are increasingly becoming the responsibility of retailers such as WalMart in the United States and Tesco in the UK (Mangina \& Vlachos, 2005).

Information technology in most major agro-food sector corporations is integrated with every function of the business. Supply chain management and information technology departments often consist of enterprise technology services, IT program management, IT sales, marketing, IT Corporate and Commercial Systems and Services and IT Supply Chain Systems and Services (ConAgra, 2013). Such technologies act as a barrier to entry for many producers and retailers. 


\subsection{2: Processed and manufactured foods}

The last three decades have seen tremendous growth in sales of processed food-sales now total $\$ 3.2$ trillion, or about three-fourths of the total world food sales (Regmi \& Gehlhar, 2005). The increase in sales in processed and manufactured foods has led to increased competition as agro-food businesses compete for increased market shares of this rapidly growing sub-sector resulting in consolidation and strategic alliances (see section 5.3.3). In the United States, the food manufacturing industry is one of the largest manufacturing sectors, accounting for more than 10 percent of all manufacturing shipments (BEA, 2012). The farm share of the "market basket" (i.e. non-processed foods) remained stable at about $40 \%$ from 1960 to 1980 but declined rapidly since then, to $30 \%$ in 1990 and 22.2\% in 1998 (Sexton, 2000). The processed food industry has experienced fairly steady growth over the 1997-2006 period. In 2006, the value of processed food shipments from the U.S. was $\$ 538$ billion, an increase of 27 percent from 1997 shipments (U.S. Census Bureau, 2013).

\subsection{3: Consolidation and vertical and horizontal integration}

Consolidation is perhaps one of the most relevant aspects of recent trends in globalized food systems. There were 316 total acquisitions in 2012 in the broader food and beverage industry, and food processors constituted nearly $1 / 4$ of these acquisitions with 83 total mergers (Food Institute, 2013). This consolidation has occurred both at the national as well as multinational level. Within the United States, perhaps the most striking forms 
of consolidation can be seen in retail activity whereas multinational activity is a relevant and an increasing phenomenon in food manufacturing (Senauer \& Venturini, 2005).

The last 20 years in particular has seen a marked increase in consolidation activity in the retail sub-system of the globalized agro-food sector through horizontal integration where major retail establishments compete for market share through acquisition of companies in geographically distributed markets. Currently the top five retail establishments represent over $57 \%$ of all retail sales in the United States up from $48 \%$ in 2006 (the top four stores - Tesco, Sainsbury's, Asda, Safeway - account for almost two-thirds of grocery sales in the UK). Table 5.1 shows the market share of the top five retailers from 2004 to 2012.

Table 2.1. Top retail establishments sales 2004-2012 $(\$ 1,000)$

\begin{tabular}{|l|r|r|r|}
\hline Store & $\mathbf{2 0 1 2}$ & $\mathbf{2 0 0 6}$ & $\mathbf{2 0 0 4}$ \\
\hline WalMart & $\$ 118,725,880$ & $\$ 98,745,400$ & $\$ 66,465,100$ \\
\hline Kroger & $\$ 61,128,860$ & $\$ 58,544,668$ & $\$ 46,314,840$ \\
\hline Safeway & $\$ 35,504,560$ & $\$ 32,732,960$ & $\$ 29,572,140$ \\
\hline Supervalu* & $\$ 28,229,188$ & $\$ 36,287,940$ & $\$ 31,961,800$ \\
\hline Ahold & $\$ 26,162,500$ & $\$ 23,848,240$ & $\$ 25,105,600$ \\
\hline
\end{tabular}

Source: Hendrickson and Heffernan, 2007 and Progressive Grocer's Super50, 2012

*Supervalu purchased 40\% of Albertson's in 2006. 2004 and 2006 data represent Albertson sales

During the 1990s, supermarkets in the United States and throughout Europe shifted to reliance on a relatively small number of specialized importers, rather than on traditional wholesale markets. Importers were expected to engage in active global procurement, as 
well as to organize the provision of a series of new services that supermarkets required (Gibbon, 2003).

Retail growth strategies based on location and size (product range and price competitiveness) have been replaced by strategies based on differentiation such as own label fresh produce and meat (Fearne \& Hughes, 1999). Buyer-driven chains link large retailers and branded marketers to decentralized networks of producers of low-cost developing countries (Gibbon, 2003). Buyer-led chains are actively driven in the sense that large retailers and branded marketers use them not merely to source products, but increasingly also to reshape their own portfolios of functional activities and to achieve higher levels of flexibility (Senauer \& Venturini, 2005).

As with retail, the production sub-system has seen significant consolidation and strategic alliances. Hendrickson and Heffernan (2007) identify three major food chain clusters that represent extensive vertical integration of production activities and account for a major portion of global production of grain and animal feed. These include the Cargill/Monsanto cluster, the ConAgra/Dupont cluster, and the Novartis (Syngenta)/ADM cluster although since their research others may have emerged (e.g. Smithfield and Tyson). These clusters assume control of food system activity from genetic seed manufacturing to grain production through to grain collection, aggregation and processing as well as meat production and processing. For example, ConAgra purchases high-oil corn seed from DuPont; contracts with farmers to grow the corn; buys 
it back for animal feed of which they control significant meat feed and processing operations (the company produces its own livestock feed and ranks third in cattle feeding in the U.S. and second in cattle slaughtering (Hendrickson and Heffernan 2007)).

In 2007, four firms controlled 60 percent of U.S. terminal grain handling facilities, with Cargill having the most capacity, followed by Cenex-Harvest States, a farmer cooperative with which Cargill has now embarked on a joint venture (Hendrickson and Heffernan 2007). Furthermore, With Cargill's acquisition of Continental, it controlled more than 40 percent of all United States corn exports, a third of all soybeans exports and at least 20 percent of wheat exports. At the global scale, the merger combines what was reported at the start of the 1990s to be the largest two global grain traders. The emergence of ADM as a major global grain trader came through the acquisition of parts of Louis Dreyfus and Pillsbury (Conner, 2003).

Processed foods have also experienced extensive consolidation in recent years. For example, ConAgra, in 2013 completed a $\$ 4.95$ billion acquisition of private-label food maker Ralcorp making it the largest private label food maker in North America (Brown, 2013). ConAgra bought Ralcorp because of its dominating presence in the private-label food space and now constitutes approximately $\$ 4.5$ billion in combined annual private label sales and about $\$ 18$ billion in total sales. Private-label food sales currently make up $18 \%$ of U.S. food sales. (Ziobro, 2013). 
Kellogg Company became the world's second-largest savory snacks company with the \$2.7 billion purchase of Procter \& Gamble's Pringles brand in 2012, which earns $\$ 1.5$ billion in sales across more than 140 countries (Food Institute, 2013). Campbell Soup Co. acquired Bolthouse Farms for $\$ 1.55$ billion, a vertically integrated food and beverage company focused on high value-added natural products and in possession of significant market positions in fresh carrots, premium beverages and private label products in the U.S (Ziobro, 2013).

In 2013, the twelve largest U.S. companies in this sector were PepsiCo, Tyson Foods, Nestle, Anheuser-Busch, Kraft Foods, General Mills, Smithfield Foods, Dean Foods, Mars, Coca-Cola and ConAgra Foods (Food Processing, 2013). In 2012, Kraft Foods, the largest in the industry at that time, employed 103,000 employees, had more than 180 manufacturing and processing facilities worldwide, and reported net revenues of \$37 billion (Food Institute, 2013). Kraft currently manufactures some of the industry's leading brands, such as Oreo, Nabisco, Oscar Mayer, Philadelphia Cream Cheese, and Maxwell House coffee.

In 2012 there was 266 percent increase in fruit and vegetable processor mergers. Tomato producer Lipman bought Branscomb Produce, Combs Produce and the Ace Tomato Co. packing house across the U.S. in California. In 2013, Seneca Foods also acquired an ownership interest in Independent Foods, a Sunnyside, Wash.-based processor of canned pears, apples and cherries (Food Institute 2013). 
Meat production as well is marked by intense market concentration in which a very small number of corporate packers accounts for the majority of meat that ends up in the grocery store. In 2007, four corporations slaughtered 83.5 percent of the nation's beef, 66 percent of the pork and 58.5 percent of the poultry (Heffernan and Hendrickson 2007).

\section{4: CONSEQUENCES OF GLOBALIZED FOOD SYSTEMS}

The major trends in the food industry over the last 50 years has led to a broad shift toward transnationalization and globalization that has been integrated into a set of transnational and transectoral production process (Murdoch et al., 2000) and global commodity chains. These global commodity chains are sector-based structures of international trade, arising from the twin phenomena of dispersal of production (through outsourcing) and market integration (through trade liberalization) (Gibbon, 2003). Like processes of modernization, analysts see globalization in the food sector as derived from agencies which aim to promote new inter-linkages between the principal actors (e.g., farmers, processors, and retailers), spread new uses and forms of knowledge (linked especially to science and technology), and establish new commodity forms within mass markets (Murdoch et al., 2000).

However, this globalization of the food system has led a growth of theoretical and practical critiques of several distinct outcomes: an increasing exploitation of large segments of society as manifested in increasing inequalities, poverty, hunger, poor health, 
and loss of cultural diversity (Koc and Dahlberg, 1999); vulnerabilities "created by a global economy operating in real time" (Gwynne et al., 2003), particularly the herd behavior of investors and currency traders; and the undemocratic nature of the governance of global capitalism (Watts et al., 2003); increasing exploitation of the natural environment, which is manifested in increasing pollution, resource losses and degradation, and loss of biodiversity (Marsden, 1994) and; an increasing loss of national, state, and local political power as concentrations of economic and corporate power increase, with a corresponding reduction of democratic power and social controls (Koc and Dahlberg, 1999)

It is through these "cracks in the façade" (Leyshon and Lee, 2003) that local and regional systems have begun to emerge as alternatives to the consequences of the global system. For example Hendrickson and Heffernan (2002) argue that food system alternatives challenge the time-space distantiation that characterizes the continuing development of the dominant agro-food system. Local food has recently emerged as a banner under which people attempt to counteract trends of economic concentration, social disempowerment and environmental degradation resulting from the globalized agro-food regime (Hinrichs, 2002). At the center of this discourse is the local as a place for connections and resistance. For example, Allen et al. (2003) attest that people are working to construct new initiatives that challenge the existing food system. Localizing food seems to manifest both oppositional and alternative desires, providing an opportunity for directly personal relationships between producers and consumers. They 
apply concepts articulated by Williams and Harvey such as alternative, oppositional, militant particularism and global ambition to examine the local as a site of resistance.

\section{5: LOCAL AND REGIONAL FOOD SYSTEM STRUCTURES AND SUPPLY CHAINS}

Lack of a publicly recognized definition for "local food" presents a challenge for identifying differences at the structural scale. Despite the growing use of the term "local" in academic and civic discourse, there is no consensus on a precise definition. (King, 2010). As mentioned above, most theorizing pertaining to local and regional food systems has stemmed from a reaction to the external costs of the global system. As such, a wide variety of themes have emerged in the literature specific to aspects of local and regional food that are distinct from that of the globalized system. Such themes include elements of structure (Hendrickson et al, 2001; Hendrickson and Heferman, 2002; Christopherson, 2006; Wrigley et al, 2005), scale (Born and Purcell, 2006) management practices, authenticity and embededness (Watts, Ilbery, \& Maye, 2005) and geography (Selfa \& Qazi, 2005; Martinez, 2012).

The structural differences between the local and global systems are best articulated through definitions of supply chains. Local and regional food systems are an example of where short supply chains present a spatial alternative to conventional supply chains (e.g. Renting et al., 2003). Using a strictly geographic definition, local food refers to food produced near its point of consumption in relation to the modern or mainstream food 
system (Peters et al., 2008). In this sense, the geographically defined of local food may very well travel through traditional supply chains.

The structural configuration of supply chains associated with the qualitative definition however is slightly different. What is unique about these local supply chains is that information must be conveyed about the product that enables consumers to recognize it as a local food product. That is, local food supply chains strive to establish a bond between the producer and the consumer, even when separated by intermediary segments in the supply chain (Renting et al., 2003). Marsden et al. (2000), describes three types of localized food supply chains: face-to-face, where consumers buy a product direct from the producer/processor on a face-to-face basis; spatially proximate, where products are sold through local outlets in the area and consumers are immediately aware of its local nature and; spatially extended, where products are sold to consumers who are located outside the local area and who may have no knowledge of that area. Here, the key is to use product labeling and imagery to transfer information about the production process and the area to the consumer (Ilbery et al., 2003).

A body of research has also emerged specific to producers selling their products locally. Here, most research can be placed under the geographic definition of local and regional food systems as differentiating the supply chains associated with the producers is challenging. King et al. (2010) found that at the national scale, farms that participate in local food supply chains relative to export-oriented farms have a more diverse portfolio 
of products and market outlets. They showed that small farms may diversify product offerings to defray large fixed costs across multiple sources of revenue, or they may use multiple types of local market outlets. Outlets used by local and regional food producers include direct to market channels including farmers' markets, roadside stands, on-farm stores, and community-supported agriculture arrangements (CSAs) and intermediated marketing channels including sales to regional distributors and grocery stores, restaurants, or other retailers (Martinez, 2010). A small portion of local and regional foods is also sold through institutional channels such as through farm to school programs. In 2007, more than half of U.S. local food sales were from farms selling exclusively through intermediated marketing channels such as grocers, restaurants, and regional distributors. Farms using both direct-to-consumer and intermediated marketing channels accounted for a quarter of local food sales ( $\$ 1.2$ billion). Only $\$ 877$ million (roughly $18 \%$ ) was generated by farms that participated exclusively in direct to consumer sales (e.g., farmers markets, roadside stands, on-farm markets, CSAs) (Low and Vogel, 2011).

\section{6: REGIONAL SCIENCE}

Next, I turn my attention to literature specific to the fields of Regional Science and Economic Geography. I highlight these fields because I use the theoretical and methodological formulations to investigate the evolution of the new food economy in terms of the city-region. First, I focus on the foundational scholars of Regional Science, for the most part because it is these foundational thinkers that provide the contextual framework for the theories of economic development and New Growth Theory from 
which I draw to formulate my hypotheses. Additionally, the field of Regional Science has given birth to advanced methods of regional analysis, including approaches to measuring aspects of agglomeration economies. I draw on these methods to perform my spatial analysis presented in Chapter V. Central to Regional Science is the concept that geographic space matters. Aspects of the effects of geographic space are addressed in all of the theoretical underpinnings of the field and many of the methods are concerned with how to incorporate space into analytical techniques. I focus my review of Regional Science specifically on location theory and methods of regional and spatial analysis, primarily because it is these arenas within the field of Regional Science that provide a useful lens through which to evaluate aspects of the new food economy that I outlined above.

Location theory is concerned with the macroeconomics of space. Broadly speaking, location theory provides the theoretical foundations for a wide array of topics including: analysis of land use patterns and urban form, spatial interaction, spatial diffusion, trade area analysis, location of decisions of the firm and industrial location analysis, location of service centers and network analysis. While aspects of regional growth and urban form related to Walter Christaller's central place theory, as well as aspects of New Growth Theory are closely related to - and in many respects subsets of - location theory, I will address each of these in later sections. Here I focus on location theory as the basis for locational decisions. 
Location theory was originally developed because of the recognition for incorporating transportation costs into price theory. Transportation costs are different from other production costs because they can impose certain recurring types of spatial arrangements. Beckmann (1999) identifies two ways in which geographic space affects economic relationships: through the uneven distribution of natural resources and through distance separating economic activities. Distance separating activities can be thought of both in terms of how economic activities affect other activities carried out in adjacent locations (neighborhood effects) as well as costs incurred by moving goods (transportation costs). These concepts are the articulation of many of the works outlined above however the work of Alfred Weber and his theory of industrial location (1909) which tries to explain and predict the location patterns of the industry and Von Thunen's isolated state theory (1826) provide the backbone of this sub-field of Regional Science. Weber's theory emphasizes that firms seek a site of minimum transport and labor cost whereas Von Thunen's theory attempts to explain the value of land (and subsequent land use patterns) based on the distance to a marketplace. Whereas Weberian models are concerned with facility location, Von Thünen based models are interested in the spatial variation of phenomena across geographic space. When industries function at multiple scales, both of these types of models can be used to represent the location activity of that sector and in aggregate and can serve as a framework to begin to understand regional economies as a whole. 
Multiple books have been written on location theory (e.g. Beckman, 1968,1990; Gabszewicz et al. 1986; Nickel and Puerto, 2005; Chan, 2001, among many others) and a dedicated scientific journal Location Science was devoted to present methods associated with location problems ${ }^{7}$. Modern day location science is concerned primarily with spatial interaction models -including trade area analyses, spatial diffusion models and network analyses.

Spatial interaction models are those models concerned with what Beckman termed: neighborhood effects - that is the effects of economic activities on other activities in close proximity. There are many examples of such models in the literature spanning a wide array of journals concerned with topics ranging from geographic analysis, to business, to urban studies. Such models include spatial interaction (e.g. Fotheringham, 1983; Pooler, 1993; Black 1995; Boyle and Flowerdew. 1997; Fotheringham, et.al. 1999), diffusion models concerned with the distance decay effects on how activity diffuses over space (e.g. Hagerstrand, 1967; Morrill 1968; Graff and Ashton, 1993; Mottomley and Fildes 1998; Murnion and Healey 1998; Fingleton, B., \& Lopez-Bazo 2006), and gravity models based on Reilly's law of retail gravitation concerned with trade area analysis and capture (Huff 1963; Wagner 1974; Carter 1993; Lowe and Sen 1996; Anderson and van Wincoop 2003).

Most significant however are the contributions of Regional Scientists specific to regional

\footnotetext{
${ }^{7}$ Started in 1995 was eventually incorporated into Computers and Operational Research.
} 
analysis and measuring spatial phenomena (e.g. clustering and agglomeration). For example, Anselin (1995), Anselin et al. (2006), and Anselin and Getis (1992) have written at length about the application of GIS for Regional Science particularly for applications pertaining to spatial statistics and spatial econometrics. Additionally, Rey

and Anselin have collaborated on major open source library for spatial analysis pertaining to spatial statistics and economic analysis (see Rey and Anselin 2007; Rey 2009). I have drawn extensively from Anselin's advances in spatial analysis in particular his specification of how to measure Local Indicators of Spatial Autocorrelation (LISA). I use LISA statistics to measure aspects of clustering among local and regional food producers.

\section{7: NEW GROWTH THEORY AND AGGLOMERATION}

While Regional Scientists have long provided theoretical analyses of industrial location choice aspects of sources of growth have only recently appeared in the literature. Following work by Porter (1990) and Krugman (1991), there has emerged a different strand of literature concerning industrial clusters both in industrial organization and international trade. New growth theorists argue that economic growth depends on the accumulation and spillovers of knowledge between individuals. New growth theory is often attributed to Robert Lucas (1988) and extended by Paul Romer (1994).

Krugman (1991) and Romer (1986) recognized the presence of agglomeration externalities and suggested they represented a means of increasing returns. Central to 
their analysis are theoretical perspectives implicit in the field of Regional Science. In particular is the work of Alfred Marshall in the late 1800's who theorized the importance of what Fujita et.al. (1999) refer to as centripetal forces. Marshall identified three sources of external economies: geographically concentrated industry can support specialized providers of inputs introducing external economies of scale; an industrial concentration supports a thick local labor market, especially for specialized skills, so that employees find it easier to find employers and vice versa, and; a local concentration of economic activity may create more or less pure external economies via information spillovers (Krugman 1998). In this sense, increasing returns at the regional level are a direct result of externalities (centripetal forces) resulting from the geographic clustering of economic activity.

For Krugman and new economic geography, these externalities represented a mechanism that facilitated increasing returns. In Krugman's model, economies bifurcate into a core that represents industrial agglomeration and a primarily agricultural periphery. Yet Krugman's assessment considered only the first two of Marshall's sources of externalities as the evaluation of knowledge spillovers in his mind were not tractable because they left no paper trail. In doing so Krugman turned his back on one of the driving centripetal forces of agglomeration and resulting structural makeup of regions. Instead Krugman used his ideas to extend theories of international trade. 
This is not to say knowledge spillovers are unimportant to economic development: rather at the core of my analysis of local food systems are the concepts of knowledge accumulation and innovation diffusion. Both Romer (1991) and Lucas (1988 and 1993) focused on knowledge spillovers as an important mechanism underlying endogenous growth (Audretsch and Feldman 2003). The work of Romer and Lucas set the stage for an extensive body of literature pertaining to the importance of knowledge spillovers and endogenous processes of technological change for the development of regional economies. At the same time a empirical work was showing that the knowledge production function varied at different levels of aggregation. For example, Griliches (1984) found strong empirical evidence that supported the existence of the knowledge production function at the level of the country however this relationship became less robust at finer spatial scales (Audretsch and Feldman 2003). These findings suggest the presence of an externality - one that subsequent researchers linked to aspects of agglomeration.

Audretsch and Feldman (2003) provide an excellent framework for understanding the application of agglomeration effects under different theoretical lenses. They identify distinct differences between what they call the Marshall-Arrow-Romer model, the Porter model and the Jacobs model. The former predicts that local monopoly is superior to competition because it allows firms to capture benefits of investing in R\&D whereas both the Porter model and the Jacobs model advocate competition because greater competition across firms facilitates the entry of new firms specializing in new products. The Porter 
model however predicts that benefits of externalities are realized within a specific industry therefore advocates regional specialization whereas the Jacobs model advocates regional diversification. Each of these models rely to a large degree on realizing some positive externality, and both the Porter and Jacobs model inherently invoke the concept of geographic proximity as a key factor in the development of economies.

With the theoretical structures of endogenous growth, the new economic geography and diffusion theory in place, a wide body of empirical research began to appear concerning the spillover of knowledge and the effects of agglomeration on the growth of regions. Anselin et al. (2006) consider the diffusion of innovation as constrained by geographic space. They looked at data for 43 states and 125 metro areas in the US to determine the influence of university research centers have on innovation and found that innovation in private firms is influenced within 50 miles. Fichser and Varga (2003) also considered distance effects of knowledge diffusion using Austrian data. They found that factual knowledge travels much further than tacit knowledge. Rosenthal and Strange (2004) found that the effect of localization economies in the first mile is from 10 to 1000 times larger than the effect two to five miles away. Numerous other theoretical and empirical studies have emerged that analyze the extent of spatial agglomeration of activities for a variety of industries (see. Fujita and Thisse, 2001 and Rosenthal and Strange, 2004 for theoretical and empirical examples respectively). These literature directly inform my hypotheses presented in the first chapter in that I attest that because local and regional food system actors participate in a nascent industry, they will be more likely to benefit by 
knowledge related externalities, and empirical work has shown that the degree of such externalities vary depending on the degree of spatial clustering. In the next section I explore the literature that link food systems research

\section{8: AGRO-FOOD STUDIES AND ECONOMIC DEVELOPMENT}

Recently, a body of literature has emerged that looks at whether localized food systems offer economic development opportunities (Bellows and Hamm 2001; Winter 2003; Swenson 2009). Mardsen et al., (1999), Ross et al. (1999), Marsden et al. (2000), Goodman (2002), Hinrichs (2003), Winter (2003) and Ikerd (2005) have all suggested that expansion of local foods may be a development strategy for rural areas particularly those areas that have experienced negative effects of globalization. On the other hand, others (Goodman 2002; Watts et al. 2005) have questioned the benefits of local foods as a strategy for economic development. Even with the recent explosion in the agro-food literature the amount of research pertaining to food systems as a driver of economic development is lacking. Outside of the work of Blay-Palmer and Donald (2006) and Donald (2008), and to some degree Winter (2003) and Watts et al. (2005), little attention has been given to the concept of the city-region as a unit of analysis, and whether agglomeration externalities are a requisite condition to foster the emergence of new food system economies. By bridging the literature specific to Regional Science and Economic Geography with the agro-food literature, there exists an opportunity to evaluate the impact of local and regional foods in the context of the region. 
A variety of theoretical rationales have been presented for hypothesizing why local and regional food systems might benefit regional economies. Most are tied to the concept of import substitution that is evaluated within the context of export-base theory. The most common belief is that local and regional supply chains and markets are assumed to provide farmers with a higher share of the food dollar, and monies spent at these businesses circulate throughout the region, reducing leakage and creating multiplier effects resulting in greater regional economic benefits (USDA, 2012). Other rationales include the hypothesis that they support endogenous growth by attracting and retaining talented professionals and that they can attract outside government spending and private investment which in turn results in regional growth. Certainly, there are numerous other theoretical frames that facilitate the analysis of local and regional foods for contributions to regional and community well-being (for example, resilience, actor network and or food nutrition) however, my focus is specific to economic development so I only considered the frames presented above. Each is briefly described below.

\subsection{1: Import substitution}

The notion of import substitution was popularized in the 1950s and 1960s as a strategy to promote economic independence and development in developing countries (Bruton, 1998). Import substitution is - as the name implies - the substitution of goods and services imported from outside the region with those produced within it. Import substitution specific to local and regional foods has been presented as a potential mechanism that might drive economic development mainly associated with reducing 
"leakage" of economic activity from the system. Traditionally, the concept of import substitution has been analyzed using a Keynesian framework. While Keynesian models are generally used to establish the effects of exogenous demand for exports originating from a region (situated in export base theory), implicit in these model is a region's propensity to spend locally. That is, if a region can decrease imports without increasing its overall propensity to spend, regional income is assumed to grow. In addition to the decrease in imports (less money leaving the system or leakage), substituting imports generates a multiplier effect as impressive as promoting exports (Elvin, 2008). Persky and Carlson (1993) found that every dollar of import substitution in an industry has just as large an effect on total output as an additional dollar of exports.

In the Portland Metro Region, recent research through a USDA Sustainable Agriculture Research and Education program (Cogan Owens Cogan, 2012) indicated that the Portland region currently imports over 95 percent of the food consumed. The report estimates that if $10 \%$ of food currently imported from outside the region was locally produced, this would generate approximately $\$ 470$ million in increased local economic wealth per year, not including economic multipliers.

However, the analysis took a narrow view of import substitution. Viewed from the classical sense, economists would dismiss such attempts of import substitution largely because the potential for employment gains resulting from trade theory argues that spatial divisions of labor involve a superior use of resources (Markusen \& Schrock, 2008). If for 
example, the region is required to reduce productive capacity of other (more productive) sectors to meet the increase in demand for agricultural output, or reduce its export base to a greater degree than what the import substitution makes up for (e.g. by taking export oriented agricultural products that are highly adapted to grow in the Portland region out of production to have the land to increase local food production, some of which might not be suitable for that production), the economic benefits might not be realized.

\subsection{2: Multiplier effects}

Proponents of import substitution point to its ability to reduce leakage resulting in multiplier effects superior to those that result from exporting goods. Multiplier effects occur when an injection of extra income in a region leads to more spending, which creates more income at the regional scale. The multiplier effect refers to the increase in final income arising from any new injection of spending. In food systems, local and regional systems are thought to have greater multiplier effects because of both forward (movement of the product through the system that generate demand for processing or other services) and backward (purchases of inputs required to grow the product) linkages.

In direct to market supply chains, nearly all wages and proprietor income is retained locally. Producers receive a greater share of retail prices in local food supply chains than they do in mainstream chains (King et al. 2010), and producer net revenue per unit in local chains ranges from about equal to more than seven times the price received in mainstream chains (Martinez, 2010). However, in a recent national study, King et al. (2010) 
found that producers in direct to market supply chains assume responsibility for additional supply chain functions, such as processing, distribution, and marketing, to capture revenue that would otherwise be accrued by third party sources. Although farms in direct market supply chains retain nearly 100 percent of the retail price, costs incurred to bring their product to market total between 13 and 62 percent of the retail price (Martinez, 2010).

Direct to market producers may also create increased demand for backward linkages. For example, evidence exists that suggest that large farms are less likely to purchase their farm inputs locally (Foltz et al., 2002; Foltz \& Zeuli, 2005). Because producers that participate in local and regional food systems tend to be smaller in size, this would suggest that they purchase more inputs locally, lending to the increase in the multiplier effect.

However regional economies also retain a large share of income from the traditional, export oriented agro-food sector. These mainstream supply chains rely on national and international networks to deliver products to consumers, but many supply chain functions, such as retail distribution services, are performed locally and contribute to regional economic activity (King et al., 2010). For example, several national retail establishments have major distribution centers located in the Portland metro area contributing significantly to regional income and jobs. 
Furthermore, many mainstream retailers source locally and, responding to growing demand for local products, these retailers are beginning to make explicit the products they do offer from local sources. Whole Foods, the leading natural foods retailer in the United States, markets locally grown products, touting a variety of social, environmental, and quality benefits (Whole Foods 2006). Wal-Mart, the top grocery retailer with over $\$ 118$ billion in annual sales sources $\$ 400$ million annually from local sources. In addition Safeway states that over $30 \%$ of their produce is sourced through "regional" growing partners. Seasonality however plays a major role in the share of revenue retained locally; some mainstream supply chains obtain products from local growers during certain times of the year and from national and international growers in the offseasons (Martinez et al., 2010). For example, here in the Portland region, Kroger sources some produce locally but only during the summer months.

Even though mainstream supply chains do benefit regional economies, proponents of local and regional food systems argue that the local and regional systems retain a much greater share of the total value of the product and therefore offer greater potential for multiplier effects. In recent years a growing body of research has been conducted pertaining to the potential multiplier effects of different production activities. Most of this research stems from either case studies or economic impact assessments that are used to measure the multiplier effects of different changes in final demand of different products. Economic impact assessments measure the economic activity associated with a specific kind of chain effect of linked purchases. As a business buys from and sells goods 
and services to businesses in other sectors of the economy and to final users, the firm stimulates additional economic activity by the other businesses and within other economic sectors. I highlight some of this research later in this chapter.

\subsection{3: Benefiting regional economies by attracting outside dollars}

The Keynesian framework also is a convenient lens of which to consider the economic impacts resulting from infrastructure projects that attract investment (or government spending) from outside the region such as regional "food hubs", As both investment and government spending are key variables in the analysis of regional income growth in the Keynesian model, the support of these "food hubs" could potentially lead to increased regional income if they are successful at attracting either federal spending or investment from private capital. While sources of funding are available from the former (numerous federal and grant opportunities exist to support the development of food hubs nationwide), private investment has traditionally been harder to attract because of the uncertainty of returns ${ }^{9}$.

Furthermore, agri-tourism has the capacity to generate additional dollars in the local economy as visitors from outside the region spend money in associated regional travel. While agri-tourism has been found to be more common among the larger, more established farms (Vogel, 2012), many small farms that participate in local and regional

\footnotetext{
${ }^{8}$ A regional food hub is a business or organization that actively manages the aggregation, distribution, and marketing of source-identified food products primarily from local and regional producers to strengthen their ability to satisfy wholesale, retail, and institutional demand (USDA)

${ }^{9}$ Based on conversations with key informants.
} 
food supply chains commonly offer services related to agri-tourism (Ilbery \& Maye, 2005). Agri-tourism activities might include "farm-stays", u-pick or novelty attractions (e.g. corn maze's or tractor rides). Attracting investment or government spending, tourism and import substitution are all rationale originating from export-base theory. However, as I highlight in following chapters, the export-base lens is limited in its ability to evaluate the potential of local and regional food systems as an economic driver. In the next section I present the concept of local food as an amenity, a concept originating from endogenous growth. I cover aspects of endogenous growth more thoroughly in later chapters and examine how it can be used to consider broad impacts of local and regional food systems to regional economies.

\subsection{4: Local food as an amenity}

A growing body of research has been conducted regarding the importance of amenities in terms of regional development (Deller, et al., 2001; Partridge, 2010; McGranahan, et al., 2011) although no research has specifically looked at a strong food culture as a potential benefit in terms of amenity-based development. Florida (2002) asserted that a footloose "creative class" is drawn to high amenity areas, thus providing these areas the advantage of an influx of knowledge and creativity. As Boschma and Fritsch (2009) note, the presence and attraction of the creative class in Florida's (2002) model is part of a mechanism through which economies grow where people, not jobs, come first. Lowamenity areas may lack this influx, whatever their level of creative class (McGranahan et al., 2011). 
Amenity-based development is especially attractive for rural areas because of their higher concentrations of natural resources and recreational amenities and because it places a high priority on protecting existing culture along with economic development. And those rural areas immediately adjacent to urban areas that are endowed with amenities have the potential to contribute to the overall health of the region. Recent research pertaining to the contribution of amenities to regional economic development includes evaluation of amenities on housing prices (Wu, 2008; Hoehn et al., 1987), population migration (Porel, 2982; Graves, 1983; Knapp and Graves, 1989; Glaeser, 2008) and wages and employment (Roback 1988; Deller \& Tsai, 1999). As mentioned above, no literature currently exists that consider the impacts of local and regional food systems as an amenity based asset; an area which is ripe for future research. In the next section, I cover different methods for measuring impacts, one of which (econometrics) may be used to understand the contributions of local and regional foods as an amenity in addition to its ability to create multiplier effects and attract outside dollars.

\section{9: MEASURING IMPACTS}

Tools used to measure impacts often only cover single components rather than the broader potential contributions that local and regional food systems do or do not have on regional economies. Regardless, a variety of techniques have been employed to estimate the effects of regional food systems on economic development. Most of these tools have stemmed from the underpinnings of Regional Science presented above. O'Hara and 
Pirog (2013) identified three distinct classes of methods for measuring impacts: InputOutput modeling, computable general equilibrium models and econometric methods.

Input-Output (IO) analysis is an economic impact assessment technique widely used by economists and regional scientists to measure and understand the distributional impacts or inter-industry linkages across an economy. The IO methodology's analytical capacity lies in its ability to estimate the indirect and induced economic effects stemming from the direct expenditures associated with a change in final demand for the goods and services produced by an economy. These indirect and induced changes in economic activity result in multiplier effects described above.

A number of recent attempts have been made to identify the multiplier effect of local and regional foods using IO models (e.g., Feenstra et al., 2003; Henneberry et al., 2009; Hughes, et al., 2008; Swenson, 2008, for Iowa). All these studies find positive impacts on jobs and income. However, while the IO framework can be used to estimate the direct, indirect and induced effects of increased local and regional food production and consumption, it does little to tell us of any long term contributions or endogenous factors. Furthermore, IO models are generally derived from national accounting matrices, relying on location quotients to calibrate to specific regions. That is, IO models implicitly assume that there are no significant interregional variations in production and consumption patterns (i.e. the same inputs are used across all region to produce similar products). These matrices are established for the traditional food sector and all of its 
interactions. Extending these models to account for the interactions specific to local and regional food systems can be an arduous task, and most models only attempt to do so with case studies or minimal data points.

Very little research has been conducted that evaluates regional economic impacts of food systems using CGE. A drawback of these models is that their results can be less transparent since model solutions are calculated by solving many equations simultaneously. This restricts the number of sectors that can be modeled (O'Hara and Pirog 2013). Furthermore, the complexity of these models makes them less palatable for broad dissemination.

Econometric or regression based models provide a robust method for isolating effects of individual aspects of regional economies. An advantage of these advanced statistical methods for understanding impacts of local and regional foods is that if the statistical tests are well designed, the effect of local food sales on economic variables can be directly estimated (O’Hara and Pirog 2013). While researchers have provided the analytical frameworks to assess regional economic impacts of a wide array of characteristics through econometric models and there exists extensive literature pertaining to the key variables that most affect regional economies (e.g. Pellegrini, et al., 2013; Anselin, et al., 1997; Kim et al., 2005; Glaeser \& Saiz, 2003), until recently these tools had not been extended to test the effects of the food sector. Low \& Vogel (2011), Ahearn \& Sterns (2013) and Brown et al. (2014) are three teams that have begun to 
explore this topic in more detail although the latter two studies found that local food sales had small macroeconomic impacts. However, like many of the studies mentioned previously, they did not include retail institutional purchases of local food (O'Hara and Pirog 2013).

Perhaps most compelling is the recent work presented by Brown et al. (2014). In their research they provided an econometric approach to evaluating impacts of direct to market products and agri-tourism on regional economies by first assessing the impact of the share of direct to market food products relative to agricultural food products more broadly and subsequently measuring the impact of these food products on the regional economy as a whole (measured in terms of change in per-capita income growth). This two stage process is a common approach in econometrics when there is a potential endogeneity issue pertaining to a regressor. That is, because an increase in local and regional food sales may be a result of an increase in growth, an instrument variable is used to determine the proportion of the regressor that is causing, rather than caused by the growth itself. They found no significant impacts at the national scale but in some regions (e.g. the Northeast) they found significant positive effects. While their findings were inconclusive for the Portland Metro region ${ }^{10}$, by evaluating the different effects of direct to market food sales from region to region, the analysis sheds light on some of the underlying structural characteristics of agriculture as well regional economies more broadly, that may benefit (or not) from local and regional food systems.

\footnotetext{
${ }^{10}$ Their regional scale of analysis aggregated the Portland Metro area along with the entire west coast ("Far west" as defined by the U.S. Bureau of Economic Analysis)
} 


\subsection{0: CONCLUSION}

Douglas North and Charles Tiebout argued the downfalls and benefits of a demand side approach specific to economic development (articulated through export-base policies) and a supply side approach respectively. North (1955 and 1956) questioned the application of location theory for explaining growth in U.S. regions primarily because he attested that such theories were developed in the absence of a capitalistic system in which firms seek to maximize profits and that they were developed for regions under intense population pressures. He presented a theory for how regions in the U.S. grow based of their ability to export-specific commodities. That growth is inherently linked to exports. Tiebout (1956) argued that if a region is unable to respond to increased demand for exports it will be unable to take advantage of the growth opportunities. In this sense, Tiebout recognized the importance of a diversified economy with the ability to provide increased amounts of non-basic goods and services as a prerequisite to growth. Furthermore, Tiebout warned that increasing the export-base will often lead to specialization and shifts away from non-basic goods, increasing reliance on imports.

A decade later Jane Jacobs (1969) wrote at length about sources of growth. She opined that growth is a function of "import replacement". That is, while exports remain an important part of sustaining a region's economic viability, it is through the process of replacing imports that adds new work and thus enables an economy to grow. This replacement of imports by increasing production of non-basic goods and services is a product of a variety of factors however Jacobs understood the importance of the concepts 
of competition and inter-industry spillovers presented above. The concepts of "import replacement" and endogenous growth are directly related to what Markusen and Schrock (2009) term consumptive growth. Consumptive growth presents an alternative to exportbase and makes the case that distinctive consumption activities drive economies and that investments in distinctive local-serving capacity may create long-term job growth. Such theoretical lenses facilitate the understanding of how some regional economies may actually benefit from the emergence of local and regional food systems; each of which I draw from in subsequent chapters to situate my analysis. 


\section{CHAPTER III: HISTORY AND PRESENT DAY STRUCTURE OF FOOD SYSTEMS IN THE PORTLAND METRO REGION}

In this chapter I provide a brief overview of the history of food systems in the Portland region as a means to describe how the present structure has evolved. Of note in this evolution is the proximity of fertile farmland to the urban core, the rapid population increase and it's interaction with those surrounding farmlands, the emergence of public markets and distribution networks and the seminal land use laws of the late 1970's in the State. My description here is brief, and is in no way intended to be exhaustive rather I present it to help provide some context to my argument that the local and regional food system in the Portland Metro Region is best contextualized in terms of the city-region. In addition I provide an overview of the present day structure of the Portland region food system as well as a description of food producers in Clackamas County, and compare local and regional food producers against non-local food producers.

\section{1: FOOD, FARMLAND AND POPULATION GROWTH}

Food and agriculture has played a major role in the Portland Metro Region as well as throughout the Pacific Northwest for more than a century. But even before the original European settlers came to the region, evidence indicates that indigenous peoples actively cultivated the landscape for numerous foods. And these foods were used for both local consumption but also traded throughout the region for a wide variety of goods and materials (Whaley, 2010). In the 1800's, immigrants to the region brought non-native 
plants and animal species and in the late 1800's, as railroads connected distant markets, food production exploded in the region (Gibson, 1985).

The city of Portland was incorporated in 1851 with a population of about 800 and possibly as many as 1,500 throughout what is now Clackamas, Multnomah and Washington Counties. Food production and urbanization has always been closely linked in the Portland Metro Region, to a large part because of the fertile farmlands that exist. Portland became a major transportation center because of its proximity to railroads and rivers and as more people moved to the region, the surrounding lands were quickly cleared of forests and converted to farmland to grow food and livestock for both export and local consumption. Figure 3.1 is a plat map from 1884 showing the southern portion of Portland and platted agricultural lands along the river on the West Side in an area now known as John's Landing and on the East Side, primarily in the area that is now known as Sellwood. While much of the livestock and wheat production for export was being grown along the Willamette River well south of the Portland area the parcels being farmed in these areas closer to downtown were primarily used to sustain Portland's growing population (Gibson, 1985).

In 1905, Portland hosted the Lewis and Clark Centennial Exposition world's fair which contributed to its recognition. By 1910, Portland's population had jumped to over 200,000. Figure 3.2 shows the population growth by decade for the city of Portland from 1850 to 1910 . 


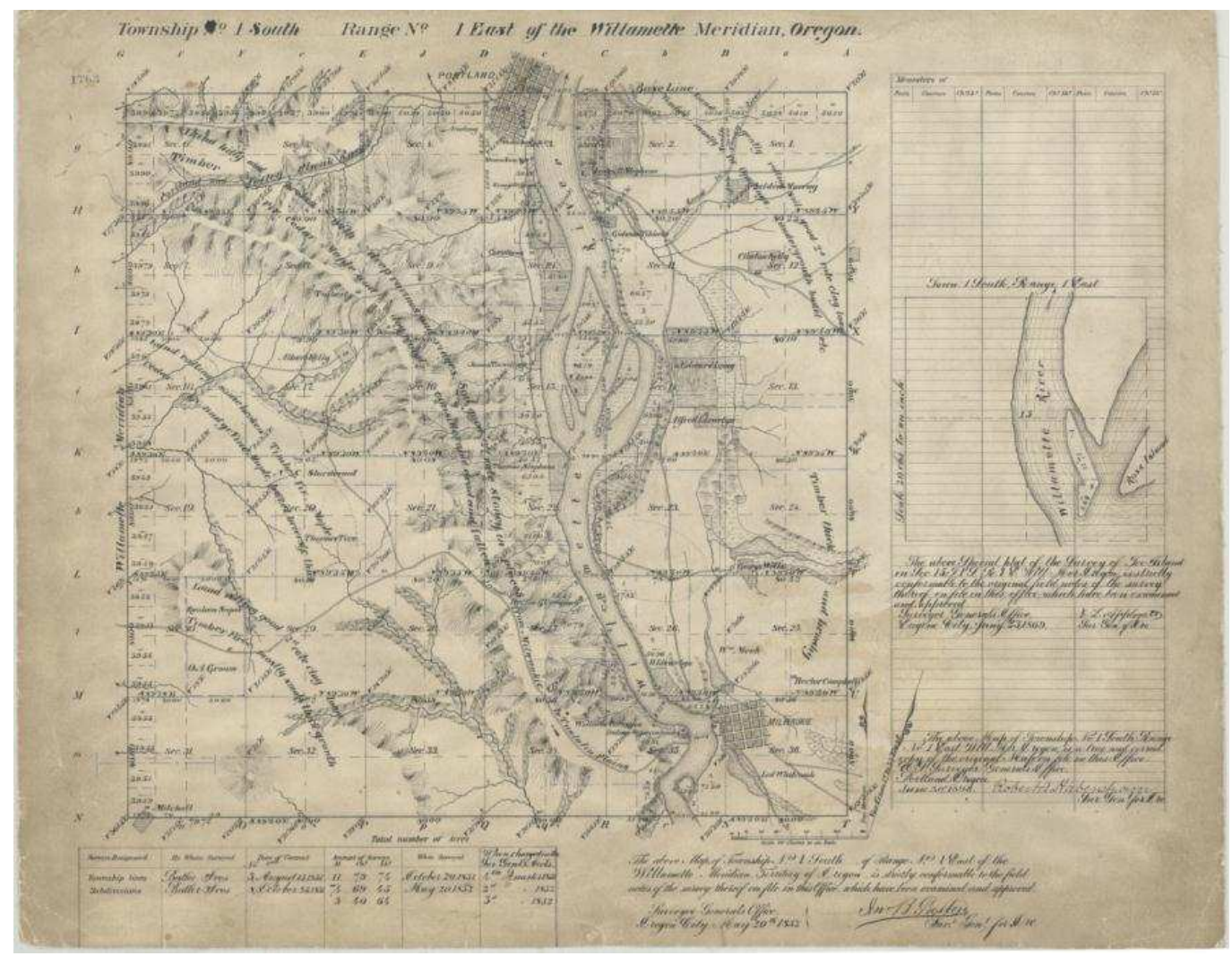

Figure 3.1: 1884 plat map showing Downtown Portland and close in agricultural lands

Source:BLM - Oregon State Office

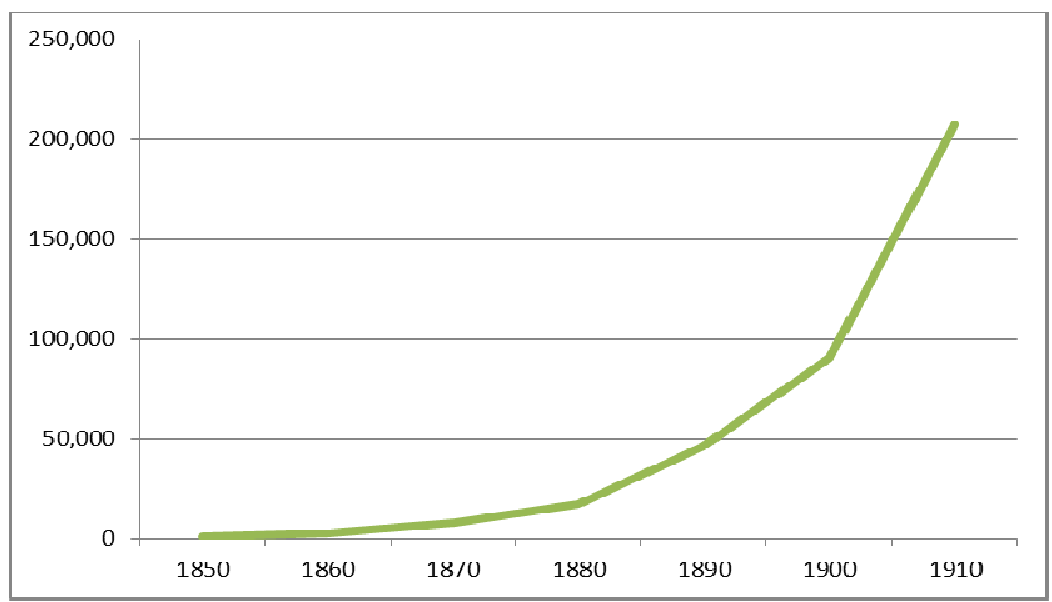

Figure 3.2: Portland population growth, 1850 to 1910 
As Portland grew, so too did the number of farms from a few hundred in the late 1800's to over 2,200 by 1950 (USDA, 2008). But the farming history of the region was more prominent in Clackamas County, where the first settlers arriving on the Oregon Trail immediately noticed the prime farmland surrounding Oregon City. People who settled in the region made their living catching and selling fish, cutting timber and producing lumber, growing and harvesting wheat and raising cattle for market. By 1910, Clackamas County had over 3,600 farms and over 300,000 acres of farmland (USDA, 2008). However the majority of the farmland under production in Clackamas County was growing wheat and livestock for export. In 1925, less than 1,000 acres of farmland were devoted to vegetables other than potatoes whereas over 2,200 acres of vegetables were produced in Multnomah County. The high rates of vegetable production in Multnomah County likely indicate these farms were being used primarily for local consumption whereas many of the Clackamas County farmlands were focused on export to distant markets.

As the city grew, vegetable production in both Clackamas and Multnomah Counties increased. By 1949, with a population of nearly 620,000 people in the Three County Region, Multnomah County was producing nearly 6,200 acres of vegetables. However, as the population continued to increase, many of these vegetable farms began to be converted to urban uses, decreasing to less than 5,500 acres by 1954. Meanwhile, 
vegetable production in Clackamas County began to increase and did until its peak in 1992 when it produced over 6,600 acres of vegetables.

Farmers grew vegetables to feed their own families as well. By 1940, there were 9,251 farms in the Three County Region or roughly $76 \%$ of all farms that reported growing vegetables for on-farm use. The total estimated value of vegetables grown for on farm consumption was $\$ 319,992$ or $54 \%$ of the total estimated value of all vegetables sold (USDA, 2008). But significant shift took place during World War II. By 1945, the estimated value of vegetables grown for on farm consumption dropped to just $28 \%$ of the total value of all vegetables sold and by 1959 , the estimated value had dropped to less than $10 \%$ of all vegetables sold. The number of farms reporting growing vegetables had dropped as well to 4,993 or just over $60 \%$ of all farms. While the Census of Agriculture no longer tracks the number of farms that are growing vegetables for consumption, this number is certainly much lower today.

\section{2: EFFECTS OF URBANIZATION ON FARMLAND STRUCTURE}

Urbanization has played a key role in the structural formation, and ultimate success of local and regional food systems in the region not only because the city represents the primary market for products of the local food system, but also because processes of urbanization play a fundamental role in shaping the agricultural landscape. Indications of these effects can be inferred by the historic rates of vegetable production close to the urban core presented above, but also by how farmlands in the region respond to 
population growth over time. To test these effects I analyzed the relationship between farmland structure and population growth in the Three County Region. I used historical NASS Census of Agricultural data coupled with population estimates from the Bureau of Census to test the effects of urbanization over time on the amount and structure of farmland. I collected or calculated attributes pertaining to farmland statistics and population estimates from 1925 to 2007. I used population as a proxy for urbanization.

I regressed a series of farmland attributes on population, value, and product type. While population (a proxy for urbanization) is a good predictor of the total farmland acres and to a lesser degree - the harvested acres, it only explains $18 \%$ of the variance of the number of farms under 10 acres. However, when using the proportion of small farms rather than the total number of small farms the explanation of the variance increased $\left(\mathrm{R}^{2}\right.$ $=.2165$ ). As population increased, the proportion of small farms increased. The results demonstrate how small farms are able to persist in urbanizing areas (or at least in the Portland Region). Table 3.1 shows the results of this analysis. Farming locations near a city can offer considerable advantages that offset many of the negative externalities associated with cities (development pressures). Urban areas present opportunities for a wide variety of positive externalities including access to markets, off-farm employment and potential sources of information. These concepts are covered in much more detail in later chapters. There was no relationship between population size and the acres of harvested fruits, nuts and berries or between population size and vegetables possibly because these activities are dependent on fluctuations of data outside of my model. In 
particular, technological changes may affect the per acre productivity resulting in significantly more volume of vegetables, fruits, nuts and berries. However, yield data were not available as part of the historic censes.

Table 3.1: Parameter estimates for predictors of proportion of small farms

\begin{tabular}{|c|c|c|c|}
\hline \multicolumn{4}{|l|}{ Residuals: } \\
\hline Min $1 \mathrm{Q}$ & Median & $3 \mathrm{Q}$ & Max \\
\hline-0.07655 & 0.00099 & 0.02153 & 0.04079 \\
\hline
\end{tabular}

\begin{tabular}{|c|c|c|c|c|c|}
\hline & Estimate & Std. Error & $\mathrm{t}$ value & $\operatorname{Pr}(>|t|)$ & sig \\
\hline (Intercept) & $2.45 \mathrm{E}-01$ & $3.26 \mathrm{E}-02$ & 7.501 & $1.20 \mathrm{E}-05$ & $* * *$ \\
\hline pop & $6.28 \mathrm{E}-08$ & $3.02 \mathrm{E}-08$ & 2.078 & 0.062 & \\
\hline \multicolumn{6}{|c|}{ 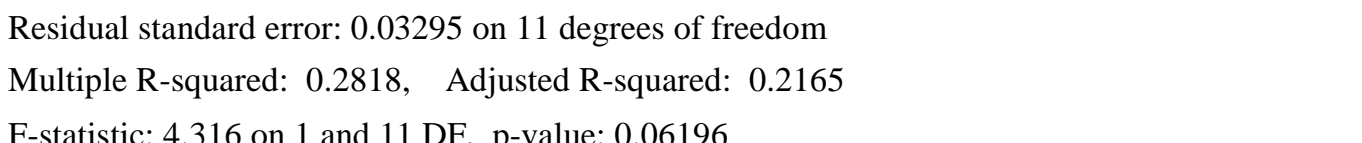 } \\
\hline
\end{tabular}

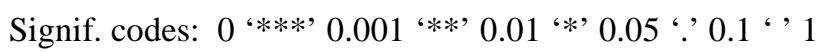

For a detailed description of the analysis and tests for violations of regression assumptions see appendix D.

\section{3: MARKETS AND DISTRIBUTION IN PORTLAND}

The farms that emerged close to the burgeoning city of Portland in the late 1800 and early 1900 's were a direct result of the growing demand for food products by the increasing population. Around this time, outlets also began to emerge which represented a means not only for farmers to sell their goods, but allowed them to engage with local merchants 
and consumers. In 1914 the city designated curb space for market stalls along Southwest Yamhill Street between 2nd and 5th avenues. Popularly known as the Carroll or Yamhill Public Market, it was an instant success. By the early 1920s, six city blocks were lined with canvas-roofed stalls, where farmers sold local fruits, flowers, poultry, vegetables, and butter and eggs. (Oregon Encyclopedia, 2006). While many local farmers sold directly to consumers at the market, the market also afforded the opportunity for farmers to sell products through intermediated channels as storefronts facing the stalls were occupied by grocers, butchers, fishmongers, delicatessens, bakeries, importers of fruits and vegetables, and other food-related businesses (Eigo \& Engeman, 2002).

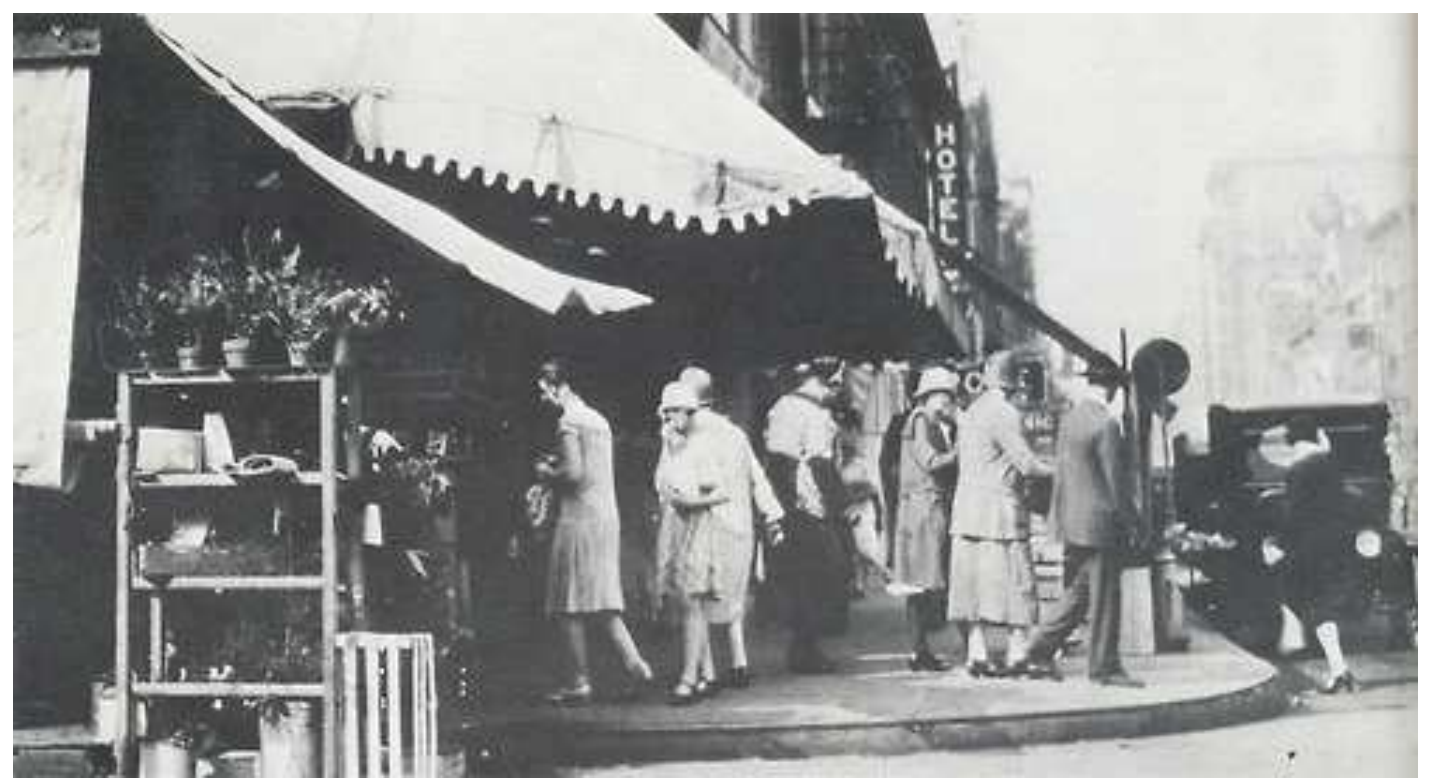

Figure 3.3: Yamhill Street Market (circa 1919) Image source: Tess (1977). 
Fred Meyer had his start in the Yamhill Market, selling coffee from a stand in the line of produce and flower stalls (Tess, 1977) and it was through interactions with farmers and customers as well as other merchants that he conceived of his idea to open a store that mimicked the variety of choices customers had when going to the Yamhill market. In 1922, he opened the first Fred Meyer store in Portland at the corner of SW 5th \& Yamhill, at the far west end of the market. His vision was to give customers more reasons to shop in his store than in any other and he placed a wide variety of stalls selling different products all under one roof and put an expert in charge of each area, setting the stage for the Fred Meyer stores we know today (The Kroger Co, 2014).

Around this time, a number of distribution companies also emerged that facilitated the movement of fresh produce from the rural periphery to the urban core. Once his store opened, Fred Meyer commissioned several of these distributors ensuring his products were fresh and streamlining the process of having to deal with dozens of individual farmers (The Kroger Co, 2014). While Fred Meyer would eventually integrate his entire distribution network, several of these distribution companies still exist and continue to deliver fresh local produce to local establishments (e.g. Sheridan Fruit Co. and Rinella Produce) (Ecotrust, 2013).

In the late 1920's Portland's planning commission deemed the Yamhill market unsanitary, congested and lacked room for expansion. This led to the building of the Portland Public Market on Front Avenue, completed in 1933. It was a large, (three 
blocks long), and sat over the river between the Hawthorne and Morrison bridges.

However the market was never successful. Free parking and acres of space could not compete with the vibrant chaos of the old Yamhill site and was eventually leased to the US Navy would lease the building and eventually the Oregon Journal newspaper purchased it. It was torn down in 1968. Today the site is part of Tom McCall Waterfront (Oregon Encyclopedia, 2006).

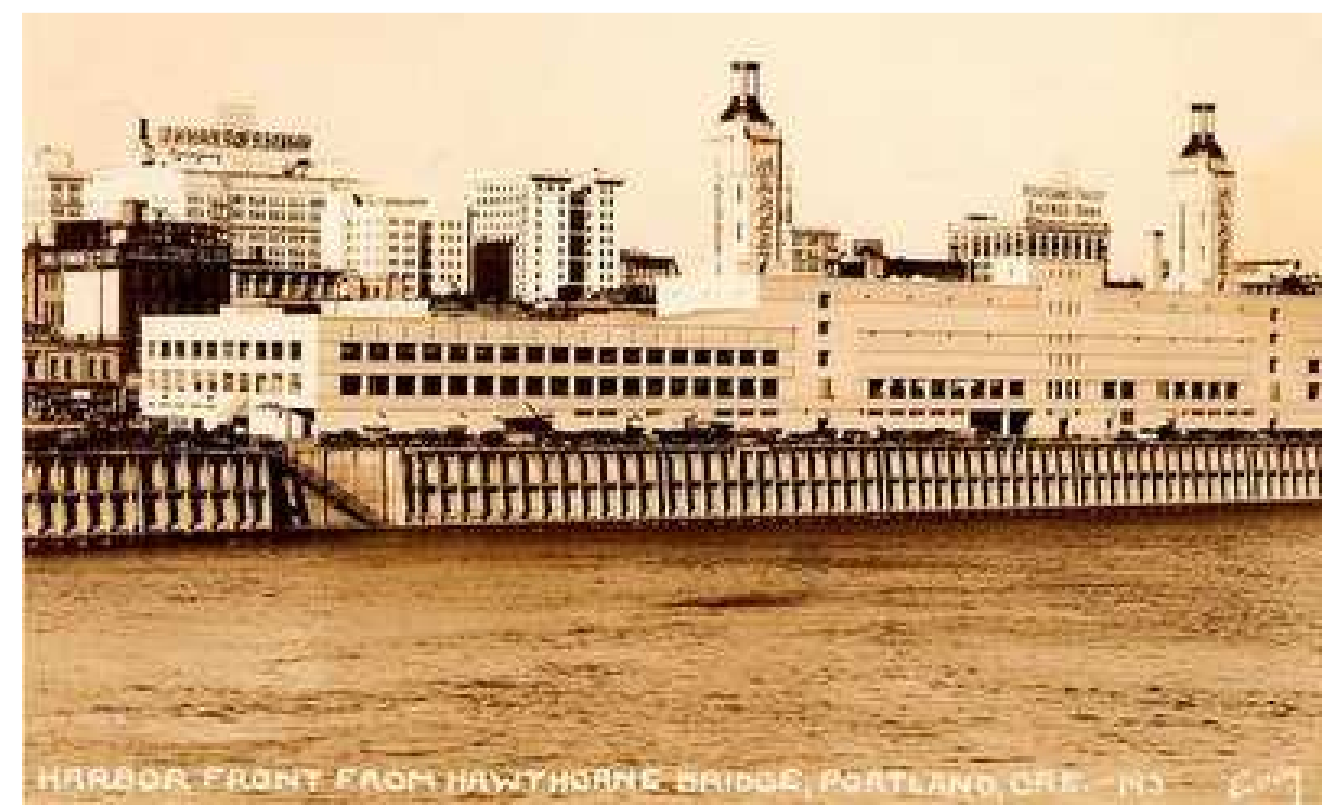

Figure 3.4: Portland Public Market (circa 1933)

Image source: Tess (1977).

\section{4: OREGON'S LAND USE PLANNING LAWS AND EFFECTS ON FOOD SYSTEMS}

Oregon adopted growth management legislation in 1973 and Portland's UGB was proposed in 1977 and approved by the state in 1980 (City of Portland, 2013). Along with phased development inside Urban Growth Boundaries (UGBs), counties in Oregon were 
given the authority of zoning rural lands for exclusive farm use and forest conservation outside these UGBs (Daniels, 1999). In addition, Oregon designated rural residential zones with 3-5 acre minimum lot sizes outside the UGB.

There has been much debate as to the actual effects of the UGB in the Portland Metro Region and whether it has actually curbed urban sprawl and preserved farmlands as was originally intended (Jun, 2004). Empirical analyses show contradicting results about the effects of UGBs on urban development patterns. Some argue that Portland's UGB has contributed to controlling urban sprawl and urbanized density increases (e.g. Patterson, 1999; Kline and Alig, 1999), while others insist that Portland's trend of suburbanization and land use patterns is no better than those of other metropolitan areas (e.g. Cox, 2001) (Jun, 2004)

To test the effects of the Portland Region UGB on farmland structure, I introduced a dummy variable in the analysis presented in section 3.2 that represented the time periods after which the UGB was established. By regressing the proportion of small farms (to total farms) on the population controlled for with the land use law dummy variable, the models predictive power increased substantially (from $\mathrm{R}^{2}=0.2165$ to $\mathrm{R}^{2}=0.4522$ ). However, there was a negative relationship indicating that after the law was introduced, the proportion of small farms decreased. The absolute number of small farms however actually increased after the land use law was put in place. The results indicate that the land use planning law actually have had significant effects on the structure of the metro 
area farmlands in that they seemed to benefit medium and large size farms more so than small farms. While small farms may very well be able to persist close to the urban core even without urban growth boundary protections, the protections afford the inter-firm spillover of knowledge within the farming industry. That is, farmers are more likely to benefit from agglomeration forces related to localization economies because the critical mass required to support specialty services related to food production will be able to persist as population increases.

The land use law that established the UGB in the Portland Metro Region, along with the proximity of fertile farmland to the urban core, and interactions of the urban core and the rural periphery have all contributed in shaping the structure of the current day local and regional food system. It is this structure and interaction that I present in subsequent chapters through an analysis of the differences between local and regional food systems relative to global export-oriented systems, the potential effects of agglomeration economies on food system producers and how geographic space plays a key role in how these effects unfold for different segments of food system participants.

\section{5: CURRENT DAY STRUCTURE OF THE PORTLAND METRO REGION FOOD SYSTEM}

In this section, I present a number of the key characteristics of the regional food economy; in particular the structure of the agricultural sector and the proportion of direct to market sales (employment and revenue characteristics of the food system components 
can be found in Appendix E). While descriptive analysis may help in defining the regional food economy as a whole, without controlling for the multitude of factors that affect regional growth, or being able to isolate the underlying elements of this structure that pertain to the local and regional food system, the analysis does little to tell us of the contributions of local and regional food systems to the regional economy. I present this data therefore only as a means to define the regional food economy as a whole.

\subsection{1: Farm size and value}

Size distribution (structure) of the Portland Metro Region's agricultural economy is significantly different than most regions in the U.S. Small farms dominate the landscape, with the average farm size of just 54 acres in 2007 (relative to the national average of 418 acres) (USDA, NASS, 2007). The 2007 USDA Census of Agriculture reported that in the Three County region, nearly $80 \%$ of all farms are less than 50 acres and over $35 \%$ are less than 10 acres in size. There are only 11 total farms greater than 2,000 acres and 7 of these are in Clackamas County. Less than $10 \%$ of the total area was accounted for by farms larger than 2,000 acres and more than $20 \%$ of the land areas was held by farms of less than 50 acres. Tables 3.2 and 3.3 show the size distribution and structure by number of farms and by acres for each county and for the Three County Region. 
Table 3.2: Number of farms by size class

\begin{tabular}{|l|c|c|c|c|c|}
\hline Farm size category & Clackamas & Multnomah & Washington & Total & $\begin{array}{c}\text { Percent of all } \\
\text { farms }\end{array}$ \\
\hline 1 to 9 acres & 1,502 & 217 & 600 & 2,319 & $36.73 \%$ \\
\hline 10 to 49 acres & 1,773 & 241 & 716 & 2,730 & $43.24 \%$ \\
\hline 50 to 69 acres & 205 & 30 & 97 & 332 & $5.26 \%$ \\
\hline 70 to 99 acres & 153 & 22 & 105 & 280 & $4.44 \%$ \\
\hline 100 to 139 acres & 125 & 14 & 59 & 198 & $3.14 \%$ \\
\hline 140 to 179 acres & 60 & 6 & 34 & 100 & $1.58 \%$ \\
\hline 180 to 219 acres & 33 & 4 & 32 & 69 & $1.09 \%$ \\
\hline 220 to 259 acres & 26 & 3 & 11 & 40 & $0.63 \%$ \\
\hline 260 to 499 acres & 64 & 14 & 52 & 130 & $2.06 \%$ \\
\hline 500 to 999 acres & 36 & 10 & 31 & 77 & $1.22 \%$ \\
\hline 1,000 to 1,999 acres & 5 & 2 & 20 & 27 & $0.43 \%$ \\
\hline 2,000 or more acres & 7 & 0 & 4 & 11 & $0.17 \%$ \\
\hline
\end{tabular}

Table 3.3: Acres by farm size class

\begin{tabular}{|l|c|c|c|c|c|}
\hline Farm size category & Clackamas & Multnomah & Washington & Total & $\begin{array}{c}\text { Percent of } \\
\text { all farms }\end{array}$ \\
\hline 1 to 9 acres & 7,385 & 1,016 & 2,865 & 11,266 & $3.34 \%$ \\
\hline 10 to 49 acres & 40,492 & 5,314 & 16,037 & 61,843 & $18.36 \%$ \\
\hline 50 to 69 acres & 11,938 & 1,737 & 5,669 & 19,344 & $5.74 \%$ \\
\hline 70 to 99 acres & 12,499 & 1,916 & 8,655 & 23,070 & $6.85 \%$ \\
\hline 100 to 139 acres & 14,383 & 1,615 & 6,723 & 22,721 & $6.74 \%$ \\
\hline 140 to 179 acres & 9,461 & 931 & 5,293 & 15,685 & $4.66 \%$ \\
\hline 180 to 219 acres & 6,459 & 762 & 6,420 & 13,641 & $4.05 \%$ \\
\hline 220 to 259 acres & 6,240 & 1,004 & 2,578 & 9,822 & $2.92 \%$ \\
\hline 260 to 499 acres & 22,144 & 4,773 & 17,872 & 44,789 & $13.29 \%$ \\
\hline 500 to 999 acres & 23,532 & 7,119 & 19,749 & 50,400 & $14.96 \%$ \\
\hline 1,000 to 1,999 acres & 6,889 & 0 & 27,193 & 34,082 & $10.12 \%$ \\
\hline 2,000 or more acres & 21,321 & 0 & 8,930 & 30,251 & $8.98 \%$ \\
\hline
\end{tabular}




\subsection{2: Value of farms, direct sales and revenue}

Most farms in the region were valued between $\$ 200,000$ and $\$ 1,000,000$ (65\%). ${ }^{11}$ Total food sales were over $\$ 3.5$ billion, the majority of these coming from livestock and poultry and their products. Vegetables, fruits, nuts and berries accounted for just under $\$ 1$ billion in sales. ${ }^{12}$ Table 3.4 shows the value of farms by value class for each county and the region as a whole.

Table 3.4: Farm value by value class

\begin{tabular}{|l|c|c|c|c|c|}
\hline Farm value class & Clackamas & Multnomah & Washington & Total & $\begin{array}{c}\text { Percent of all } \\
\text { farms }\end{array}$ \\
\hline$\$ 1$ to $\$ 49,000$ & 246 & 46 & 139 & 431 & $6.83 \%$ \\
\hline$\$ 50,000$ to $\$ 99,999$ & 198 & 43 & 114 & 355 & $5.62 \%$ \\
\hline$\$ 100,000$ to $\$ 199,000$ & 302 & 63 & 132 & 497 & $7.87 \%$ \\
\hline$\$ 200,000$ to $\$ 499,999$ & 1,365 & 161 & 494 & 2,020 & $32.00 \%$ \\
\hline 4500,000 to $\$ 999,999$ & 1,369 & 167 & 560 & 2,096 & $33.20 \%$ \\
\hline$\$ 1,000,000$ to $\$ 1,999,999$ & 367 & 53 & 207 & 627 & $9.93 \%$ \\
\hline$\$ 2,000,000$ to $\$ 4,999,999$ & 109 & 20 & 87 & 216 & $3.42 \%$ \\
\hline$\$ 5,000,000$ to $\$ 9,999,999$ & 25 & 10 & 24 & 59 & $0.93 \%$ \\
\hline$\$ 10,000,000$ or more & 8 & 0 & 4 & 12 & $0.19 \%$ \\
\hline
\end{tabular}

The 2007 USDA Census of Agriculture also showed that a total of 1,245 farms or 19.29\% of all food farms in the Three County Region (i.e., excluding products such as hay, Christmas trees, or ornamentals) reported direct to market sales. Their direct sales

\footnotetext{
${ }^{11}$ Farm value includes value of land and all structures

${ }^{12}$ Figures for farm value and sales are 2007 dollars
} 
however represented less than $4 \%$ of all food sales. The 2007 count actually represents a decrease in total farms from 2002 selling direct to market, when 1,374 farms reported direct sales however it represents an increase in terms of the proportion of all food farms that sold directly (18.44\% in 2002). These figures are significantly higher than the national average ( $6.1 \%$ of farms in 2007 and $<1 \%$ of sales) as well as the Oregon average (13.27\% of farms and $1.56 \%$ of sales in 2007). There was also a sharp increase from 2002 to 2007 in the proportion of sales through direct markets (2.1\% in 2002 to $3.94 \%$ in 2007 - an $87.1 \%$ increase). Table 3.5 shows the statewide and region-wide estimates of total sales by product category and direct sales for all categories for 2002 and 2007.

Table 3.5: Sales by crop and proportion of direct sale for the Three County Region

\begin{tabular}{|l|r|r|r|r|}
\hline Type & farms 2007 & farms 2002 & sales 2007 & sales 2002 \\
\hline $\begin{array}{l}\text { Vegetables, melons and } \\
\text { potatoes }\end{array}$ & 285 & 390 & 37,860 & 27,549 \\
\hline Fruits, tree nuts, and berries & 958 & 1,147 & 87,685 & 49,414 \\
\hline $\begin{array}{l}\text { Livestock, poultry, and their } \\
\text { products }\end{array}$ & 2,564 & 3,002 & 81,198 & 75,533 \\
\hline Poultry and eggs & 545 & 488 & 41,684 & 40,070 \\
\hline Cattle and calves & 1,395 & 1,631 & 12,396 & 9,237 \\
\hline $\begin{array}{l}\text { Milk and other dairy products } \\
\text { from cows }\end{array}$ & 52 & 52 & 12,504 & 13,890 \\
\hline Hogs and pigs & 196 & 266 & 1,471 & 906 \\
\hline Sheep, goats, and their products & 458 & 475 & 836 & 814 \\
\hline Total (food products) & 6,453 & 7,451 & 275,634 & 217,413 \\
\hline direct sales (food products) & 1,245 & 1,374 & 10,850 & 4,575 \\
\hline proportion of direct sales & $19.29 \%$ & $18.44 \%$ & $3.94 \%$ & $2.10 \%$ \\
\hline $\begin{array}{l}\text { Proportion of direct sales } \\
\text { (Statewide) }\end{array}$ & $13.27 \%$ & $12.88 \%$ & $1.56 \%$ & $0.83 \%$ \\
\hline
\end{tabular}


A total of 4,074 farms or $64 \%$ of the region's total farms and ranches reported a net loss in 2007. There are variety of reasons farms stay in operation despite farm losses, but one common explanation is that the farm provides other types of returns such as asset appreciation and a dwelling. Furthermore, most families operating small farms rely on off-farm income for support (Brown et al. 2014). I will cover this point later in the chapter.

\section{6: DIFFERENCES BETWEEN LOCAL AND NON-LOCAL FOOD PRODUCERS IN CLACKAMAS COUNTY}

I conclude with a brief analysis of differences between local and non-local food producers in Clackamas County to highlight general differences that might be observed at the regional scale. This analysis draws on the Clackamas County Producers' Survey ("the Survey") used extensively throughout this dissertation. The dataset is described in detail in the following chapter. For a detailed analysis of all agricultural production in the County see appendix F. The Survey presented a series of questions specific to the location of the final sale of products. Four different geographies were specified: international, national, regional (West Coast) and local (Portland Metro area). Also included was a category for "other" that allowed room for explanation. Respondents were able to specify any or all of the geographies and in some cases, respondents specified both local as well as non-local for their products. A total 719 respondents answered the question specific to geography of product sales $(71.3 \%)$. Of these $350(48.6 \%)$ sold their products exclusively to local markets, $95(13.2 \%)$ sold some but not all of their product(s) 
locally (local non-exclusive) and 275 (38.2\%) didn't sell any product locally (non-local). This indicated that producers to a large degree were either participating in local or nonlocal supply chains but rarely both. I therefore stratified the population into two categories: local-exclusive, and non-local (which included all but three of the producers who were local-nonexclusive) $)^{13}$.

Of the respondents who answered the question(s) pertaining to geography of product, all but 23 (696) answered the question pertaining to what types of products they produced and of these, 326 respondents stated that at least $15 \%{ }^{14}$ of their farm income came from sales of food products ${ }^{15}$ however, many of these were ranchers dealing exclusively in livestock. There were 132 respondents who answered the geography question and stated that at least $15 \%$ of their farm income was derived from food products other than livestock. Of the 326 food producers (including livestock), $44.8 \%$ were non-local and $55.2 \%$ were local exclusive. This proportion was roughly equivalent when the livestock producers were removed (56.1\% local exclusive and $43.9 \%$ non-local).

I used the above strata to perform a series of group tests to identify differences between local and non-local producers. Using chi-square tests, I found that local producers were more likely to grow food $\left(\chi^{2}=5.1883, \mathrm{df}=1, \mathrm{p}\right.$-value $\left.<0.1\right)$. Of the food producers,

\footnotetext{
${ }^{13}$ There were three respondents who indicated they sold products directly to consumers who also indicated selling product in export markets - these were grouped with local producers. See chapter IV for description.

${ }^{14}$ I used 15\% as a threshold for classifying food producers assuming anything under this amount was used for subsistence or other non-traded uses.

${ }^{15}$ Food product categories included: berries, livestock, eggs, fruits and nuts and vegetables.
} 
local food producers were more likely to grow produce. This is likely due to the fact that produce products are more perishable and as such are more likely to be sold close to where they are produced. Local food producers were more likely to use social media than their nonlocal counterparts. Because local food producers are more likely to sell their product directly $\left(\chi^{2}=45.4604, \mathrm{df}=1, \mathrm{p}\right.$-value $\left.<0.001\right)$, they probably rely on these forms of social media to market their products. They were also less likely to have perceived barriers to markets $\left(\chi^{2}=6.1268, \mathrm{df}=1, \mathrm{p}\right.$-value $\left.=0.01332\right)$ and less likely to view access to labor as a barrier (see below). As expected, local food producers (as well as local producers more broadly) were far more likely to market their products directly.

I also performed series of one-way, analysis of variance (ANOVA) tests to determine whether there was a difference in the mean age of the producer for local exclusive and non-local food producers (of all food producers and the subset of non-livestock food producers) as well as to test whether there was a difference in the number of employees (estimated fte's). Local food producers were found to be younger (mean $=60.7$ years) compared to non-local producers (mean $=64.3$ years). Results indicated that these means differed significantly, $F(1,282)=4.791, \mathrm{p}<.1$. When livestock was removed from the set of food producers, there remained a difference however this difference was no longer significant $($ local producers mean $=57.7$, non-local producers mean $=61.2, \mathrm{~F}(1,117)=$ $2.265, \mathrm{p}=0.135$ ). Local food producers were also found to employ fewer employees $($ mean $=1.8 \mathrm{fte}$ 's $)$ compared to non-local producers $($ mean $=4.8 \mathrm{fte}$ 's $)$. Results indicated that these means differed significantly, $\mathrm{F}(1,218)=8.412, \mathrm{p}<.01$. This in all likelihood is 
directly related to the fact that local producers tend to farm smaller parcels and therefore have smaller operations. However, it also has economic development implications. Further analysis showed that local food producers employed more workers per acre (local producers mean $=2.6$, non-local producers mean $=1.2, \mathrm{~F}(1,117)=5.161, \mathrm{p}=0.015)$.

\section{7: CONCLUSION}

The history and current structure of the Portland Metro Region food system has implications for economic development, particularly in terms of the distribution of farms across the landscape and how small farms as well as agricultural land in general, has been able to persist close to the urban core. This proximity tends to reduce transport costs of producers transporting goods to urban markets but also facilitates the exchange of information that originates from the urban core. This is born out in the characteristics of local food producers relative to non-local producers as I have shown in the previous section but also is something that I explore at length through my spatial and qualitative analyses presented in chapters V and VI. In the next chapter I turn to a description of my methods and the data used throughout this dissertation. 


\section{CHAPTER IV: DATA AND METHODS USED IN DESCRIPTIVE, QUANTITATIVE AND QUALITATIVE ANALYSES}

\section{1 - METHODS}

I applied a mixed methods approach that draws on a wide variety of historic records and documents, contemporary literature, secondary data, a recent survey of producers in Clackamas County a set of open ended interviews with food producers in the region and participant observations through two workshops associated with my place of employment (Ecotrust). I used these data sources to both differentiate the local food system sector from its more outward facing counterpart through descriptive analysis as well as quantify differences based on key variables including aspects of geographic space. Subsequently, through a series of open ended, semi-structured interviews of local food system participants identified through existing contacts in the community, I explored some of the key themes pertaining to knowledge accumulation and innovation diffusion in the context of aspects of regional economic development such as agglomeration economies, knowledge spillovers, business life cycle and central place characteristics.

My process followed a four phase data collection and analysis approach (figure 4.1) that included: 1) a comprehensive review and descriptive analysis of existing literature and historical datasets and quantitative analysis of Clackamas County Producers' dataset produced as part of Clackamas County's agricultural opportunities assessment survey to differentiate the systems by highlighting differences between supply chains, producers 
and products of each system; 2) manipulation and spatial analysis of the same Clackamas County Producers' dataset to identify patterns of clustering; 3) qualitative analysis to investigate aspects of innovation and knowledge accumulation including primary data collection through semi-structured interviews of food system participants focusing on food producers and; 4) an overview of the theoretical frames and potential implications for economic development resulting from local and regional food systems using the above data sources, participant observation, and recent empirical research pertaining to food systems and economic development.

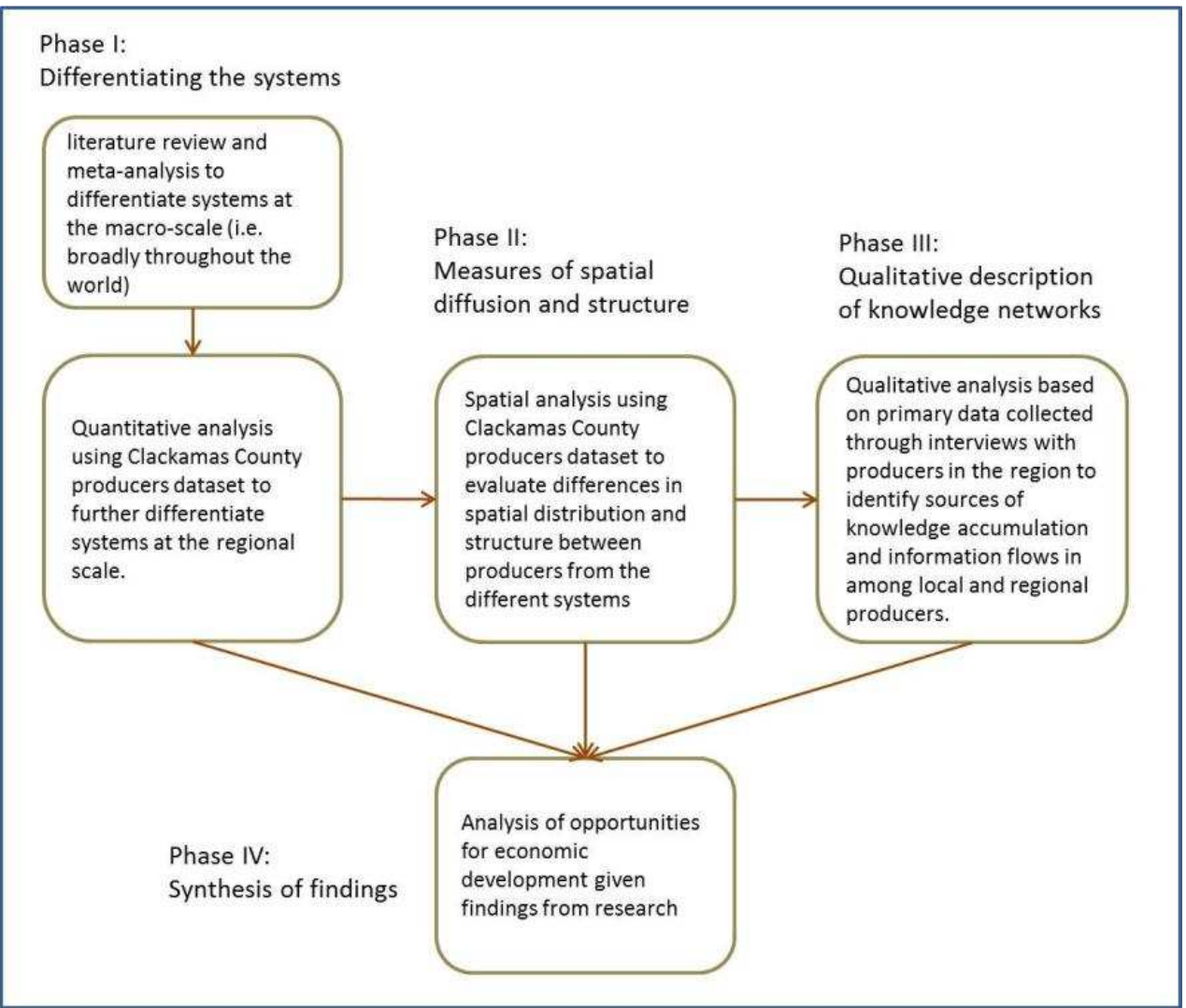

Figure 4.1: Graphical representation of the four phase approach 
The research design was specifically tailored to test the hypotheses presented above.

Methods for testing each of the hypotheses are covered in table 4.1. A more detailed

description of the four-phased approach follows.

Table 4.1: Methods for testing research hypotheses

\begin{tabular}{|c|c|c|c|}
\hline Hypothesis & $\begin{array}{l}\text { Research } \\
\text { design }\end{array}$ & Description & Data sources \\
\hline $\begin{array}{r}\text { The nfe can } \\
\text { be } \\
\text { differentiated } \\
\text { is new and } \\
\text { growing }\end{array}$ & Descriptive & $\begin{array}{l}\text { Qualitatively and } \\
\text { quantitatively describe the } \\
\text { recent emergence of the new } \\
\text { food economy in the Portland } \\
\text { area as well as around North } \\
\text { America and Europe. }\end{array}$ & $\begin{array}{l}\text { USDA agricultural censes } \\
\text { (early 1900's to 2007), USDA } \\
\text { economic research service, } \\
\text { other secondary data, historic } \\
\text { and planning documents } \\
\text { Clackamas County Producers } \\
\text { Survey and academic research }\end{array}$ \\
\hline $\begin{array}{r}\text { Actors in the } \\
\text { nfe are } \\
\text { subject to } \\
\text { aspects of } \\
\text { agglomeration } \\
\text { different than } \\
\text { export- } \\
\text { oriented } \\
\text { actors }\end{array}$ & $\begin{array}{l}\text { Qualitative } \\
\text { analysis }\end{array}$ & $\begin{array}{l}\text { Qualitative analysis to uncover } \\
\text { aspects of innovation and } \\
\text { innovation diffusion specific } \\
\text { to products and marketing of } \\
\text { products. }\end{array}$ & $\begin{array}{l}\text { semi-structured interviews } \\
\text { with food system actors } \\
\text { (producers, distributors, } \\
\text { processors and retailers) }\end{array}$ \\
\hline $\begin{array}{r}\text { NFE actors } \\
\text { will cluster } \\
\text { close together } \\
\text { and close to } \\
\text { urban core }\end{array}$ & $\begin{array}{l}\text { Quantitative / } \\
\text { spatial analysis }\end{array}$ & $\begin{array}{l}\text { Stratify the sample according } \\
\text { to participation in local food } \\
\text { networks and perform a series } \\
\text { of spatial analyses using } \\
\text { measures of dispersion on each } \\
\text { segment. }\end{array}$ & $\begin{array}{l}\text { Clackamas County producers } \\
\text { survey, Clackamas County } \\
\text { Processors / Distributors } \\
\text { database, metro taxlot } \\
\text { data,Foodhub database }\end{array}$ \\
\hline $\begin{array}{r}\text { Urban and } \\
\text { regional form } \\
\text { will affect the } \\
\text { contributions } \\
\text { of nfe to } \\
\text { regional } \\
\text { economies }\end{array}$ & $\begin{array}{l}\text { Descriptive / } \\
\text { historic }\end{array}$ & $\begin{array}{l}\text { Qualitative and quantitative } \\
\text { analysis of how land use and } \\
\text { regulatory considerations (e.g. } \\
\text { Oregon's landuse goals) as } \\
\text { well as social and political } \\
\text { characteristics, affects the } \\
\text { efficiencies and emergence of } \\
\text { the new food economy. }\end{array}$ & $\begin{array}{l}\text { USDA agricultural censes } \\
\text { (early 1900's to 2007), USDA } \\
\text { economic research service, } \\
\text { other secondary data, historic } \\
\text { and planning documents and } \\
\text { academic research }\end{array}$ \\
\hline
\end{tabular}




\subsection{1 - Descriptive analysis}

Using secondary data, documents, and academic research for key geographies, I qualitatively and quantitatively analyzed the recent emergence of the new food economy in the Portland area, as well as around North America and Europe. This analysis highlights the key theoretical lenses that have been applied in food systems analyses. I then use these models to situate my analysis of the Portland Metro Area food system. There is an abundant amount of literature that attempts to characterize local and regional food systems by juxtaposing them against the global, dominant systems. I drew on this literature, coupled with secondary data, in an attempt to differentiate the two systems in terms of differences pertaining to discrete economic sectors. Data include key statistics and publications from multiple sources including: USDA agricultural censes (early 1900's to 2007), USDA Economic Research Service documents and data, processor and distribution data from Oregon Department of Agriculture and OSU extension reports among others. I focused my analysis on differentiating key components of the different systems including; supply chains, producers and products. 


\subsection{2 - Quantitative analysis}

At the heart of my quantitative analysis is a dataset resulting from the Clackamas County Producers' Survey as part of the Clackamas County Agricultural Opportunities Assessment. The survey was conducted in late 2011 and early 2012 resulting in a database representing 1,009 agricultural producers in Clackamas County. In the fall of 2011, Clackamas County Business and Economic Development Division mailed to all known producers in the County a letter asking for participation in the survey, instructions on how to fill out the survey through a web based portal and a request form for a paper version of the survey for those who didn't have web access or otherwise preferred a hard copy version. After six weeks, those producers who did not respond to the original mailing were mailed a supplemental letter asking for their participation in the survey. 4,014 requests were mailed and 1,009 entries were recorded representing over a $25 \%$ response rate. To verify statistical relevance, I compared several questions in the Survey against estimated 2011 figures from the USDA NASS 2007 Census of Agriculture (described in detail in the following sections). Although not published publicly, the County granted me rights to use the data in my analysis. A detailed list of all survey questions and number of responses for each question can be found in Appendix A.

The data was used to both supplement my analysis of hypothesis 1 - the new food economy can be differentiated from the export oriented agro-food sector - as well as to test hypothesis $2 b$ - the new food sector is dominated by smaller actors clustered close together and close to the urban core - described in section 1.5.3. 
Using the market and outlet information, I first filtered the data to insure only agro-food producers were considered (e.g. producers of nursery stock or other non-food items were not considered in my analysis). Subsequently, I stratified the sample into two discrete categories - producers that target local and regional markets (Portland metro exclusively) and producers that export their products outside the region. Less than $10 \%$ of food producers participated in both local and non-local supply chains and only three of these marketed their products directly. I grouped the three respondents who marketed their products directly to consumers with the local-exclusive segment and the others with the non-local category. Using these categories I employed hypothesis-testing statistics to determine if the segments of the population were significantly different based on a wide array of variables. I used chi-square and ANOVA tests to determine whether local food producers are more likely to produce specific types of crops, have smaller farms, have different demographic characteristics, participate in different supply chain channels, have different sources of financing, and/or receive their information from different sources. The analyses are presented in detail in Chapter V.

\section{2: TESTING THE REPRESENTATIVENESS OF THE CLACKAMAS COUNTY PRODUCERS' SURVEY}

To test for representativeness at the County scale and at the Three County Region scale, I compared several key variables against the USDA NASS 2007 Census of Agriculture. Specifically, I compared the survey against the Census for age distribution, proportion of 
farms that market products directly to consumers, the proportion of farms by crop type and the proportion of acres by crop type. While I used more attributes in my group comparisons in chapter $\mathrm{V}$, there was no direct way to test for the representativeness of these attributes, as they were not available in the 2007 Census.

\subsection{1: Age distribution comparison}

Because the 2012 Census data was unavailable at the time of this analysis, I "grew forward" the age distribution of the 2007 Census data to insure temporal consistencies between the Census and the Clackamas County Producers' Dataset. To do so, I used the 2002 Census data to simulate a number of age distributions by randomly distributing a sample of individuals across their respective age category in 2002 and adding 5 years to derive adjusted age categories in 2007. I then took the average residual difference between the actual 2007 and the adjusted 2007 across 100 simulations for each age category to estimate the addition or attrition of individuals at each age category. Figure 4.1 shows the 2002, 2007 and predicted 2007 age distributions. 


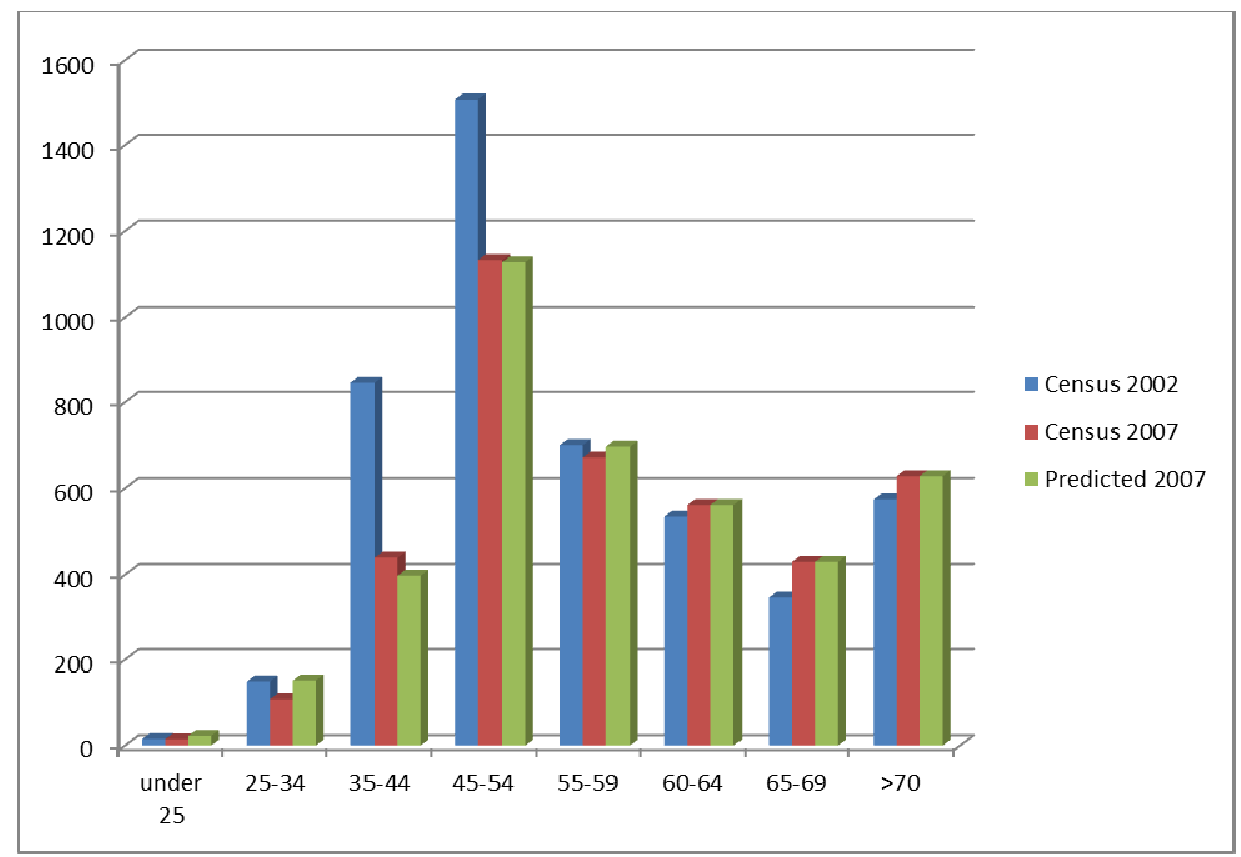

Figure 4.2: 2002, 2007 and predicted 2007 census age distribution

I then added 4 years to a sample of randomly distributed individuals across age categories in 2007 and applied the average residual by age category derived from the first step assuming the 2002 to 2007 attrition / addition rates by category were the same between 2007 and 2011, to estimate the age distribution in 2011. Figure 4.2 shows the 2002, 2007 and predicted 2011 age categories. Finally, I randomly distributed the predicted 2011 categories across their respective age categories and re-categorized them to match the age categories reported in the Survey. 


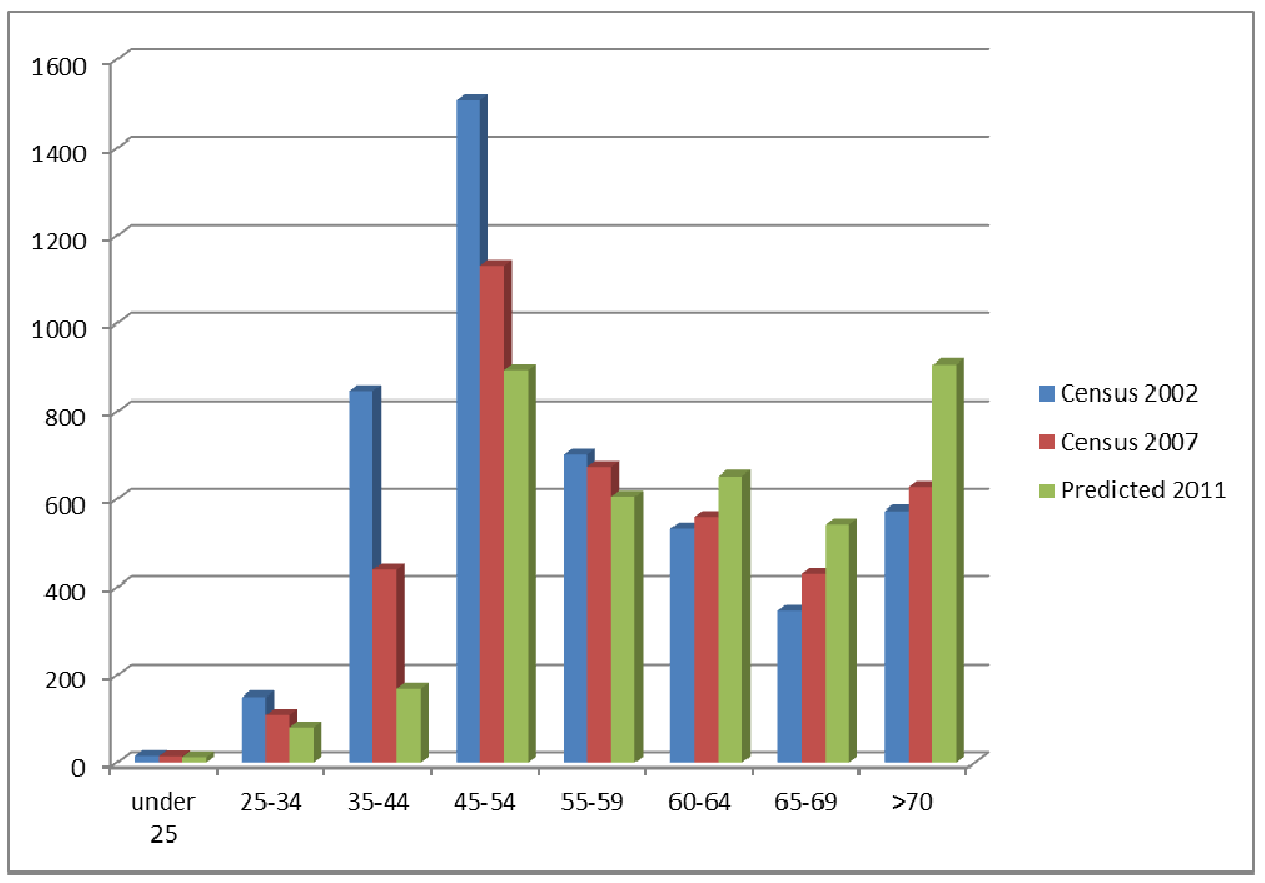

Figure 4.3: 2002, 2007 and predicted 2011 census age distribution

Figure 4.3 shows the 2011 predicted age distributions and the actual age distributions reported in the Producers' survey. The age distributions between the Census and the Survey match fairly well. As seen in the figure, the survey looks to have overrepresented the older age categories and but seems fairly consistent with other categories. It is difficult to assess the reason behind this over-representation but it might affect the results when considering aspects of local and regional food systems as Lowe and Vogel (2011) showed that producers who are involved with local and regional supply chains tend to be younger. However, considering the Survey results specific to directly marketed foods is consistent with the Census data, the over-representation of older age categories is less of a concern. 


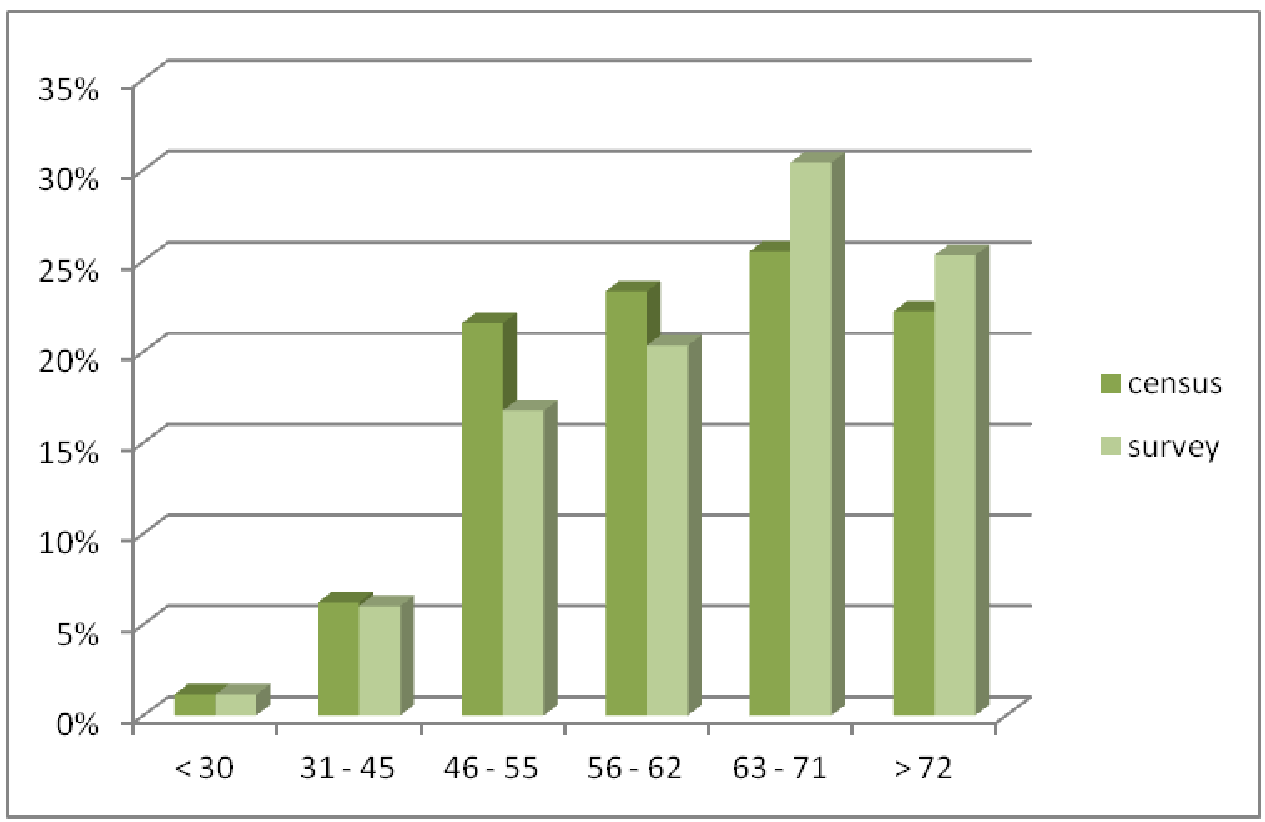

Figure 4.4: Proportional age class comparison between the 2011 predicted Census of Agriculture and Survey respondents

\subsection{2: Comparison of the share of direct sales}

I then evaluated the ratio of the total number of farms that directly marketed food products to consumers relative to all farms for both the 2007 Census of Agriculture and the Survey (expressed as percent share of farms). I assumed the same annual growth rate in terms of this ratio using data from the 2002 and 2007 Census of $0.91 \%$ to estimate the ratio for 2011. The ratio reported in the Census for Clackamas County was $17.99 \%$ in 2002 and $19.73 \%$ in 2007. The ratio reported in the Census for the Three County Region was $18.66 \%$ and $19.72 \%$ for 2002 and 2007 respectively. The estimated ratio from the Census data for 2011 was $21.26 \%$ and $20.44 \%$ for the County and the Three County 
Region respectively. The ratio reported in the Survey for 2011 was $20.71 \%$. Table 4.2 shows the farms that marketed food products directly to consumers, the total farms and the ratios for 2002, 2007 and predicted 2011 reported in the Census of Agriculture and the farms that marketed food products directly to consumers, the total farms and the ratio for 2011 reported in the Survey.

Table 4.2: Share of number of farms that market directly

\begin{tabular}{|l|c|c|c|c|}
\hline Census & $\begin{array}{l}\text { Farms selling } \\
\text { direct }\end{array}$ & All farms & $\begin{array}{l}\text { Share of direct } \\
2007\end{array}$ & $\begin{array}{l}\text { Estimated share } \\
2011\end{array}$ \\
\hline Clackamas & 787 & 3989 & $19.7 \%$ & $\mathbf{2 1 . 6 \%}$ \\
\hline Multnomah & 133 & 563 & $23.6 \%$ & $26.1 \%$ \\
\hline Washington & 325 & 1761 & $18.5 \%$ & $17.0 \%$ \\
\hline Total & 1245 & 6313 & $19.7 \%$ & $\mathbf{2 0 . 6 \%}$ \\
\hline $\begin{array}{l}\text { Clackamas } \\
\text { Survey }\end{array}$ & 209 & 1009 & & $\mathbf{2 0 . 7 \%}$ \\
\hline
\end{tabular}

\subsection{3: Comparison of crop types.}

I compared both the number of farms and total acres under production for different crop types between the Census and the Survey. Reported crop proportions did not significantly change between 2002 and 2007 therefore I directly compared the proportions from the 2007 Census against the 2011 Survey. I compared proportions for both Clackamas County as well as the Three County Region against the Survey response proportions to gain an understanding of representativeness at the County and Regional scales. Tables 4.3 and 4.4 show the proportion of farms and acres devoted to each crop category for both the Census and the Survey. 
Table 4.3: Proportion of farms of different crop types under production (Census v. Survey comparison)

\begin{tabular}{|l|c|c|c|c|c|c|}
\hline Farms & $\begin{array}{c}\text { Clackamas } \\
\text { farms } \\
\text { (Census) }\end{array}$ & $\begin{array}{c}\text { Regional } \\
\text { Farms } \\
\text { (Census) }\end{array}$ & $\begin{array}{c}\text { Regional } \\
\text { Proportion } \\
\text { (Census) }\end{array}$ & $\begin{array}{c}\text { Clackamas } \\
\text { Proportion } \\
\text { (Census) }\end{array}$ & $\begin{array}{c}\text { Survey } \\
\text { Farms }\end{array}$ & $\begin{array}{c}\text { Survey } \\
\text { Proportion }\end{array}$ \\
\hline $\begin{array}{l}\text { Fruits and } \\
\text { nuts }\end{array}$ & 361 & 897 & $13.87 \%$ & $10.96 \%$ & 95 & $11.46 \%$ \\
\hline Other crops & 4 & 7 & $0.11 \%$ & $0.12 \%$ & 8 & $0.97 \%$ \\
\hline Field crops & 48 & 294 & $4.55 \%$ & $1.46 \%$ & 71 & $8.56 \%$ \\
\hline $\begin{array}{l}\text { Vegetables } \\
\text { and melons }\end{array}$ & 499 & 1,115 & $17.25 \%$ & $15.15 \%$ & 63 & $7.60 \%$ \\
\hline Berries & 376 & 800 & $12.37 \%$ & $11.41 \%$ & 52 & $6.27 \%$ \\
\hline $\begin{array}{l}\text { Seed crops, } \\
\text { grasses \& } \\
\text { pasture }\end{array}$ & 2,006 & 3,352 & $51.85 \%$ & $60.90 \%$ & 540 & $65.14 \%$ \\
\hline Total & 3,294 & 6,465 & & & 829 & \\
\hline
\end{tabular}

Table 4.4: Proportion of acres of different crop types under production (Census v. Survey comparison)

\begin{tabular}{|l|c|c|c|c|c|c|}
\hline Acres & $\begin{array}{c}\text { Clackamas } \\
\text { acres } \\
\text { (Census) }\end{array}$ & $\begin{array}{c}\text { Regional } \\
\text { acres } \\
\text { (Census) }\end{array}$ & $\begin{array}{c}\text { Region } \\
\text { Proportion } \\
\text { (Census) }\end{array}$ & $\begin{array}{c}\text { Clackamas } \\
\text { Proportion } \\
\text { (Census) }\end{array}$ & $\begin{array}{c}\text { Survey } \\
\text { Acres }\end{array}$ & $\begin{array}{c}\text { Survey } \\
\text { Proportion }\end{array}$ \\
\hline $\begin{array}{l}\text { Fruits \& } \\
\text { nuts }\end{array}$ & 5,316 & 14,826 & $9.06 \%$ & $7.35 \%$ & 5,307 & $11.68 \%$ \\
\hline Other crops & 217 & 217 & $0.13 \%$ & $0.30 \%$ & 562 & $1.24 \%$ \\
\hline Field crops & 1,328 & 14,429 & $8.82 \%$ & $1.84 \%$ & 5,060 & $11.13 \%$ \\
\hline $\begin{array}{l}\text { Vegetables } \\
\text { and melons }\end{array}$ & 2,857 & 7,350 & $4.49 \%$ & $3.95 \%$ & 4,531 & $9.97 \%$ \\
\hline Berries & 3,535 & 9,656 & $5.90 \%$ & $4.89 \%$ & 1,652 & $3.63 \%$ \\
\hline $\begin{array}{l}\text { Seed crops, } \\
\text { grasses \& } \\
\text { pasture }\end{array}$ & 59,032 & 117,082 & $71.58 \%$ & $81.67 \%$ & 28,338 & $62.35 \%$ \\
\hline Total & 72,285 & 163,560 & & & 45,450 & \\
\hline
\end{tabular}

There were fairly significant differences between the Survey and the Census for both the proportion of farms and proportion of acres for both vegetables and field crops. Many 
more producers reported growing vegetables in the Survey than in the Census. This may be due to the amount of vegetable production that does not enter into traditional supply chains. That is, producers in the Survey may have indicated vegetable production for onfarm use (consumption, trade or animal feed) whereas the Census only reports vegetables sold. The differences in field crops were in all likelihood associated with conflation of seed crops and pasture land.

\section{3: SPATIAL ANALYSIS}

Geographic Information Systems (GIS) offer an ideal framework for collection, storage, analysis and display of spatial data. In of itself GIS can be used as a powerful tool to answer a suite of research questions pertaining to regional food production activity in the Portland metro region. More importantly, GIS can serve as a framework to answer very specific questions through spatial analysis that can test the hypotheses specified above. In particular, GIS is well suited to answer three types of questions: what are the site characteristics and existing conditions for any given location and how do they differ between different locations; what are the spatial distribution patterns of actors across the landscape relative to each other (spatial structure) and; what are important distance measures in terms of estimating transportation costs and diffusion of knowledge and technology (spatial diffusion). I used three measures to test hypothesis $2 \mathrm{~b}$ - participants in the new food economy farm smaller plots of land, are clustered close together and are close to the urban core. 
The starting point for my analysis was to get an understanding of where food system actors currently exist. Specific locations were assigned to each record in the Clackamas County producer data set through a process of geo-coding. Geo-coding uses site addresses to map - in geographic space - the locations of each producer. Once geocoded, I performed a series of analyses known as exploratory spatial data analysis (ESDA) to test for measures of spatial distribution and structure of agricultural producers in Clackamas County. Distribution refers to the diffusion of actors away from the urban core and structure refers to the clustering of actors with thematic similarities. The spatial analyses and results are presented in detail in Chapter VI.

To test the spatial representativeness of the data I tested for measures of spatial autocorrelation within the spatial sample relative to how agricultural lands are distributed throughout the County. These methods are described in more detail in chapter VI.

\section{4: QUALITATIVE ANALYSIS}

One of the fundamental themes underlying my hypotheses is that geographic space constrains the diffusion of innovation and knowledge accumulation; that innovations for new sectors are largely an urban process and therefore the emergence of the new food economy is regional in scale. While I have outlined the theories that support this hypothesis, empirical data pertaining to innovations and knowledge accumulation are rarely observable. For this reason, I applied a qualitative approach in which I interviewed 14 food system actors focusing on producers to gain a rich understanding of the processes 
of innovation and the sources of knowledge and to help explain the findings of my spatial analysis.

My interviews were conducted in the fall of 2013 and early winter of 2014. Through these semi-structured interviews I presented a set of open-ended questions leaving room for as many additional questions as necessary. Prior to conducting these interviews, I submitted an application for Human Subjects Review to The Institutional Review Board and Portland State University and subsequently received permission to move forward with the interviews. I drew on these interviews to test differences in the local / global binary and support my quantitative analyses. That is, my line of inquiry was focused on understanding patterns that had emerged in my quantitative analysis specific to producers who participated in local and regional supply chains. Furthermore, I presented a series of questions aimed at understanding whether sources of knowledge, inspiration, and innovation could be used to describe differences from a more globalized system.

Additionally, I asked questions about producers' backgrounds and sources of knowledge pertaining to not only production efficiencies and product innovations but also processes of sales and marketing. Finally I asked several questions pertaining to the meaning of a "neighbor" and whether "neighbors" were important in product or process innovations either directly or indirectly. While each interview did not follow this specific list, I used it as a framework to conduct my interviews. The general rubric used as a guideline to conduct my interviews is presented in appendix $\mathrm{C}$. 


\subsection{1: Sample selection}

I used a snowball sampling technique (see Thomson, 1997), where I developed a list of potential interviewees through my professional, personal, and academic contacts I had previously made in the local and regional food system community. In addition to interview questions pertaining to my primary research hypothesis, I asked that they provide names and contacts of other potential interviewees who they deemed as knowledgeable in the subject matter. This technique, while not intended to derive a representative sample, is a well-accepted approach in qualitative research that provides a means of accessing more impenetrable or hard to identify social groupings.

I contacted 16 individual producers from my original list, eight of whom agreed to participate in the research. From these interviews, I obtained 12 additional names and contact information (not on my original list), four of whom agreed to participate in the research of which I was able to obtain an additional six names and contact information, two of whom also agreed. I contacted potential interviewees via email and if they agreed, I sent them a letter of consent prior to the interview. Interviews were conducted in person or over the telephone. Each interview was recorded and recordings were subsequently transcribed. I used the transcriptions to both quantify aspects of the individual interviewees as well as identify themes specific to information flows and importance of social networks. Data was used as part of my qualitative analysis presented in Chapter VI. 
The resulting data were used to supplement my quantitative analyses and derive information pertaining to producers' perspectives of processes of knowledge accumulation.

\section{5: PARTICIPANT OBSERVATION}

In addition to the qualitative interviews, I participated in two different workshops attended by experts in local and regional food supply chains and food systems more broadly. I attended these meeting as a representative of my place of employment (Ecotrust). The first meeting was held on March $11^{\text {th }}, 2014$ and included leaders and stakeholders in the Oregon business community. The meeting was specific to the research needs for developing strategies to foster economic clusters specific to food systems. A key topic of the discussion included the potential to foster local and regional food systems. I contributed input to the meeting, sharing some of my experiences gained through the research presented here as well as through my experience working in food systems more broadly. I collected detailed notes of the meetings paying close attention to the different aspects of cluster development strategies for the different sectors. Information which I gleaned from this meeting was used to support my synthesis presented in Chapter VII.

The second meeting was held on April $18^{\text {th }}, 2014$ and included food systems researchers, food producers, distributors and retailers, investors and representatives from the Oregon Department of Agriculture. The focus of this workshop was specific to food 
infrastructure needs to foster more local and regional production and consumption. Like the first meeting, I contributed input to the meeting, sharing some of my experiences gained through my research presented experience working in food systems. Topics included a top-level discussion around the definition of local and regional food systems, the primary potential future drivers and barriers to the system and a deep dive into some of the infrastructure needs specific to different food crops grown here throughout the State and the Region. I used the information obtained from this workshop to help support my analysis of the differences between the local and regional and export oriented food systems as well as to support my analysis of economic develop potential of local and regional food systems presented in Chapter VII.

\section{6: DISTRIBUTORS' AND PROCESSORS' SURVEYS}

In 2012, Clackamas County Business and Economic Development Division conducted interviews and administered surveys with 42 unique processors, distributors and institutional purchasers in the region. Included in the survey were questions specific to business type, size, revenues, growth plans, perceived trends in the industry, barriers or challenges to doing business and locational information about origin and final sales of products. A complete list of questions is listed in Appendix B. I drew on the survey to support my description of the complexities and interconnections between the local and regional system and the export oriented system. 
Additionally, I drew on a set of interviews of regionally based distributors conducted by Ecotrust in the summer of 2013. The data included interviews with seven distributors that represent the majority of intermediated local and regional food products in the region. These data included questions more focused on the local procurement and logistics including, proportions, barriers and constraints, seasonality and perceived growth opportunities. Like the Clackamas County Distributors and Processors dataset, I drew on this survey to support my description of the complexities and interconnections between the local and regional system and the export-oriented system as well as to define some of the barriers to fostering local and regional food systems presented in chapter VII.

\section{7: SUPPLEMENTAL SECONDARY DATA}

As mentioned above, throughout this dissertation I drew from a wide array of secondary data and academic literature and research. Secondary data included digital data downloaded or otherwise obtained from a variety of sources including: the USDA, National Agricultural Statistics Service (NASS) 2007 Census of Agriculture as well as historic Censes (1910-2007); the Metro Regional Land Information System parcel boundary data (2010), data from the U.S. Bureau of Economic Analysis (2012) and from the U.S. Bureau of Census (2010). I have drawn heavily from the U.S. NASS Census of Agriculture. I provide additional detail of these data, and process steps in the next section. Detailed metadata specific to each of the other data listed sets can be found through the websites listed in the references section of this chapter. 


\subsection{1: USDA Census of Agriculture}

The United States Department of Agriculture (USDA), National Agricultural Statistics

Service (NASS) conducts an Agricultural Census every five years. The Census provides a detailed picture of U.S. farms and ranches and the people who operate them. It is the only source of uniform, comprehensive agricultural data for every state and county in the United States. For this research, I drew from historic censes dating back to 1910, as well as the 2002 and 2007 censes to verify the representativeness of the Clackamas County producers dataset (above) and to perform inferential analysis pertaining to the influence of urban areas on agriculture over time including aspects of farm size and off-farm employment and descriptive analysis specific to a wide variety of agricultural characteristics both nationally, in Clackamas County and in the Three County Region.

The statistical census data are summarized at the county, state, and U.S. levels and are available in a digital format (for recent years). Historic data required scanning digital archives and hand entering data into a spreadsheet. Data specific to any single attribute was rarely available throughout all censes. Furthermore, collection and or recording processes would sometimes change for a given attribute from one census to the next. As such, I had to make assumptions about some of the time series attributes used in various analyses. Specifically, I had to reconcile difference in reporting over time for off-farm employment, crop categories and farm sizes. Each of these is briefly described below. 
Data pertaining to off-farm employment used in Chapter VI was not recorded prior to the 1949 census. From 1949 to 1964 data was recorded as: "with other income of family exceeding the value of farm products sold"; in 1959 to 1969, this attribute was recorded as: "farms reporting off-farm work of 100 days or more"; in 1974 and 1978 it was reported as: "farm operators reporting days of work off-farm" which included categories for 100-199 days as well as 200 or more days. For these censes, data was also recorded for "principal occupation"; in1982 through 1997 the attribute was recorded as: "operators by principal operation" and starting in the 2002 census it was reported as: "primary occupation" which included two categories, one for farming, and the other for "other". Given that the 1974 and 1978 data included attributes for both the number of days of off farm work that matched prior censes and "principle occupation" which matched (to some degree subsequent censes) and the number of farms reporting more than 100 days of work coming from off the farm and the principle occupation being "other" were roughly equivalent, I made the assumption that I could treat each of the reportings from the different censes as the same variable. 


\section{CHAPTER V: ANALYSIS OF SPATIAL DISTRIBUTION AND STRUCTURE OF FOOD PRODUCERS.}

\section{1: INTRODUCTION}

In this chapter I use a series of spatial analyses to test hypothesis $2 \mathrm{c}$ : food producers participating in the new food economy farm smaller plots of land, are clustered close together and are close to the urban core. This hypothesis directly stems from theoretical constructs presented by a wide array of disciplines. Specifically, drawing from the industry lifecycle literature, I posit that because local and regional food producers are participating in a younger economic sector (as described in Chapter I), they will be more active in product innovations that are fostered by urbanization economies relative to nonlocal producers. The concept of urbanization economies is directly related to aspects of agglomeration that can be quantified through spatial analyses.

Determinants of agglomeration have been understood and well-studied for over a century (see chapter II) and numerous theoretical and empirical studies have been carried out to analyze the extent of spatial agglomeration of activities for a variety of industries (see. Fujita and Thisse, 2001 and Rosenthal and Strange, 2004 for theoretical and empirical examples respectively). Presence of agglomeration forces are revealed through both the spatial distribution and the spatial structure of firms in geographic space ${ }^{16}$ and while multiple methods have been proposed for measuring the degree of agglomeration for different regions and industries, the tendency of local and regional food producers to

\footnotetext{
${ }^{16}$ I use the terms distribution and structure presented by Audretsch and Feldman (2003) to refer to the distribution of firms away from the urban core the proximity of firms to each other respectively.
} 
cluster has received little research attention and has not undergone rigorous statistical analysis (Boys and Hughes, 2013). For my analyses I used Geographic Information Systems (GIS) and spatial statistics to measure the spatial distribution (distance to the urban core) and structure (spatial clustering) of food producers in Clackamas County.

In the following section (5.2) I first give a detailed description of the data used throughout this chapter and the steps in which I prepared the data for spatial analysis. In section 5.3, I present the different methods for measuring agglomeration and discuss the rationale for choosing the Moran's Index as my preferred approach. Next, in sections 5.3.1 through 5.3.4, I describe a three-stage approach to quantifying the presence of spatial clusters and test for spurious clustering effects. In section 5.4, I quantify the differences between local and non-local food producers in terms of aspects of spatial distribution measured as proximity to the urban core before turning to an analysis of the differences in firm size between local and non-local food producers in section 5.5. In section 5.6, I conclude with a discussion of the implications of my analyses.

\section{2: DATA}

The Clackamas County agricultural producers' dataset represents responses from 1,009 individuals (see chapter III for a detailed description of the dataset, collection methodology and representativeness). Testing for measures of spatial distribution and structure required spatially explicit observations with enough information to differentiate 
the populations of local exclusive and non-local identified in the last chapter ${ }^{17}$. Of the 1,008 observations, only 491 provided useable addresses and an additional 37 provided names or business names that could be compared against the Clackamas County Assessor's records to identify probable addresses. In order to get the data into a Geographic Information System for analysis, the data was geocoded. I created a local Clackamas County Address Locator using address data obtained from the Regional Land Information System (RLIS) - the Metro regional government's dataset. I then edited the address fields and standardized all records to ensure the maximum number of addresses was correctly matched using the geocoding engine. Each record was validated using additional mapping sources. When aerial validation showed a non-agricultural land use the record was removed from the analysis. All respondents who had duplicate entries in the table were also removed. However, duplicates were maintained whenever there were different addresses identified indicating that one owner farms multiple agricultural land parcels.

The geocoder identifies a point along a street route. I then associated the GIS point with a parcel polygon derived from the Clackamas County Assessor's office taxlot dataset. Survey and tabular attributes were maintained in an output GIS data layer. The geocoding process resulted in a total of 631 parcels representing 313 of the 528 respondents with useable addresses or names with which could be used for matching to locations. I then compared the remaining 215 entries against the County Assessor's

\footnotetext{
${ }^{17}$ For the purposes of this analysis, local non-exclusive was grouped with non-local.
} 
taxlot database on a record-by-record basis to insure as robust a dataset as possible. An additional 155 survey respondents were mapped to an additional 273 parcels resulting in a total of 904 parcels representing 468 respondents. This represented slightly more than $11.7 \%$ of the County's 3,989 producers. $^{18}$

Because many land owners hold adjacent properties, and these adjacencies would result in spurious measures of agglomeration, it was necessary to dissolve boundaries of adjacent parcels with the same owner. Within the GIS, I used an automated tool that merged these adjacent properties based on the owners name found within the County Assessors database, resulting in a total of 682 polygons. Many property owners however are listed with slightly different names (e.g. both as Last, First, Middle initial and Last, First initial) therefore I conducted an extensive review the assessors database on a property by property basis to ensure that adjacent polygons did not belong to the same owner. When I found adjacent polygons that obviously belonged to the same owner but had slightly different spellings of the names, I standardized the name and re-ran the GIS process to merge the polygons.

I created unique spatial datasets for testing measures of both spatial structure as well as spatial distribution for a wide number of variables. These were created by selecting cases where and individual answered the question specific to the variable under consideration. For example, to test for clustering of local food producers, I first selected only those

\footnotetext{
${ }^{18}$ USDA, NASS 2007 Census of Agriculture
} 
respondents who answered the question of the geographic focus of food sales. A new spatial data set was then created from this selection. Table 5.1 shows the variables of interest and the number of records / polygons associated with each respective spatial data set.

Table 5.1: Sample size for spatial variables considered

\begin{tabular}{|l|l|c|c|}
\hline Spatial Dataset & \multicolumn{1}{|c|}{ Variable of interest } & $\begin{array}{c}\text { Number of } \\
\text { polygons* }\end{array}$ & $\begin{array}{c}\text { Answered yes to } \\
\text { variable of interest }\end{array}$ \\
\hline All agricultural parcels & In sample & 8,251 & 569 \\
\hline Geography of product & Local producer & 400 & 198 \\
\hline Food production & Food producer* & 493 & 232 \\
\hline Geography of food & Local food producer & 232 & 114 \\
\hline Geography of interest & Future local & 267 & 150 \\
\hline Type of product & Produce producer*** & 493 & 65 \\
\hline Type of product & Vegetable producer**** & 493 & 30 \\
\hline
\end{tabular}

* parcels of contiguous ownership represented as a single polygon

**at least $10 \%$ of income comes from food production (not including livestock feed)

**at least $25 \%$ of income that comes from berries, fruits and nuts or vegetables

$* * *$ at least $25 \%$ of income that comes from vegetables

The table represents the different sample sizes for different analyses. For example, 400 respondents could be mapped AND answered the question specific to geography. Of these, 198 said they marketed their products exclusively through local channels.

\section{3: ANALYSIS OF SPATIAL CLUSTERS TO TEST FOR THE PRESENCE OF AGGLOMERATION}

My analysis focuses on to what degree firms cluster between the two sectors and at what scale these clusters unfold. While numerous contributions have been made to measure agglomeration, there is no general agreement on the criteria that a measure of 
agglomeration should satisfy (Guillain and Gallo 2007; see also Combes and Overman, 2004; Bertinelli and Decrop, 2005). Furthermore, Duranton and Overman (2002) argued that measurements of spatial agglomeration should: 1) be comparable across industries; 2) control for overall agglomeration trends across industries; 3) separate spatial concentration from industrial concentration; 4) be unbiased with respect to the degree of spatial aggregation and; 5) admit a clear statistical significance test. In addition they argue that effective agglomeration indices must, for practical reasons, be computable in closed-form from accessible data and that an index is almost meaningless if it is not justified by a suitable model.

Guillain and Gallo (2007) argue that measuring spatial agglomeration of economic activities in a meaningful way requires: first, an evaluation of both the concentration of activities and their location patterns; second, an assessment of the statistical significance of these agglomerations; and third, must account explicitly for the spatial dimension of the data. My selection of a modeling process therefore paid particular attention to these criteria.

There are two classes of models that have emerged that are used to measure agglomeration: discrete-space indices and indices of clustering based on distance density measurements, which are independent of political boundaries or other arbitrary units of analysis (Lafourcade et.al. 2007). Continuous-space measurements - while difficult to interpret and very difficult to calculate with accessible data - are based on absolute 
distance measurements, independent of spatial unit size and hence they are not prone to the spurious correlations which arise during the aggregation processes in the discretespace models.

Having the benefit of a robust dataset, with a wide array of location specific variables, I applied a continuous-space approach. A number of continuous-space, statistical indices have been developed. Among such indicators are the statistics proposed by Cliff and Ord (1981), Getis and Ord (1992), Geary’s C (1954), or Moran (1950). Following Guillain and Gallo's approach (2007), I draw on measures of both Local and Global spatial autocorrelation to quantify the degree of clustering, agglomeration and the structure of dispersion between the two segments of producers. My process followed a three-stage analysis. This three-stage analysis required the conditions of previous stages met before subsequent measures could be tested.

Global spatial autocorrelation can be defined as the coincidence of value similarity with locational similarity across the study region (Anselin, Varga, \& Acs, 2000). Positive spatial autocorrelation occurs when high or low values of a random variable tend to cluster (agglomerate) in space. For this analysis I use Moran's Index as my primary method for measuring global spatial autocorrelation (as well as a derivative for measuring local spatial autocorrelation) because of it being both a well-accepted standard as well as fairly intuitive to interpret. 
The Moran's formula is given by:

$$
I=\frac{M \sum_{i=1}^{M} y_{i} \sum_{i=1}^{M} w_{i l} y_{l}}{S_{0} \sum_{i=1}^{M} y_{i}{ }^{2}}
$$

(equation 5.1)

Where $y_{i}$ is a measure of activity in location $i$ expressed as the deviation of an attribute for feature $i$ from its mean $\left(x_{i}-X\right), w_{i, j}$ is the spatial weight between feature $i$ and $j, M$ is equal to the total number of features and $S_{0}$ is the aggregate of all the spatial weights:

$$
S_{0}=\sum_{i=1}^{n} \sum_{j=1}^{n} W_{i, j}
$$

equation 5.2)

The Moran's $I$ is the correlation coefficient between $y_{i}$ and its neighbors' counterparts that enables the detection of departures from spatial randomness and to determine whether neighboring areas are more similar than would be expected under a purely random spatial distribution (Lafourcade et.al. 2007). I use the Moran's I (and derivatives of) to test three primary but different aspects of spatial distribution in the Clackamas County Producers' dataset. First, I look at the sample itself, to determine if there is any spatial sample bias. If there appears to be significant - and a large degree of positive - global spatial autocorrelation, subsequent measures could be subject to the underlying spatial bias of 
the sample itself. Second, I use Moran's I to test for clustering of local exclusive vs. nonlocal producers (as well as a series of other variables to rule out their influence on any resulting clustering) and finally, I used a local measure of spatial autocorrelation proposed by Anselin (1995) known as Anselin's Local Moran's to test the significance of specific clusters to determine if local clusters are more significant and therefore prevalent across the landscape.

Like the Moran's $I$, a local index of spatial autocorrelation (LISA) measures clustering as a function of distance and the distribution of values of interest. Unlike the Moran's I however, a LISA allows for the identification of location specific similarities. A LISA allows for the decomposition of global indicators such as Moran's I into the contribution of each individual observation (Anselin 1995) and thus meeting Guillain and Gallo's criteria that the analysis account explicitly for the spatial dimension of the data. Like the Moran's I the LISA also returns specific statistics which allow for the interpretation of the magnitude in addition to the significance of local clustering. This has advantages of the Getis-Ord approach in that the Getis-Ord identifies local clusters but does not return a statistical measure that can be used to interpret the significance of the cluster itself.

A LISA can actually use any number of statistical measures of spatial autocorrelation. Anselin (1995) describes a LISA as any statistic that; 1) for each observation gives an indication of the extent of significant spatial clustering of similar values around that 
observation and; 2) the sum of LISA's for all observations is proportional to a global indicator of spatial association.

Anselin's Local Moran's is given as:

$$
I_{i}=\frac{x_{i}-\bar{X}}{S_{i}^{2}} \sum_{j=1, j \neq \mathrm{i}}^{n} w_{i, j}\left(x_{j}-\bar{X}\right)
$$

(equation 5.3)

Where $x_{i}$ is the value of an attribute for feature $i$, Xar is the mean value of the corresponding attribute for all features, $w_{i, j}$ is the spatial weight between feature $i$ and $j$ and;

$$
S_{i}^{2}=\frac{\sum_{j=1, j \neq i}^{n}\left(x_{j}-\bar{X}\right)^{2}}{n-1}-\bar{X}^{2}
$$

(equation 5.4)

With $n$ equal to the total number of features.

Both the Moran's I and Anselin's Local Moran's draws on an $M x M$ spatial weights matrix $W$, as the matrix whose generic element $w_{i l}$ is the relative weight of location $l$ for location $i$ and $w_{i i}=0$ (Lafourcade et.al. 2007). Definition of $w_{i l}$ can rely on a number of different approaches to identifying neighbors or "proximity. Since weights matrices are used to create spatial lags that average neighboring values, the choice of how to construct 
the weights matrix will determine which neighboring values will be averaged. This leaves the model results sensitive to conceptualization methods for the weights matrix. This definition of neighbor (or what the analyst means by "close") is a fundamental criterion in assessing spatial autocorrelation, and care must be taken in identifying an appropriate means of defining the spatial weights matrix both in terms of the conceptualization of the model and any threshold distances that might be used.

Consequently, the different means of this definition also affords the opportunity to measure different aspects of spatial autocorrelation pertaining to the same dataset. I will return to this concept in my discussion of the results.

Through informational interviews (see chapter VII) most producers indicated that the concept of a neighbor holds constant for a fixed threshold and then diminishes with distance after that threshold. All neighbors within this threshold distance exert the same influence. Therefore I used a conceptualization method known as the "zone of indifference" where features within the specified critical distance of a target feature receive an equal weight in terms of how they influence computations for that feature. Once the critical distance is exceeded, weights (and the influence a neighboring feature has on the target feature) diminish with distance. However, given the sensitivity of the analyses to the conceptualization method, I performed tests to insure results were not influenced by the method selected. 
To test the sensitivity of the conceptualization method, I evaluated the Moran's I using both inverse distance and inverse squared distance (in addition to the zone of indifference) conceptualization methods constrained by equivalent and varying threshold distances. The tests were performed using the local / non-local variable as described in the Stage II analysis below. While the differences between the respective indices are substantial, the trend of each (in terms of the slope relative to the change in the distance threshold) remains equivalent between the three methods. Figure 5.1 represents the comparison of the three different conceptualization methods over variable threshold distances.

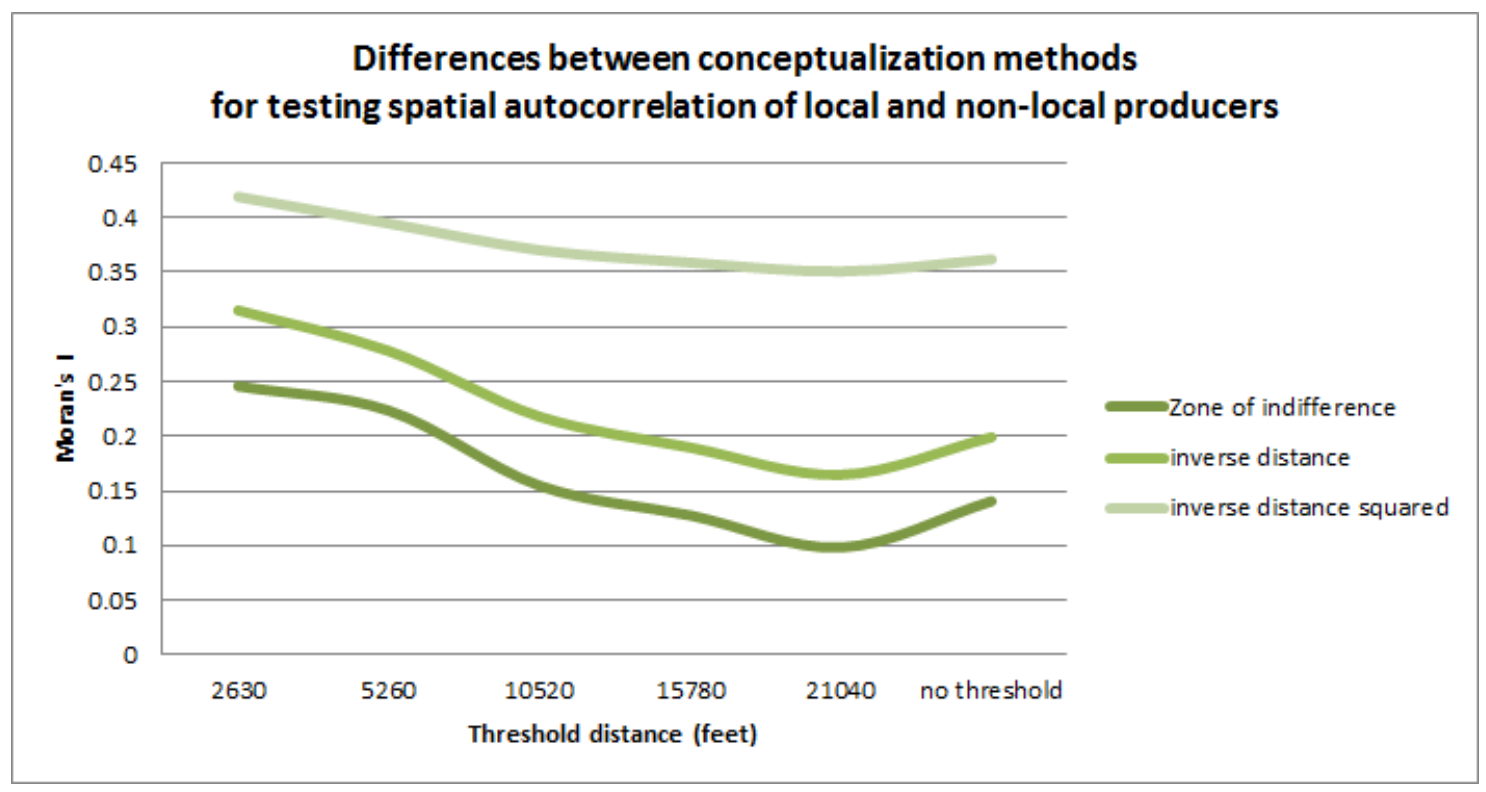

Figure 5.1: Differences between conceptualization methods for testing spatial autocorrelation

The sensitivity analysis does not necessarily tell us that one method is more desirable than another rather, interpretation of the magnitude of the Index should be considered 
relative to measures using the same conceptualization method (for each stage of the analysis) and should not be considered without evaluation of the significance (as measured by the Z-score). Considering these sensitivities, I now turn to the three-stage analysis.

\subsection{1: Stage I: Using Moran's I to test spatial bias in the sample}

For exploring the distribution of the sample, I measured spatial autocorrelation using a zone of indifference conceptualization method as specified above. I parameterized my analysis by testing a range of values resulting from the threshold parameter through this range. I measured Moran's $I$ at 1/2, 1, 2 and 3 miles. These measures were selected based on conversations with producers who generally thought of their neighbors as people within a three mile threshold. I developed a spatial weights matrix based on the neighbors of focal parcels where each neighbor within the threshold distance was given an equal weight and the parcels outside of this threshold were given a weight that

diminished with distance. Further, as proposed by Anselin (1988), the weights matrix was row-standardized so that each row was divided by the sum of the row elements. This mitigated the effects of parcel size on the analysis. The measure was calculated for a variable that represented whether any given parcel was within the sample. All sampled parcels were attributed with a value of one and non-sampled parcels (zoned agricultural) with a value of zero. Table 5.2 shows the results of the analysis for each distance threshold. 
Table 5.2: Moran's I at different distance thresholds for Stage I analysis

\begin{tabular}{|c|c|c|c|}
\hline Distance & Moran's I & Z-score & P-value \\
\hline $1 / 2$ mile & 0.033977 & 7.1673 & $<0.001$ \\
\hline 1 mile & 0.01692 & 6.7232 & $<0.001$ \\
\hline 2 miles & 0.00589 & 4.5263 & $<0.001$ \\
\hline 3 miles & 0.00476 & 5.4018 & $<0.001$ \\
\hline
\end{tabular}

While the magnitude of the Index is quite small (indicating relatively little clustering of the sample) the measure for each distance threshold remains significant. This indicates that a small number of parcels were significantly clustered, resulting in a small but significant global measure. This does not necessarily mean that subsequent analyses (stage II and stage III) will result in spurious clustering; rather the attributes of the observations that are leading to the significance for each variable must be evaluated relative to parcels that are leading to the significance of the clustering of the sample. I used the local measure of spatial autocorrelation described above (Anselin Local Moran's) to first identify the nature of the spatial structure of the clustering to which subsequent measures could then be compared. If values of a given attribute are found more commonly than others within the set of observations that lead to the significance measure of the sample, then clustering measures could in fact be attributed to an underlying spatial bias of the sample itself rather than the explicit variable being tested. Figure 5.2 shows the location of respondents (independent of their characteristics) that were significantly clustered close together. 


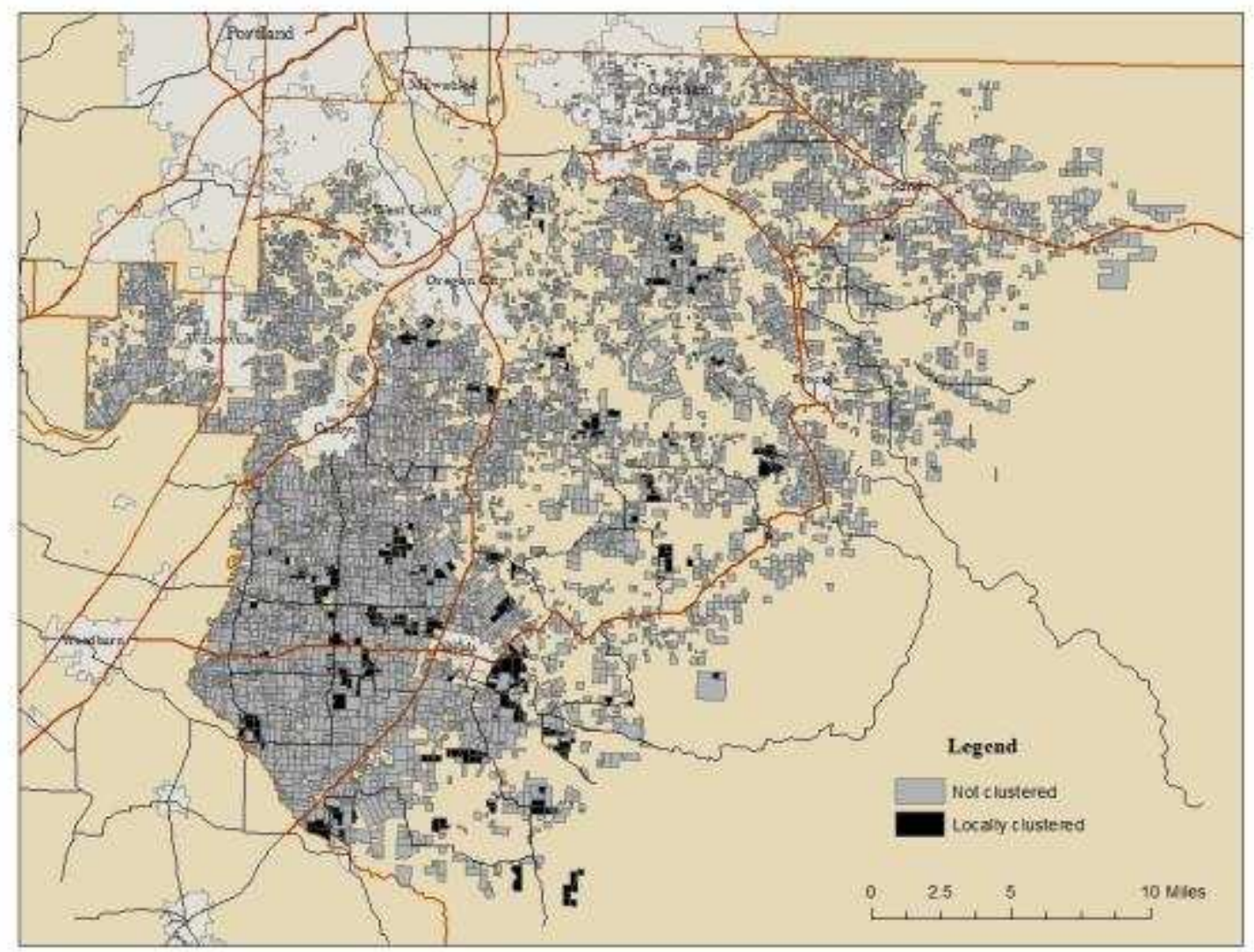

Figure 5.2: Map of locally significant clusters within the spatial sample

I found a total of 186 of the 569 polygons of the sample (roughly $33 \%$ ) to be part of a significant cluster of respondents using the Anselin Local Moran's with the zone of indifference conceptualization method and a two-mile threshold. Of these, 148 answered the question pertaining to the geography of their product sales and roughly $1 / 2$ of these were local exclusive (76). Of the polygons that were found to be significantly clustered and answered the geography related question, there was no significant difference between those that answered the question as local exclusive and those that answered either non-local or local non-exclusive $\left(\chi^{2}(1)=0.322, p>0.1\right)$. Although this 
measure alone does not rule out the possibility of spatial sample bias, if there was a significant difference between the two categories, the subsequent analyses - and results thereof - would be highly suspect. Table 5.3 shows the number of polygons for each variable that were coincident with those that were found as leading to significant clustering of the sample.

Table 5.3: Proportion of variables within significant local sample clusters

\begin{tabular}{|l|r|r|r|r|}
\hline Variable & Total * & \% of polygons & yes & \multicolumn{1}{l|}{ no } \\
\hline sample & 186 & $32.7 \%$ & na & na \\
\hline local producers & 148 & $37.0 \%$ & 76 & 72 \\
\hline food producer & 175 & $35.5 \%$ & 78 & 97 \\
\hline local food producers & 72 & $31.0 \%$ & 40 & 32 \\
\hline future local & 102 & $38.2 \%$ & 62 & 40 \\
\hline produce & 175 & $35.5 \%$ & 16 & 159 \\
\hline vegetables & 175 & $35.5 \%$ & 8 & 167 \\
\hline
\end{tabular}

*the total number of polygons that answered the question specific to the variable that were found within locally significant clusters exhibited by the sample.

\subsection{2: Stage II: Measuring intra-sample spatial autocorrelation using Moran's I}

Next, I defined the degree of clustering present among local and non-local food producers in the sample. To do so, I removed from the analysis those parcels that were not sampled. The analysis then differs from the stage I analysis in that I attempted to detect whether clustering is occurring among the different types of food producers across a sparsely populated sample. In this case, I made an assumption that the distribution and density of the sample is representative of the distribution and density of the population as 
supported by the relatively small indices found from the stage I analysis. Because the sample is non-contiguous in nature however, there may not be enough observations to identify clustering within smaller threshold distances. Regardless, I performed the analysis at the same threshold intervals used in the stage I analysis.

Like the difference between sampled and non-sampled parcels in the stage I analysis, the parcels within the sample were differentiated between local and non-local with a one and zero respectively. Once non-sampled parcels were removed, the absolute condition of every neighbor was definable and therefore any detected clustering can be attributed to the data itself, given consideration of possible erroneous phenomena such as the clustering of the sample.

As mentioned above, the weights matrix was defined based on a zone of indifference relationship between a focal parcel and all of its neighbors, constrained by threshold distances of one half, one, two, and three miles and diminishing weight with distance past this threshold distance. Therefore, every neighbor within the threshold distance of the focal property was assigned an equal weight representing an equivalent conceptual influence on the focal property regardless of parcel size or proximity. As in the Stage I analysis the weights matrix was row-standardized. Table 5.4 reports the Moran's $I$, the z-score and significance (p-value) for all food producers for each threshold distance. 
Table 5.4: Spatial autocorrelation of food producers at different distance thresholds

\begin{tabular}{|l|r|r|l|}
\hline Distance threshold & \multicolumn{1}{|l|}{ Moran's I } & z-score & p-value \\
\hline $1 / 2$ mile & 0.34884 & 5.5943 & $<0.001$ \\
\hline 1 mile & 0.33406 & 5.3301 & $<0.001$ \\
\hline 2 miles & 0.27627 & 6.3532 & $<0.001$ \\
\hline 3 miles & 0.19943 & 5.9944 & $<0.001$ \\
\hline
\end{tabular}

The stage II analysis indicated that there was a strong and significant amount of clustering among the local and non-local food producers across the study region. Furthermore, the magnitude of the Index at each distance threshold was significantly greater than the clustering exhibited by the sample, indicating that while some sample bias may have influenced the results, it does not explain all of the clustering exhibited. To illustrate this point, I removed the polygons that were identified as being part of a significant cluster within the sample and re-ran the stage II analysis on the remaining polygons in the local food data set (192 polygons) for the one mile threshold. While the resulting Index decreased it remained significant $(I=0.2123, \mathrm{p}<0.001)$. This subsequent analysis, however, was only conducted to assess the degree of uncertainty introduced by the sample bias to the original measures expressed in table 6.4.

\subsection{3: Stage III: Evaluating clustering of local and non-local producers}

The stage II analysis was used to determine spatial distribution of local and non-local food producers at the global scale but tells us little of the spatial structure at the local 
scale. That is, the stage II results showed that clustering exhibited by the spatial distribution of local and non-local producers was significantly greater than the clustering exhibited by the sample itself (stage I analysis) not whether this clustering is a result of the clustering of the local producers themselves (as compared to the possibility of the non-local producers clustering).

To test the degree of clustering within the two different segments, I employed a local index of spatial autocorrelation (Anselin local Moran's) as described above. Using the same distance thresholds of one half, one, two and three miles and the zone of indifference conceptualization method where the influence on the focal polygon is equal to the distance threshold and diminishes with distance past the threshold, I evaluated the significance of local clusters specific to the producer categories (local v. non-local). The LISA identifies those polygons that are found within each significant cluster (local cluster v. non-local cluster). Figure 5.3 and Figure 5.4 show these clusters for the one half and three-mile threshold distances respectively. 


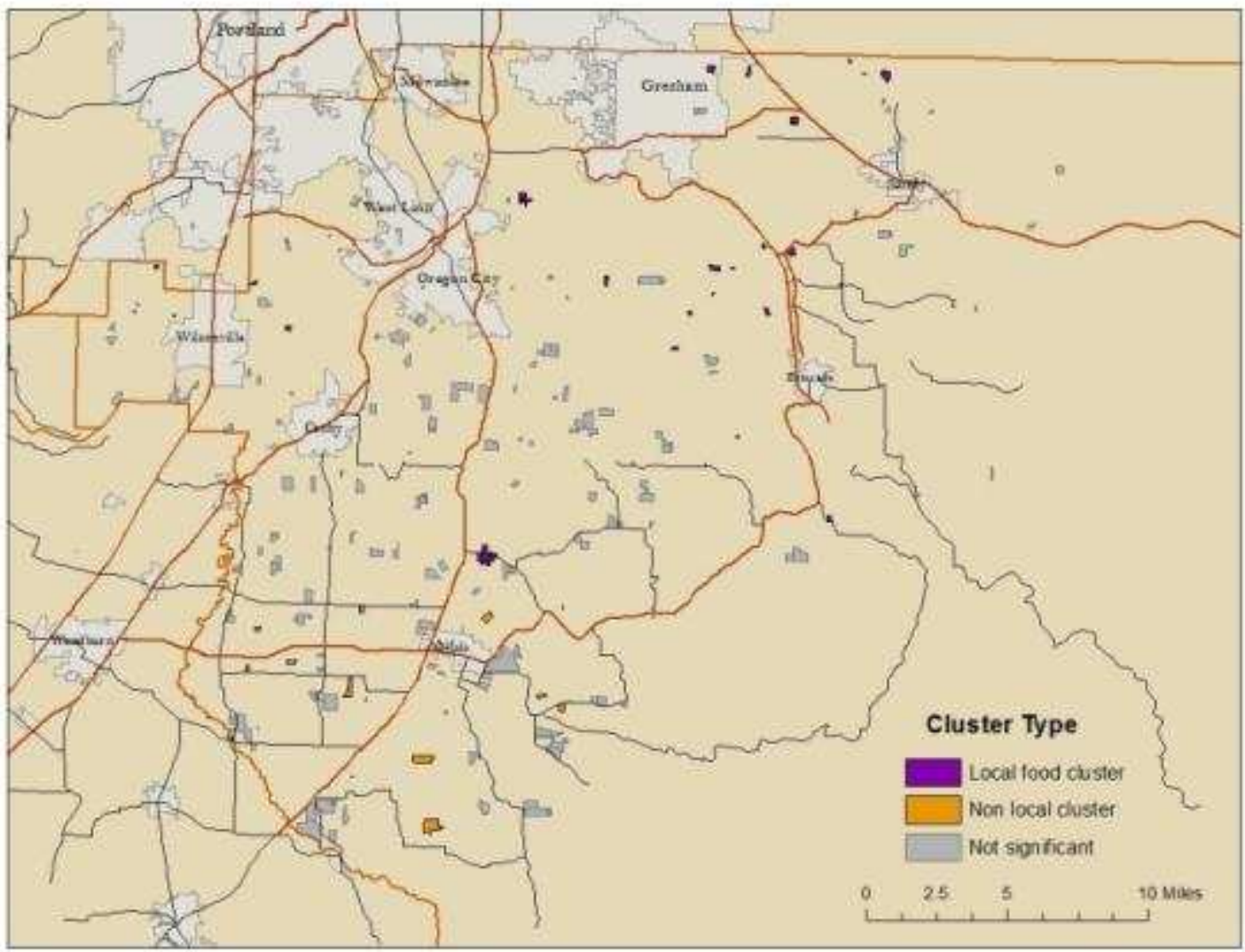

Figure 5.3: Map of locally significant clusters using a 1/2 mile distance threshold

The maps demonstrate the sensitivity of the Index to a threshold distance but also indicate how the underlying forces of agglomeration may take hold at different scales. I will address this concept in a later section. 


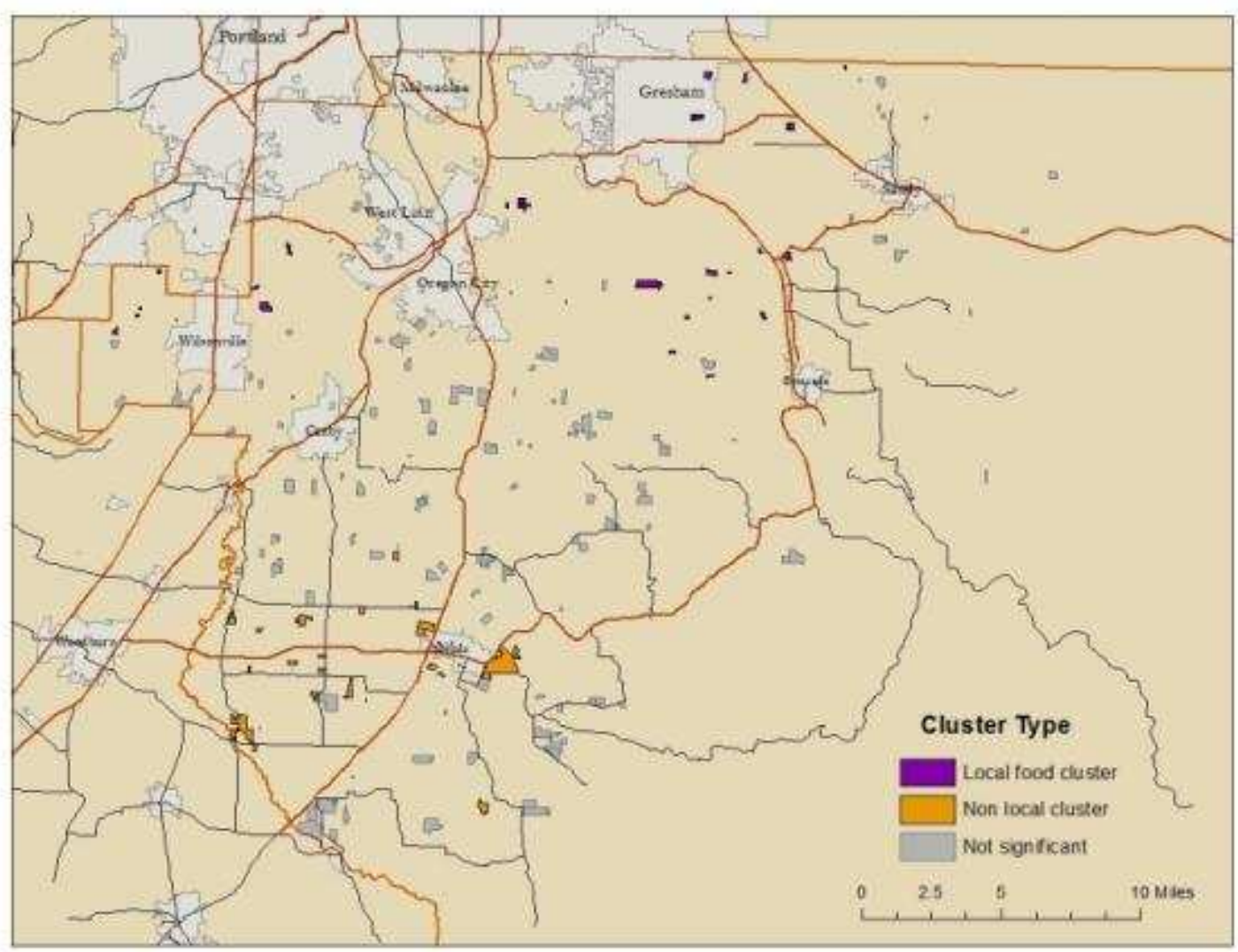

Figure 5.4: Map of locally significant clusters using a three mile distance threshold

I performed a series of group tests (Chi-square) on each threshold distance to determine whether differences in clustering were significant. Local food producers were significantly more likely to cluster at the lower threshold distances but there was no significant difference between the clustering of local and non-local producers at the larger threshold distances. Table 5.5 shows the proportion of each segment that was found within significant local clusters and the difference tests at each distance threshold. 
Table 5.5: Clustering differences of local and non-local food producers at different distance thresholds

\begin{tabular}{|l|c|c|r|l|l|}
\hline Distance threshold & Local $^{1}$ & non-local & Chi-square & p-value & Signif $^{2}$ \\
\hline $1 / 2$ mile & $29.8 \%$ & $10.2 \%$ & 14.09 & $<0.001$ & $* * *$ \\
\hline 1 mile & $23.7 \%$ & $12.7 \%$ & 4.71 & $<0.05$ & $*$ \\
\hline 2 mile & $23.7 \%$ & $23.7 \%$ & $6.37 \mathrm{E}-05$ & $>.1$ & \\
\hline 3 mile & $28.1 \%$ & $28.1 \%$ & 0.015 & $>.1$ & \\
\hline
\end{tabular}

1) Proportion of segment found in local cluster

2) Signif. codes: 0 ‘***’ 0.001 '**' 0.01 ' $*$ ’ 0.05 ' 0.1

\subsection{4: Testing for erroneous cluster effects}

While clustering is present and more significant among the local producers at the smaller distance thresholds, this may not necessarily be directly attributed to second nature, nonpecuniary forces of agglomeration such as knowledge spillovers. Rather, clustering may occur through other forces such as first nature causes (e.g. factor endowments expressed as the location of specific growing conditions that support activities that are more likely to be local or path dependent sources such as land use policies or phenomena that promote the co-location of activities e.g. small parcels tend to be clustered together). While this latter effect directly supports my hypothesis (and corroborates the results identified in section 6.5 of this last chapter) that actors participating in the local and regional sector are more likely to be smaller (i.e. look for smaller parcels), the spurious clustering that would result may be misinterpreted. To test for these potential causes of clustering, I applied both the stage II and stage III analysis on the data for both my sampled data set as well as the larger, taxlot data of all agricultural producers in the County. 
First, nature forces of agglomeration include aspects of factor endowments. In the case of agricultural production, these include environmental conditions for growing specific types of crops. Depending on soil and micro-climate conditions, agricultural lands in Clackamas County are capable of growing a wide range of crop types. Furthermore, these types of conditions often exhibit spatial heterogeneity across the landscape, varying only a small amount with distance. The main issue arising from this phenomenon is that because of the homogenous spatial dispersion of environmental factors that affect the types of crops and their productivity, clustering could be associated with specific crop types. As identified in my last chapter, local producers are more likely to produce vegetables than non-local producers; therefore, the clustering of vegetable growers might influence the clustering seen among the local producers. To test for this, I performed the stage II and stage III analyses on a binary attribute that identified units as vegetable producing.

I found moderate but significant clustering at the global scale $(I=.132, \mathrm{z}=3.66, \mathrm{p}<-$ 0.001) of vegetable producers. Using the stage III analysis I found 17 of the 495 respondents who answered the product question that I mapped to be part of a significant local cluster of vegetable producers at the one-mile distance threshold. Of these, four were local exclusive and only one of those was found in the local exclusive cluster. 
I performed both the stage II and stage III analysis on polygon size (merged parcels of the same owner) to determine if the clustering exhibited among the local food producers was an effect of parcel size. Row standardization ameliorates spurious significance of clustering because of parcel size, however; if parcels of the same size are found to cluster (i.e. smaller parcels are clustered close together) the clustering of the local producers may be a result of the parcel clustering rather than the hypothesized $2^{\text {nd }}$ nature causes. For the sample, I found only nominal but significant clustering using the Global Moran's $I$ ( $I=$ $0.082, Z=2.629, p<0.01)$ and a total of nine units as identified as being part of a significant local cluster of either large or small polygons (stage III analysis). Of these polygons, eight were associated with the clustering of larger units and only one associated with smaller parcels. Furthermore, only two of the nine units were identified as participating in local and regional supply chains, both associated with large unit clusters. This indicated that the clustering found among the local food producers was not an artifact of the clustering of parcel sizes.

Evaluation of clustering of parcel sizes for all agricultural taxlots in the County yielded dramatically different results, however. I found larger degree of significant clustering using the Global Moran's $I(I=0.383, Z=8.241, p<0.001)$. A total of twenty-eight of these units were identified as being part of a significant local cluster of either large or small polygons (stage III analysis). Of these polygons, fourteen were associated with the clustering of smaller units and eight of these units were identified as participating in local and regional supply chains. 
These seemingly contradictory findings actually indicated that the sample may not be robust enough in size to evaluate local measures of spatial autocorrelation at the smaller scales. That is, because my dataset is a sample of the larger population, below a certain threshold distance, the number of parcels may be too small to accurately predict the measure. To test this point, I developed an automated model to randomly select samples of decreasing sizes and test the degree of local spatial autocorrelation after each iteration on various distance thresholds. For each sample size iteration, 10 sets of sample random samples were compared. Results showed that the proportion of units that were classified as being part of either a high or low value local clusters (i.e. high values were clustered together or low values were clustered together), varied across distance thresholds but this variation remained consistent after each iteration until the sample size dropped below 500 , at which point the half mile distance threshold began to produce inconsistent results (expressed by the standard deviation across all 10 samples). Below a sample size of 200, both the one-half mile and one mile distance thresholds produced inconsistent results. Figure 5.5 shows the relative stability of the distance threshold measures across a range of sample sizes. 


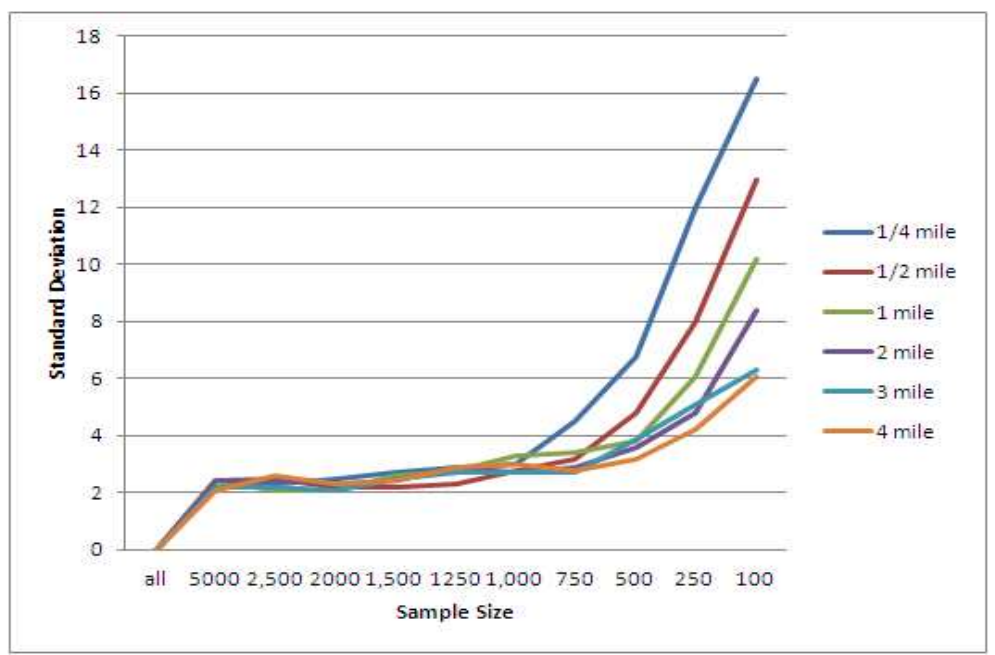

Figure 5.5: Influence of sample size on the stability of distance thresholds

The results tell us that given our small sample size (232) of respondents who produce food and answered the geography-specific question(s) that could be mapped, results of the local indicator of spatial autocorrelation cannot be trusted under the one mile threshold as the sample is too sparse to accurately capture the degree of heterogeneity at such small scales.

\section{4: SPATIAL DISTRIBUTION}

Proximity to urban areas is an essential component in business planning for producers participating in local and regional food supply chains to a large degree because the urban core is the primary location of their market. But producers benefit from urbanization economies as well. For example, Valente (1996) found that innovativeness of Brazilian farmers was directly related to the number of trips they took to the closest major city. In addition to key factors such as transportation costs associated with both forward and 
backward linkages in the supply chain or access to markets, diffusion effects of knowledge may also play a key role not only in location decisions but also business success. As such, I used a distance measure to analyze differences in distance to the urban core across food producers in the different segments (local and non-local) as a means to understand the potential benefits from urbanization economies, and how those may be realized differently than producers participating in export oriented supply chains. The analysis was conducted to test hypothesis $2 \mathrm{c}$ : we would expect local and regional food producers to be closer to the urban core than their outward facing export oriented counterparts.

For my distance measure I created a cost surface based on a weighted road distance to all locations in the study region. The surface was calculated by creation of a least costdistance function within a GIS. The cost-distance function is a raster approach based on the node/link cell representation used in graph theory. Every link is assigned a value that represents an impedance to move between nodes weighted by the distance between the nodes. The least cost-distance is determined by the combination of connected links with the lowest sum from any given node to a specified source node. In this case, the impedance was derived from the cost surface represented by transportation networks, weighted by the type of network present at any given location (e.g. freeways represent a smaller impedance than surface streets). Table 5.6 shows the impedance value used for each road type. 
Table 5.6: Impedance values assigned to road types

\begin{tabular}{|l|c|}
\hline Road type & Surface weight \\
\hline Freeway & 1 \\
\hline Highway or major arterial & 2 \\
\hline Arterial & 4 \\
\hline Feeder / surface street & 6 \\
\hline
\end{tabular}

The impedance value was used as a multiplier in the cost surface analysis, so every grid cell along the road network contained the value of the minimum distance along the network back to the urban core, multiplied by the sum of impedance values. The urban core was identified as those neighborhoods with both a population density of at least 13 people per acre and a land use diversity index of $0.73 .{ }^{19}$ All neighborhoods selected had to be contiguous with the downtown neighborhood. Table 5.7 shows the neighborhoods selected as part of the urban core.

\footnotetext{
${ }^{19}$ Land use diversity index derived from the EPA smart growth database (http://www.epa.gov/smartgrowth/smartlocationdatabase.htm) 
Table 5.7: Urban core neighborhoods

\begin{tabular}{|l|c|}
\hline \multicolumn{1}{|c|}{ Name } & Area (sq miles) \\
\hline OVERLOOK & 3.18 \\
\hline BOISE & 0.43 \\
\hline ELIOT & 0.84 \\
\hline IRVINGTON & 0.65 \\
\hline SABIN-IRVINGTON & 0.11 \\
\hline ALAMEDA-IRVINGTON & 0.11 \\
\hline NORTHWEST DISTRICT & 1.34 \\
\hline GRANT PARK & 0.46 \\
\hline PEARL & 0.45 \\
\hline HOLLYWOOD & 0.18 \\
\hline LLOYD DISTRICT & 0.51 \\
\hline SULLIVAN'S GULCH & 0.32 \\
\hline LAURELHURST & 0.67 \\
\hline KERNS & 0.83 \\
\hline OLD TOWN/ CHINATOWN & 0.28 \\
\hline GOOSE HOLLOW & 0.34 \\
\hline BUCKMAN & 1.15 \\
\hline DOWNTOWN & 0.94 \\
\hline GOOSE HOLLOW/SOUTHWEST HILLS & 0.08 \\
\hline SUNNYSIDE & 0.60 \\
\hline HOSFORD-ABERNATHY & 1.30 \\
\hline RICHMOND & 1.27 \\
\hline CORBETT/TERWILLIGER/LAIR HILL & 1.70 \\
\hline BROOKLYN & 1.72 \\
\hline
\end{tabular}

I then developed an automated routine using the Mapquest routing API that returns estimated travel times between two points. I delivered a set of "to" and "from" coordinate pairs to the routing engine to derive a sample of estimated times from spatially random locations outside of the urban core $(n=640)$. Because an output of the costdistance algorithm is a surface identifying the closest (in cost-distance terms) source cell (the urban core) to every given cell in the surface, I could match the sampled locations to 
the closest (in cost-distance terms) location along the edge of the urban core. I then estimated the relationship between the cost-distance values and the travel times using Ordinary Least Squares simple regression $\left(\mathrm{R}^{2}=0.8931\right)$. The resulting coefficient was used to predict travel times (in minutes when traveling by automobile) across the entire cost surface. The output was a continuous surface of travel time estimates that could be calculated for every parcel in my producer's data sample. This approach yielded results that are more accurate than using zonally aggregated travel times (e.g. traffic analysis zones) as zones in rural areas tend to be larger and therefore subject to well-known issues pertaining to the modifiable areal unit problem (Openshaw, 1984). Figure 5.6 shows estimated travel times for the study area.

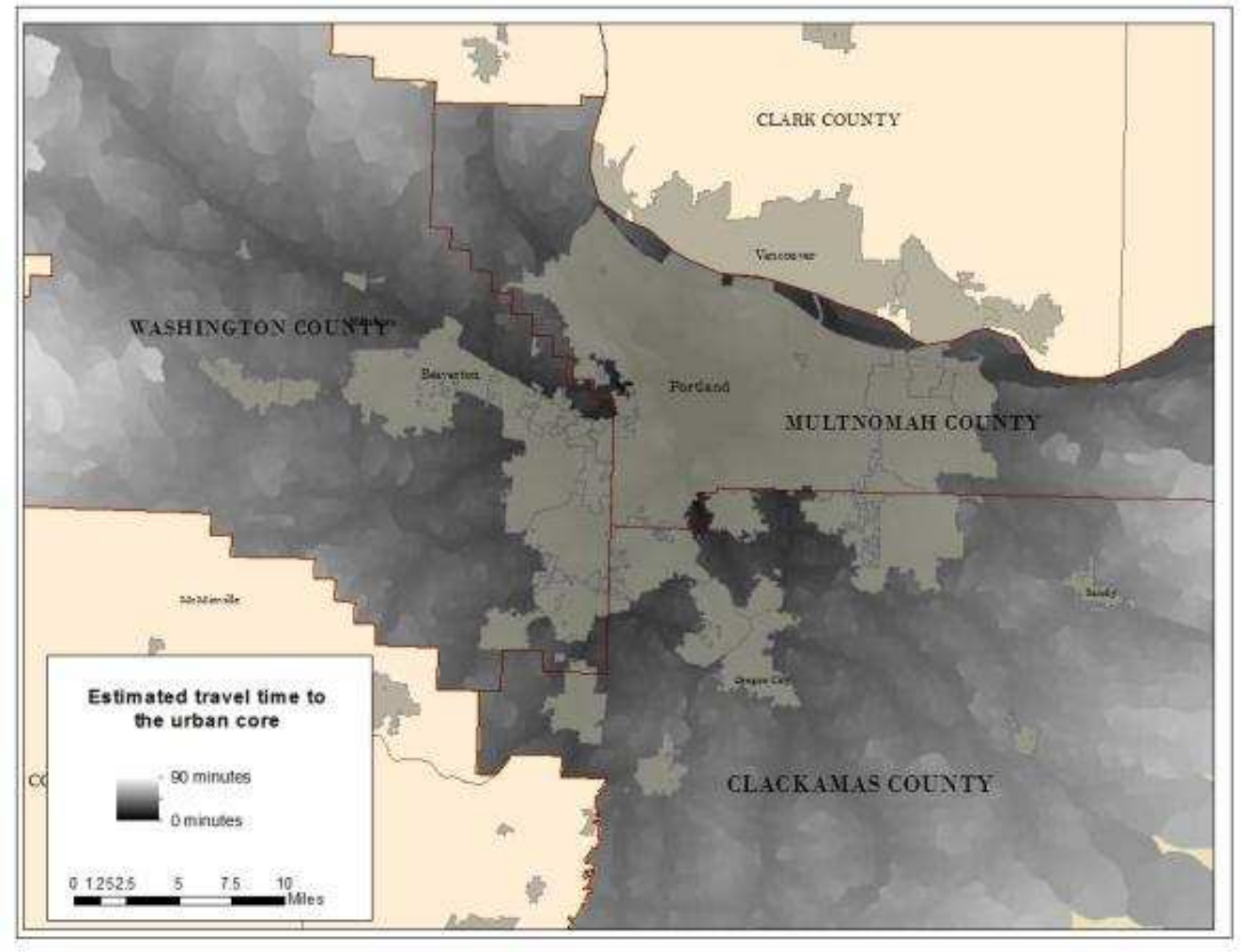

Figure 5.6: Map of travel times to the urban core 
I then calculated average travel time for each parcel in the sample and stratified by segment (local vs. non-local). I performed a one-way, analysis of variance to test whether there was a difference in the mean distance to the urban core for local exclusive and non-local food producers. As expected, local producers were found to be closer in terms of time-distance to the urban core $(\mathrm{M}=35.35$ minutes $)$ compared to non-local producers $(M=41.732$ minutes $)$. Results indicated that these means differed significantly, $\mathrm{F}(1,484)=65.99, \mathrm{p}<.001$.

\section{5: SIZE OF FIRM}

For agricultural producers, acres under production are highly correlated with agricultural output (Dimitri et. al., 2005), a measure of size of firm. Using the producers' survey, 547 respondents answered the question pertaining to acres in active production and of these 415 answered the question(s) pertaining to geography. As expected, local producers were found to have far fewer acres under production ( $\mathrm{M}=35.64$ acres $)$ compared to non-local producers ( $\mathrm{M}=107.51$ acres). Results of a one-way ANOVA indicated that these means differed significantly, $\mathrm{F}(1,413)=14.47, \mathrm{p}<.001$.

\section{6: DISCUSSION}

My results show that local and regional food producers in Clackamas County are more likely to cluster at smaller scales (1 mile), are found significantly closer to the urban core and tend to have less acres under production. These findings directly support my 
hypotheses $2 \mathrm{~b}$ : "We would expect the new food sector to be dominated by smaller actors clustered close together and close to the urban core." However, I was only able to indirectly control for size of operation in my analysis of spatial structure (clustering) and was unable to account for the effects of proximity to the urban core on parcel size. Specifically, one would expect a significant degree of endogeneity pertaining to the causal relationship between proximity to the urban core and parcel size. An analysis of the relationship between parcel size and distance to the urban core for the Portland Metro region yielded an extremely high correlation $\left(R^{2}=0.891\right.$ - see appendix $\left.D\right)$. That is, parcel size is directly related to proximity to the urban core ${ }^{20}$ and would need to be controlled for using an instrumental variable. However, data was unavailable to derive a meaningful instrumental variable to estimate the impact of proximity to urban core on parcel size.

Likewise, it is highly likely that similar endogeneity issues pertain to the influence of both proximity to the urban core and parcel size on the spatial structure (clustering) of the data as spatial distribution and structure are highly correlated in the regional context. So while I can say that local and regional producers are more likely to be clustered on smaller parcels close to the urban core, I cannot describe the independent influence each of these variables has on the outcome (i.e. local or non-local producer).

\footnotetext{
${ }^{20}$ This is directly related to the Von Thunen's isolated state theory and the concept of land rents relative to central cities: By extension, smaller parcel sizes will be associated with higher land rents.
} 
Furthermore, it is impossible to derive from the data a meaningful way to explain the causes of the resulting distribution and structure. For example, the difference in the spatial distribution of local and non-local producers may very well be exclusively related to the economic motivation of the actors to reduce transport costs (local and regional food producer's markets are in the urban core whereas export-oriented producers might be more interested in locating close to transportation networks, processing facilities or distribution centers often of which are located outside the urban core). However, while this in all likelihood is a significant motivation behind the distribution patterns of the local and regional producers it does not preclude these producers from benefiting from urbanization economies that are different than the non-local producers.

Furthermore, reduction of transportation costs does not explain the variation in the structure of the segments (i.e. the difference of the degree of clustering between local and non-local food producers diminishes as the neighborhood size increases). It is possible that these differences in the scales at which local and non-local producers cluster is due to the different forces of agglomeration that are at play. Drawing from the industry lifecycle literature, I posit that because local and regional food producers are participating in a younger economic sector, they will be more active in product innovations that are fostered by urbanization economies relative to the non-local producers. That is, agglomeration externalities may be realized and exploited differently by the different production segments of the food sector - and that these differences are revealed through the spatial structure of the firms in each sector. Neffke et.al (2011) found that businesses 
take advantage of different types of agglomeration externalities along the spectrum of the industry lifecycle. In later stages of sectoral development, three kinds of spatial developments are expected: (1) a cumulative causation based process of growth within the preliminary urban settings; (2) a dispersion process towards suburban and adjacent rural regions to take advantage of larger parcels and cheaper land, and; (3) spatial growth transmittance and firm dispersion based on functional network spatial relationships which are predominantly non-contiguous in character.

On the other hand, actors in younger sectors rely more on non-pecuniary forms of agglomeration externalities (e.g. knowledge spillovers). The marginal cost of transmitting tacit knowledge rises with distance (Audretsch 1998). As tacit knowledge and human interaction become more valuable in the innovation process, geographic proximity becomes crucial to the innovation process. The theoretical basis for my assessment rests on the fact that these externalities are realized differently for actors in the new food economy than they are for actors or firms in the export oriented traditional food sector and therefore spatial structure can be differentiated between the two sectors.

Forces at work in the agglomeration process therefore depend on the spatial scale considered (Anas et al., 1998; Rosenthal and Strange, 2001; Fujita and Thisse, 2001). Guillain and Le Gallo (2007) allude to the inherent differences in scale to the different forms of agglomeration. As such I have applied measures of agglomeration at varying scales to detect whether different forces of agglomeration might be present. To date, no 
such research exists that quantitatively assesses at what specific scales these different forces unfold.

This does not preclude firms engaged in export oriented food production from benefitting from non-pecuniary forces of agglomeration, rather the nature of the agglomeration forces are fundamentally different. I found clustering of the local and regional food producers at smaller distance thresholds but as you increase the threshold you get an increase in the proportion of clustering of the non-local producers. This could mean that pecuniary and non-pecuniary effects of agglomeration unfold at different scales. The non-local producers are clustering to take advantage of pecuniary effects such as labor pooling, shared processors, and accesses to distribution networks whereas the local producers are clustering to take advantage of knowledge spillovers or at the very least benefit from knowledge spillovers.

These concepts while difficult to quantify given the data, are explored in the next chapter by drawing on a set of qualitative interviews that I conducted with local and regional food producers. 


\section{CHAPTER VI: INNOVATION DIFFUSION AND KNOWLEDGE ACCUMULATION OF FOOD PRODUCERS IN THE PORTLAND METRO REGION}

\section{1: INTRODUCTION}

In the last chapter I explored aspects of geographic space in terms of the spatial dispersion and structure of food producers in Clackamas County. My primary motivation for doing so was to empirically test differences in how local and regional producers were spatially arranged relative to export oriented producers. I did so in an attempt to understand if such differences could be analyzed in terms of the economic development opportunities inherent in these patterns depicted by forces of agglomeration economies. That is, forces at work in the agglomeration process depend on the spatial scale considered (Anas et al., 1998; Rosenthal and Strange, 2001; Fujita and Thisse, 2001) (Guillain and Le Gallo, 2007) and my analysis sought to investigate the inherent differences in scale specific to these different forces of agglomeration.

I posit that the new food economy is indeed new, and I have attempted to differentiate it from the export oriented food sector both in terms of supply chain and participant characteristics including spatial dispersion and structure of the producers in each system. As shown in the last chapter, firms participating in the export-oriented system were more dispersed, and producers who sold their products within the Portland Metro Region were clustered closer together and closer to the urban core. However, the analysis falls short of explaining the multitude of factors that may influence firm location decisions and 
product and market choices. In this chapter, I explore some of these factors, in particular, the importance of knowledge in business success and how knowledge is accumulated at the firm level. I draw on a set of qualitative interviews, focusing on producers throughout the region who participate in local and regional food systems. Specifically, this chapter is focused on testing hypothesis $2 \mathrm{~b}$ :

We would expect this new food sector to be active in product innovations that are fostered by both "Jacobian" and "Porter" externalities (relative to the global food system that is vertically integrated, seeks out process innovations, cheap land and cheap labor).

That is, because the fundamental nature of the products and supply chains with which actors in the new food economy are associated, these actors are affected by very distinct forces of agglomeration. Given the new food economy is indeed new and growing; I tested whether the food system actors in the new food economy were affected by agglomeration forces and if so, to what extent these forces differed for the different actors and for what reasons. My analysis did not compare how agglomeration forces differed for local and regional food system producers relative to export-oriented producers.

\section{2: FORCES OF AGGLOMERATION}

Businesses cluster in geographic space for a variety of reasons. This clustering can be seen among firms in a specific sector or across firms in different sectors. Firms may cluster to take advantage of a specific resource (natural or otherwise) that is concentrated 
in a given location, to take advantage of localization externalities such as industry specific specialists (i.e. specialized legal services), specialized labor pools or increased access to intermediate inputs, as well as to take advantage of urbanization externalities such as access to government services or infrastructure, or urban amenities for employees. Firms also cluster for non-pecuniary reasons as well, mostly having to do with the spillover of knowledge. This spillover may take effect across firms in related industries (Marshall, 1890; Arrow, 1962; Romer, 1986), across firms in the same industry in a competitive cluster (Porter, 1990) or across firms in different industries (Jacobs, 1969). See Chapter II for a detailed description of literature pertaining to agglomeration economies. Figure 6.1 represents a conceptual diagram of the different sources of agglomeration

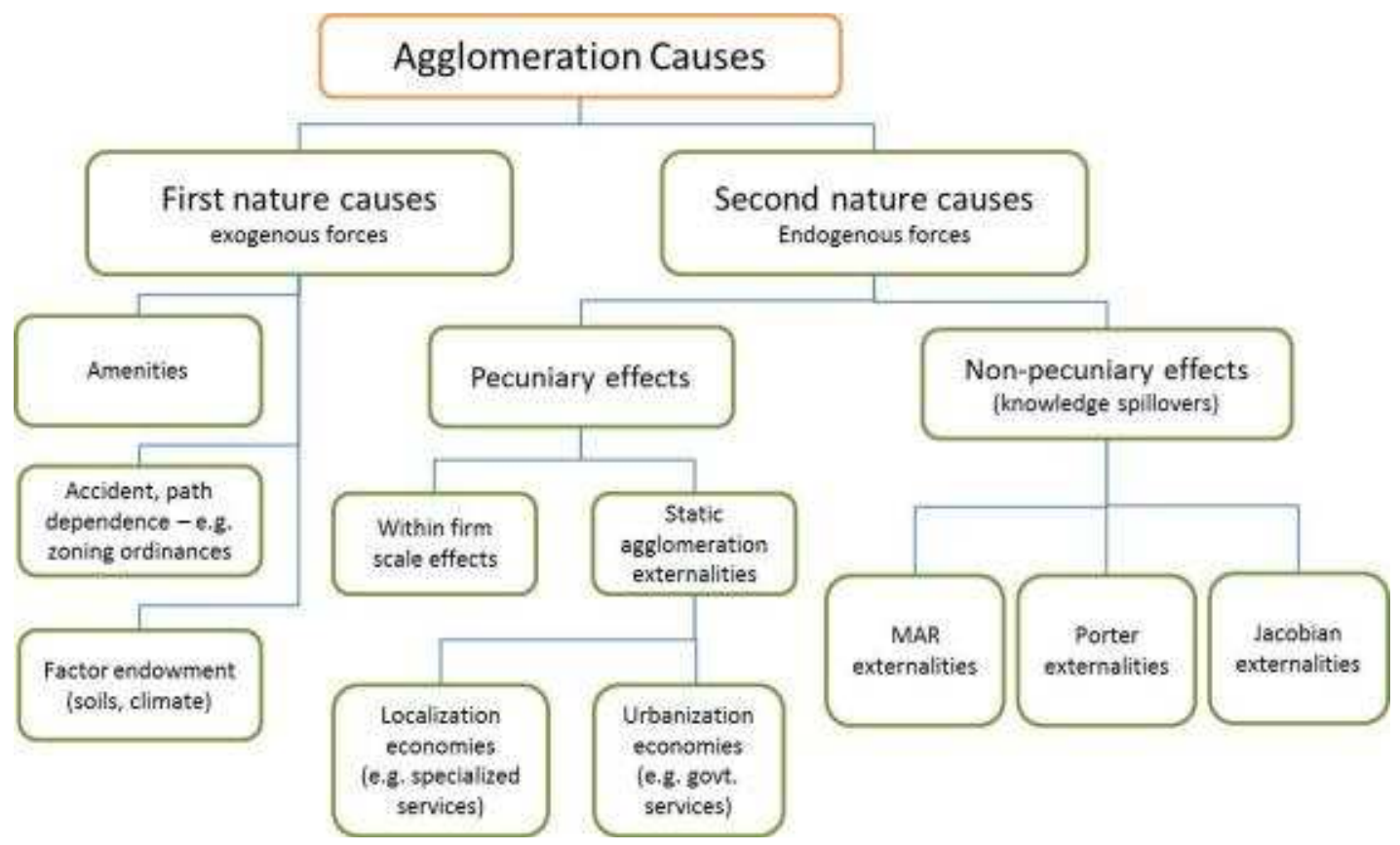

Figure 6.1 Causes of agglomeration (Adapted from: Christ, J.P. 2009) 
For food producers, first nature causes are usually thought of as the primary driver behind location decisions. The natural endowments of specific locations (such as soils and climates) are primary factors that affect what types of food can be grown where. But these drivers unfold at large scales as the factors are generally spatially homogenous across smaller scales like the Portland Metro Region. While first nature causes explain the types of products and the structure of farmland in a given region, they do little to explain the variation within a region. Food producers have been shown to benefit from second nature causes of agglomeration as well. Schultz (1951) hypothesized that farms benefit from the consequences of economic development originating in cities, including better markets for capital, labor, inputs and products. Furthermore, urban development can enhance the farmers' perceptions of the level of public services and the quality of the farm family's social and community life (Heffernan and Elder, 1987). Furthermore, knowledge has been shown to diffuse in agricultural communities with greater social ties and when farmers are closer together in geographic space (Hagerstrand, 1967). My analysis presented here aims to explore some of these forces of agglomeration among local and regional food producers in the region.

\section{3: SELECTED PRODUCERS IN THE PORTLAND METRO REGION}

In the following sections, I present information that I gleaned from a set of semistructured interviews with food producers. The process of sample selection as well as

contact and interview procedures is described in detail in chapter III. Interviews were 
conducted in late 2013 and early 2014. My aim was identify forces of agglomeration specific to producers within the local and regional food system. I therefore focused on local and regional food producers for my interviews. In addition, I have drawn on supplemental interviews of distributors conducted by Ecotrust in the fall of 2013 and the distributor / processor survey conducted by Clackamas County in late 2011 as part of the Clackamas County Agricultural Opportunities Assessment. In addition to questions specific to processes of innovation diffusion and knowledge accumulation, I also asked questions pertaining to a suite of characteristics specific producers' businesses.

I interviewed 14 individual producers, all but three were participants exclusively in local and regional supply chains, two participated in both local and regional supply chains as well as more traditional export oriented supply chains and one participated solely in export oriented supply chains. All of the local exclusive producers I interviewed sold their products either directly to consumers or to restaurants. The other three used intermediated supply chains for some of their products. All the interviewees owned or leased farms in the Portland metro area with the exception of the one export oriented producer. Acres under production ranged from less than one to over 1,000 acres. All but two of the producers I interviewed were relatively new to farming or ranching (less than 15 years). Eleven were business owners and three employees of farm businesses. All but four owned the land that they farmed or grazed. Table 6.1 shows the characteristics of each producer interviewed. 
Table 6.1: Interviewee characteristics

\begin{tabular}{|c|c|c|c|c|c|c|}
\hline acres & $\begin{array}{l}\text { years } \\
\text { farming }\end{array}$ & $\begin{array}{l}\text { own / } \\
\text { lease }\end{array}$ & $\begin{array}{l}\text { primary } \\
\text { owner / } \\
\text { employee } \\
\end{array}$ & markets & products & supply chain \\
\hline 7 & 9 & own & owner & csa, restaraunts & vegetables & direct \\
\hline 20 & 7 & na & employee & $\begin{array}{l}\text { farmers' } \\
\text { markets }\end{array}$ & vegetables & direct \\
\hline 38 & 10 & own & owner & csa/ farm coop & vegetables/berries & $\begin{array}{l}\text { Direct / } \\
\text { intermediated }\end{array}$ \\
\hline 10 & 10 & lease & owner & csa & $\begin{array}{l}\text { rabbits / chickens } \\
\text { / lamb pork }\end{array}$ & direct \\
\hline 5 & 20 & own & owner & $\begin{array}{l}\text { csa / farmers' } \\
\text { market }\end{array}$ & vegetables & direct \\
\hline 10 & 5 & na & employee & csa & vegetables & direct \\
\hline 0.33 & 9 & own & & $\begin{array}{l}\text { Farmers' } \\
\text { markets, } \\
\text { restaurant }\end{array}$ & veg, eggs & direct \\
\hline 100 & $20+$ & own & owner & $\begin{array}{l}\text { Farmers' } \\
\text { markets / csa / } \\
\text { restaraunt }\end{array}$ & veg & direct \\
\hline 1.5 & 4 & na & employee & $\begin{array}{l}\text { Farmers' } \\
\text { markets, } \\
\text { restaurants }\end{array}$ & vegetables & direct \\
\hline 55 & 7 & own & owner & $\begin{array}{l}\text { Farmers' } \\
\text { market (1) / } \\
\text { csa }\end{array}$ & $\begin{array}{l}\text { vegetables / } \\
\text { sheep }\end{array}$ & direct \\
\hline 1400 & 6 & own & owner & $\begin{array}{l}\text { Local meat } \\
\text { producers }\end{array}$ & hay/pasture & $\begin{array}{l}\text { Intermediated / } \\
\text { direct }\end{array}$ \\
\hline 10 & 2 & na & employee & csa & vegetables & direct \\
\hline 50 & 14 & $\begin{array}{l}\text { own and } \\
\text { lease }\end{array}$ & owner & $\begin{array}{l}\text { distributor / } \\
\text { wholesaler }\end{array}$ & vegetables & Intermediated \\
\hline 10 & 12 & own & owner & processor & vegetables/berries & intermediated \\
\hline
\end{tabular}

\section{3: AGGLOMERATION EFFECTS}

\subsection{1: Pecuniary effects}

Each producer benefited to some to degree from pecuniary forces of agglomeration. In some cases these were more pronounced than others. Sources included: access to specialty contracting services (e.g. machinery work for on-farm infrastructure or field preparation), input sourcing, specialty services (e.g. banking or legal services specific to 
business operation), strategic business partnerships and price premiums for products associated with urban markets. The urban core seemed to be the source of pecuniary externalities for producers participating in direct to market supply chains, and in particular those who sold products at farmers' markets. The producers' who sold products through CSAs benefited from strategic partnerships, either with neighbors or with businesses in the urban core. Strategic partnerships included partnering with neighbors to offer "whole basket" shares that included products that the interviewee did not produce. Partnerships with businesses in the urban core included selling CSA shares to employees at an existing (large) business.

The one producer I interviewed who participated in export oriented supply chains benefited from pecuniary effects of agglomeration as well. The sources of these benefits included the sources listed above however he seemed to rely much more on sourcing of inputs, specialty services, contracting services for on-farm work and labor pooling. These benefits were realized through peripheral towns (e.g. Molalla) more so than originating from the urban core (Portland).

Furthermore, the majority of producers ( 9 of the 14) relied on off-farm employment to sustain farming operations. This off-farm employment (either by the interviewee or their partner) constituted not only a pecuniary benefit by bringing in additional income but also provided a key source of information and links to the more traditional economy. I cover off-farm employment among producers in greater detail in Chapter VIII. 


\subsection{2: Non-pecuniary effects}

Producers relied on a wide array of information to run their operations. The different types of information included knowledge of markets, farming practices, seed sources, products and information pertaining to business resources. Sources of information were highly dependent on the type and size of the operation, the proximity of the operation to the urban core, the level of interaction with neighbors and the supply chains in which the producer participated.

There was a distinct difference between producers who sold their products exclusively through farmers' markets and those that sold their products exclusively through Community Supported Agriculture shares (CSAs). The producers who marketed their products exclusively at farmers' markets depended extensively on the market itself for different types of information particularly information pertaining to new products, pricing and production management practices. One individual who I interviewed stated, "I arrive early to the market so I have the opportunity to walk around to the other stalls and talk with folks who are setting up." This is a customary process for this individual and her primary method for collecting information for most of her business decisions specific to pricing, product display and product development. Another interviewee stated that they glean information specific to farming practices and even "hired one of my employees from the market who was working at the time for another farm" (a form of inter-firm spillover). Another interviewee spoke extensively about his "neighbors" referring to proprietors of other stands. 


\section{4: SOURCES OF AGGLOMERATION EXTERNALITIES}

\subsection{1: Connection to the urban core}

The majority of interviewees were closely connected to aspects of the urban core. Three of the fourteen people I interviewed lived within Portland city limits, two of whom commuted to their farms to work and one of whom farmed an urban parcel. As mentioned above, nine of the interviewees relied on off-farm employment as an income source for the farm and all of these jobs were within the urban core. Furthermore, all except for one of the producers who marketed their products at farmers' markets did so at one or more markets in the urban core.

From the producers I interviewed it is clear that the urban core is not only a primary source of income (either through selling products or through off-farm employment) but also a source of non-pecuniary externalities as identified above. The reliance on the urban core for income or information did seem to vary however depending on the marketing strategies of the producers. For example, producers who marketed products through farmers' markets seemed to have a much stronger connection to the urban core than those that marketed their products through CSAs. Those who used intermediated supply chains also seemed to have a close connection to the urban core (other than the one export oriented producer) because; to a large degree many of their business contacts (e.g., distributors or restaurants) were located in the urban core. Those producers that sold products to restaurants, reported more trips to the urban core and seemed to have stronger social ties in the city. These producers garnered extensive information from 
chefs in the city and benefited from specific formal and informal networks (e.g., farmer chef collaborative). The majority of those that I interviewed also benefited from urban amenities. "Whenever I go out, I always go to Portland, there's just not a lot to do around my farm and almost all of my friends live in Portland."

Furthermore, all except one of the local-exclusive producers were actually raised in an urban or suburban environment (the one not raised in an urban environment was raised on the farm). Only one of the producers participating in intermediated channels was raised in an urban environment. The nature of their upbringing seemed to have a major influence on their perception of the urban core. Those raised in the "city" perceived it as a resource whereas those raised in rural environments saw it as a necessity of doing business. "Once we realized products we sold at the farm stand could bring in more money than the dairy operation, we decided that we would try our luck at the farmers' markets in the city. I remember the first time we went to a market; my Mom's knuckles were white from holding the steering wheel so tight. Once we got big enough, we hired people to sell products at the markets." This distinction, while seemingly subtle, is an indication of how these individuals exploit the potential benefits that they can realize from agglomeration economies.

\subsection{2: The concept of "neighbor"}

In some cases, interaction with neighbors was actually an important aspect of how individuals I interviewed obtained both information pertaining to products or practices. 
For example, multiple informants stated they glean extensive information about farming practices, product viability and even markets from their neighbors. Furthermore, many of the interviewees benefited from pecuniary effects from their neighbors as well.

Neighbors were a source to borrow machinery, to hire part time or contracting services or, in some cases even partner with to sell products. One interviewee reported that once she met one neighbor it opened the door for a network of services: "I needed some excavation work done and Chris told me of a neighbor about a mile down the road who has a trackhoe - although this person couldn't help me out at the time, he provided the name of another neighbor who could. Now I have two different people I can turn to when I need tractor work done."

However, variation between the strength of ties with neighbors seemed to be attributed to the type of neighbor or personality of the producer more so than any location specific decisions or particular marketing channels. "When I first bought the farm, I went around and knocked on all my neighbors doors to introduce myself." Like benefits realized from the urban core, the perception of one's neighbors made a huge difference in whether any given interviewee realized benefits, whether pecuniary or non-pecuniary. In two cases, interviewee's didn't even know who their immediate neighbors were. In both cases, these producers were surrounded by hay and grass seed or livestock operations and felt as though what they were doing was so different than what their neighbors were doing that they couldn't benefit in any way from them. 
The concept of a neighbor meant very different things to the different interviewees. Those with rural upbringings seemed to conceptualize neighbors at much larger scales (this could be that they also farmed larger plots of land). However, in one case, neighbor meant the closest person who was employing similar practices (e.g. growing vegetables to sell at a farmers' market); this neighbor was nearly ten miles away. As mentioned above, those interviewees who sold their products exclusively at farmers markets actually perceived other vendors at the markets as neighbors, with whom they had as strong as ties if not stronger than their actual neighbors at the farm. For example, one respondent reported that 'I'm always checking in to see what neighbors are up to, what price they're setting for the peppers, or what unique way they're stacking their veggies to get customers to come to their stall."

\subsection{3: Clusters}

Two of fourteen people I interviewed benefitted from a neighborhood scale cluster of economic activity. One of these micro-scale clusters was inside the city limits of Portland, the other directly adjacent to it. Activity in the clusters included tool and machinery exchanges, business partnerships to take advantage of economies of scope (diversified product offerings) and information exchange (via an urban grange hall). This is consistent with what I found in my spatial analysis, where a small proportion of local and regional producers were found to be significantly clustered at very small scales (neighborhood thresholds of less than one mile). 


\section{5: PROFITABILITY AND OFF-FARM EMPLOYMENT}

All except the largest three operations were struggling financially. Even the larger operations worked a minimum of six days a week and employed minimal employees. Three of the producers I interviewed also had additional on-farm sources of income in the form of training, education or workshops. These training and workshops were all focused on teaching new farmers, small scale, non-mechanized sustainable practices.

Nine of the interviewees relied on off-farm income (either the interviewee or their partner). This is consistent with findings recorded by King (2010) and Vogel (2012) and indicates both that these operations benefit from supplemental income that can help sustain the farming operations and this off-farm employment represents ties to the nonfarm economy. Furthermore, all but one of the people I interviewed was relatively new to farming (within the last 15 years) and all but three grew up in urban environments. The majority of these still had strong connections to the urban core, more so than just going to the market to sell their goods. The (seemingly) most profitable operation was also one of the largest, as well as the one who had been farming the longest and had by far the most diversified marketing structure including working multiple farmers' markets, in-business CSAs and a farm stand.

To supplement my findings from my interviews, I assessed the relationship between offfarm employment and urbanization over time for the entire Portland Metro Region. I evaluated USDA Census of Agriculture historical data to measure whether population 
growth affected the rate of off-farm employment. Following methods presented by Lockeretz (1986), and using data described in section 3.2, I performed an analysis that related urbanization trends over time with off-farm employment reported by farm households. I regressed the proportion of farms whose principle occupation came from off-farm on regional population (a proxy for urbanization) while controlling for the type of production, key land use laws ${ }^{21}$ and farm size.

Table 6.2: Parameter estimates for the relationship between off farm employment and urbanization

\begin{tabular}{|l|r|r|r|r|l|}
\hline Estimate & \multicolumn{1}{|l|}{ Std.Error } & \multicolumn{1}{l|}{$\mathrm{t}$} & \multicolumn{1}{l|}{ value } & $\operatorname{Pr}(>|\mathrm{t}|)$ & \\
\hline Intercept) & $1.56 \mathrm{E}-01$ & $1.01 \mathrm{E}-01$ & 1.545 & 0.1567 & \\
\hline prop_veg & $1.78 \mathrm{E}+00$ & $6.20 \mathrm{E}-01$ & 2.863 & 0.0187 & $*$ \\
\hline avg_sz & $2.84 \mathrm{E}-03$ & $1.15 \mathrm{E}-03$ & 2.475 & 0.0353 & $*$ \\
\hline population & $9.65 \mathrm{E}-08$ & $4.50 \mathrm{E}-08$ & 2.146 & 0.0604 &. \\
\hline
\end{tabular}

Signif. codes: 0 ‘***’ 0.001 '**’ 0.01 '*’ 0.05 ‘’ 0.1 ' ' 1

Residual standard error: 0.04091 on 9 degrees of freedom Multiple R-squared: 0.7247, Adjusted R-squared: 0.6329 F-statistic: 7.896 on 3 and 9 DF, p-value: 0.006864

The results demonstrate that as the Portland Metro Area urbanized over time, the proportion of farms reporting off farm employment increased. While there is nothing inherently good or bad about this outcome it suggests a reason why small farms are able

\footnotetext{
${ }^{21}$ Oregon adopted growth management legislation in 1973 and Portland's UGB was proposed in 1977 and approved by the state in 1980
} 
to persist near to the urban core (as average farm size and proportion of off-farm employment were inversely related). This is a key characteristic in the agricultural structure of the region, contributing to the potential for agglomeration economies specific to local and regional food systems.

Local and regional producers appear to be even more dependent on off-farm employment than their export oriented counterparts, even when size of farm is controlled for. Of the producers I interviewed as part of this research, nearly $65 \%$ were associated with farms where at least $1 / 2$ of the farm income came from off-farm employment. In all of these cases, without this off-farm employment, farm related operations would not be possible. These producers also benefited from information derived from these jobs as well as links to the urban economy (see Chapter VII).

\section{6: CONCLUSION}

Table 6.3 summarizes the different types of agglomeration externalities realized by the different types of producers that I interviewed. Of the individuals I interviewed, clustering did not seem to be associated with any specific location decisions pertaining to second order causes of agglomeration (except in the two cases I highlighted above). Most people interviewed made location decisions based on perceived proximity to markets and first order effects (factor endowments or small parcel sizes). However, producers relied heavily on access to the urban core not only because of proximity to their customers but also because of pecuniary and non-pecuniary effects of 
agglomeration, including price premiums for their products, access to off-farm employment and knowledge accumulation pertaining to markets, product differentiation, product pricing and management practices. Producers benefited from knowledge spillovers at the site of sale (farmers markets, restaurants and distributors) at events in the city (conferences or informal gatherings) as well as through interactions with neighbors (even though they did not necessarily choose farm locations based on anticipated benefits realized from neighbors).

Table 6.3: Agglomeration externalities realized by different producer types

\begin{tabular}{|c|c|c|c|c|c|c|c|c|c|c|c|}
\hline \multirow[b]{2}{*}{$\begin{array}{l}\text { producer } \\
\text { type }\end{array}$} & \multicolumn{3}{|c|}{$\begin{array}{l}\text { First nature } \\
\text { causes }\end{array}$} & \multicolumn{3}{|c|}{$\begin{array}{l}\text { Urbanization } \\
\text { externalities }\end{array}$} & \multicolumn{2}{|c|}{$\begin{array}{l}\text { localization } \\
\text { externalities }\end{array}$} & \multicolumn{3}{|c|}{$\begin{array}{l}\text { non-pecuniary } \\
\text { effects }\end{array}$} \\
\hline & 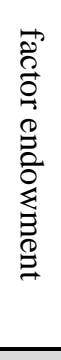 & 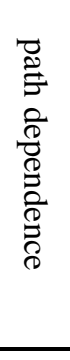 & $\begin{array}{l}\text { 莺 } \\
\text { : } \\
\text { : }\end{array}$ & 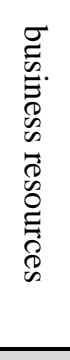 & 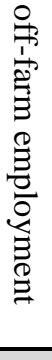 & 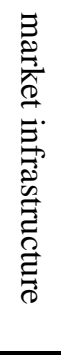 & 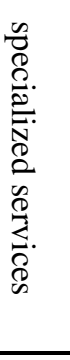 & 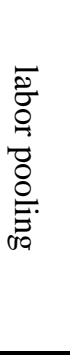 & 党 & $\begin{array}{l}\overparen{0} \\
\varpi\end{array}$ & 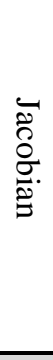 \\
\hline csa & $\mathrm{x}$ & & $\mathrm{x}$ & $\mathrm{x}$ & $\mathrm{x}$ & & & & & $\mathrm{x}$ & $\mathrm{x}$ \\
\hline $\begin{array}{l}\text { Farmers' } \\
\text { markets }\end{array}$ & $\mathrm{x}$ & & $x$ & $\mathrm{x}$ & $x$ & $\mathrm{x}$ & $\mathrm{X}$ & & & $x$ & $\mathrm{x}$ \\
\hline $\begin{array}{l}\text { inter- } \\
\text { mediated }\end{array}$ & $\mathrm{x}$ & & & $\mathrm{x}$ & $\mathrm{x}$ & & $\mathrm{x}$ & & & $\mathrm{x}$ & $\mathrm{x}$ \\
\hline $\begin{array}{l}\text { export } \\
\text { oriented }\end{array}$ & $\mathrm{x}$ & $\mathrm{x}$ & & & & & $\mathrm{X}$ & $\mathrm{x}$ & & & \\
\hline
\end{tabular}




\section{CHAPTER VII: POTENTIAL CONTRIBUTIONS OF LOCAL AND REGIONAL FOOD SYSTEMS TO REGIONAL ECONOMIC DEVELOPMENT}

\section{1: INTRODUCTION}

Because local and regional food systems have the potential to contribute to economic development as well as provide environmental and health benefits, local, regional, state and federal policy makers are increasingly interested in policy and stimulus drivers to foster the emergence and growth of these food systems. Economic development interventions and policies specific to local and regional food systems should consider the variety of actors such as producers, distributors, etc. (and their needs) that compose the whole food system. For example my analysis suggests that producers participating in farmers' markets benefit more from urbanization economies than they do from either backward linkages or technological spillovers that are traditionally considered in cluster formation. Loosely defined "cluster strategies" may not readily apply to local and regional food systems because of the complexity involved in defining the system, the interaction among actors, and actors' different needs.

In addition to the complexity of different supply chains, agricultural impacts on local economies are likely to vary depending on the structure of local agriculture, such as the size distribution of the farms and the commodity mix (Foltz, 2005; Brown et al., 2014). Furthermore, while regional structure is an important element of local and regional food systems, efficient production and distribution channels that enhance the ability of small- 
and mid-scale farmers to move products are also critical to the performance of this emerging market. Through my qualitative analysis, I found that most local and regional producers lack efficient production and distribution systems to get their products to markets. This lack of efficiency is a serious barrier in reducing price points of products. Without competitive price points, the growth of local and regional foods will be constrained as a niche or specialty market, limiting its potential impact on the economy as a whole.

On the other hand, economic development opportunities may not be fully realized by tapping into the production and distribution efficiencies of traditional supply chains because traditional systems fail to maintain information pertaining to product sourcing and production practices. Furthermore efficiencies of traditional supply systems rely on a constant and well managed supply of products. Because local and regional food systems are supplied by a myriad of producers with a wide variety of products, processors and wholesalers would have a difficult time managing a constant supply from the majority of local food producers (or from enough local producers to maintain efficient use of processing and distribution systems).

A key characteristic of the qualitative definition of local and regional supply chains is that foods reach the final consumer with information concerning the mode of production and distinctive quality assets (Renting et al.,2003). Providing production and quality information to the consumer is made easy by the fact that the number of nodes between 
the primary producer and the final consumer are minimal and the embededness of social and economic relations inherent to the system. As such, there is an intrinsic conflict then that arises from the necessity to increase efficiencies while simultaneously maintaining the "embedded" quality of the product.

It is this embedded nature of the products that affords the distinction of local and regional foods from their global counterparts and that offers the greatest potential for economic development opportunities. Future local and regional food system innovations that stem from the city-region will in all likelihood spawn from the need to be able to efficiently move local and regional food products to consumers in an economically efficient manner while at the same time maintaining embedded values and relationships and information pertaining to the mode of production and distinctive quality of the product. And while these innovations will likely emerge on their own, presenting an argument for the qualitative definition of local and regional foods as a potential source of economic development should motivate investments, policies, or subsidies to facilitate this emergence.

However, those advocating for local and regional foods as an economic development driver are challenged by economic development practitioners who argue that an export based economy is the basic engine for growth of regional economies. Despite the fact that since its inception export-base has been criticized (Blumenfild, 1955; Tiebout, 1962; Lindstrom, 1978) and extensive empirical studies have consistently failed to find a 
relationship between regional growth and growth of exports (Jung and Marshall, 1985; Sharma et al., 1991; Ghartey, 1993) many practitioners continue to believe that increasing exports is the only way to stimulate regional economies. However, regional economies grow even in the absence of a growing export base. As such, the question at hand should not be whether the localization of food production and consumption results in import substitution, but rather whether local and regional foods are a product of, and can in turn foster, endogenous processes within the context of the city-region.

A city-region based food system is distinctly different from food systems that are conceptually bifurcated into the agricultural hinterlands and consumer based urban areas. Interrelated and intermixed with regional economies, city-region local food systems may play a small but significant role as an endogenous driver of economic growth. However, this does not necessarily mean that local and regional food systems constitute a source of economic development for every region; rather the benefits that might be realized will vary from place to place. This variation is dependent on a range of factors but most important are aspects specific to the structure and composition of the current food system, the information flows and externalities realized by actors that are contingent on proximity of producers to the urban core and the growing conditions in the region. Equally important is the intersection between the city and the agricultural periphery. Both my spatial and qualitative analyses showed that it is this intersection that represents the space where local and regional food systems may offer the greatest contribution to regional 
economies. Cities represent both a place to sell products and a valuable source of agglomeration externalities; I cover this concept in more detail in the next section.

\section{2: LOCAL AND REGIONAL FOODS AND THE CITY-REGION}

Throughout this dissertation I have presented the significance of considering food systems in terms of the city-region. I have done so because aspects of urbanization play a key role in the structural formation and ultimate success of local and regional food systems, not only because the city represents the primary market for products of the local food system, but also because processes of urbanization play a fundamental role in shaping the agricultural landscape. It is the nature of the interaction of these two systems - the urban system and the agricultural system - that depicts the ultimate success of local and regional food systems in terms of economic development.

Urbanization presents numerous challenges and benefits to farmers. Negative externalities associated with urbanization increase the cost of farming and threaten the viability of the agricultural economy. Additionally, conflicts with nonfarm neighbors and vandalism are major concerns of farmers at the urban fringe (Lisansky 1986). At the same time, farming locations near a city can offer considerable advantages that offset such negative externalities. As early as the mid $20^{\text {th }}$ century, scholars questioned why small farming operations seemed to persist near the urban core, contrary to fundamental aspects of land use economics presented by Von Thünen (1966). Schultz (1951) hypothesized that farms benefit from the consequences of economic development 
originating in cities, including better markets for capital, labor, inputs and products. In addition, urban development can enhance the farmers' perceptions of the level of public services and the quality of the farm family's social and community life (Heffernan and Elder, 1987). Furthermore, local and regional producers in particular benefit from being able to market their product directly to urban consumers.

Urbanization can also influence the prices of agricultural inputs or outputs. In addition to such pecuniary externalities, urbanization also generates non-pecuniary externalities for farm families, and in particular for local and regional producers. The ability to buy food in an area in which it was produced, and in particular directly from the producer, may improve the flow of information about the food itself, but may also provide the producer with valuable insights into market mechanisms and product preferences (Morris \& Buller, 2003). Furthermore, as described in my Chapter VI, producers obtain extensive information pertaining to market conditions, pricing, product innovations and on-farm practices not only from their neighbors but also from markets where they sell their products and other sources in the city. Ultimately, even considering the negative externalities associated with urban environments, my analyses in Chapters III and V and VI show that farms still cluster close to the urban core to take advantage of positive externalities associated with agglomeration economies and those that do tend to have dramatically different characteristics and benefit from these externalities in meaningful ways. 
Farms also benefit from off-farm employment when close to urban areas. In 2007, close to one third of U.S. farm households $(686,600)$ generated income by engaging in off-farm business ventures and on farm activities independent of commodity production (Vogel, 2012). Farm households that operate off-farm businesses have been shown to have strong links to the local non-farm economy. The importance of off-farm employment is even more prevalent among small farms (Vogel, 2012). My analysis in Chapter VI showed that off-farm employment increased as the Portland Metro Region became more urbanized over time. Additionally, off-farm employment was particularly important for the producers that I interviewed, suggesting that the urban core is profoundly connected to the agricultural periphery.

As suggested in Chapters V and VI, a small farm's proximity to the urban core facilitates not only the sale of products through reduction of transport costs but also the transfer of tacit knowledge. Within the local and regional food system, the exchange of tacit knowledge is an essential aspect of doing business. Producers are required to respond to taste preferences and trends in an efficient manner and consumers require information pertaining to practices and inherent qualities of the products. The exchange of these forms of information is facilitated by regular face-to-face interactions which are made possible by the proximity of the producers to the urban core. Thus, local and regional food producers are able to persist close to the urban core in the Portland Metro Region because of the opportunities for off farm employment . 
While agglomeration externalities stem from urban forces, these urban forces can adversely affect the agglomeration economies realized by producers. For example, Rashford et al. (2003) found that farm related services that may have once clustered in urban areas disappear when neighboring farms are converted to development. In turn, farm related services disappear with urbanization, and a farmer may have to pay more for inputs or spend more time and/or travel greater distances to obtain equipment repairs. Lynch and Carpenter (2003) found that as the number of farmland acres drops below a certain threshold, the nearest input supplier may close or relocate because of insufficient demand for farm inputs. Furthermore, as processes of urbanization result in farmland conversion, farmers may no longer be able to take advantage of production based economies of scale that come from information sharing and formal and informal business relationships between neighboring farms. In addition to enhancing productivity, being part of a large farming community can be conducive to innovations and new business formation (Porter 1998) and if farmland is loss to urbanization, the amount of knowledge to spill over is minimized. For this reason, the balance between the urban area and the agricultural periphery is critical in the emergence of the new food economy, where persistence of farms close to the urban core is an important element in fostering both the accumulation of knowledge for producers and the embedded nature of products consumed by urban populations. 
In the Portland Metro Region, land use planning laws that constrain urban sprawl and incentivize preservation of farm land have helped maintain the presence of farmland, ensuring that services and suppliers persist in the region. Further, my analysis in chapter VI showed that local and regional producers benefit as much from their non-local neighbors as they did from neighbors who participated in local and regional supply chains. In this sense, the presence of farmland and in general and more specifically a farm economy, is a necessary requirement to fostering a healthy local and regional food system. In Chapter III, I showed how the land use law that created the UGB in Portland has benefited this farm economy. While the proportion of small farms actually decreased after the law was put in place (when population was controlled for), the total number of farms increased.

\section{3: THE NEW FOOD ECONOMY}

My analysis shows local and regional food systems are a new sector. However, whether or not this sector is considered new depends on how local and regional food systems are defined. The geographic definition may lump food system actors who have been functioning in traditional systems with local and regional producers who are in fact operating in a non-traditional fashion (either through production practices or distribution and marketing strategies). The qualitative definition represents a system that is new as expressed through both supply and demand drivers. Traditionally, consumers have not considered the location of production of the food they consumed as being important. However, in recent years, as I have highlighted, the growth in the popularity of products 
embedded with the values and social and economic relations has sky-rocketed.

Therefore, it is the qualitative definition of local and regional food systems and the related supply chains and consumers that constitutes this new food economy.

Additionally, when applying concepts presented by Jacobs (1969), Cortright (2002) and Marsden and Schrock (2009) among others, the new food economy presents the greatest opportunities for economic development. However, although the theoretical bases might support the notion that this new food economy offers opportunities for regional economic development, there remains a need for empirical research. This research should (1) integrate the economic implications of local and regional food systems more broadly within regional economies and (2) investigate the interactions of land use policy on the distribution and structure of these food systems. In the next section I highlight some potential areas for future research that touches on these themes.

\section{4: FUTURE RESEARCH}

While I have attempted to describe some of the fundamental aspects specific to regional economic development resulting from local and regional food systems, understanding their potential contribution to regional economies has much to be explored. Much of the preliminary work specific to conducting impact assessments such as the use of InputOutput modeling to assess multiplier effects has failed to capture both the full suite of interactions between actors as well as the intricacies pertaining to information flows. And while most of these studies show positive economic impacts, the modeling framework has substantial limitations and does little to inform policy makers and 
planners of what types of interventions might promote local and regional food systems in meaningful ways. Because of its infancy, research pertaining to this new food economy is only now beginning to emerge. Data useful for being able to assess its contributions to regional economies will continue to become more available. At the time of this research, the 2012 Census of Agriculture was not available, however, once released it will prove a valuable resource for looking at some of the longer term trends as the 2012 Census included focused attention on aspects of local and regional food production.

Furthermore, the methods for assessing both impacts of local and regional food systems to regional economies as well as impacts of urban economies on local and regional producers will continue to evolve. The work by Brown et al. (2014) is an excellent example of such evolution. In particular this research explores an approach not constrained by the limitations of Input-Output models by considering impacts more broadly (rather than focusing on multiplier effects alone). However, while their approach represents a significant advancement in assessing the contribution of local and regional food systems to regional economies, it also has several limitations that can be improved upon with more sophisticated tools and/or up-dated data (e.g. 2012 Census of Agriculture). For example, they failed to recognize effects at the regional scale. By using the county as their primary unit of analysis, they have obfuscated the potential impacts to regional economies. That is, it may very well be that benefits in terms of income growth are realized in adjacent counties to where the direct sales are being recorded. For example, a farmer who grows food in Clackamas County and sells it at the Portland 
Farmers Market is introducing indirect and induced effects within Multnomah County. Furthermore, aspects specific to the nature of food culture as a regional amenity are realized at the regional scale, not on a county by county basis. Furthermore, by only considering directly marketed food and agricultural tourism, they also failed to capture over half of the local and regional products (Lowe and Vogel, 2011). Finally, while Brown et al. found no significant contribution of directly marketed goods at the national scale, they did see effects at smaller scales, although these effects varied depending on the region. Their selection of the boundaries that defined regions however was arbitrary (they used Bureau of Economic Analysis regional boundaries), and by changing the definitions of these regions, the results would in all likelihood vary as well. This indicates that the analysis would benefit from the use of spatial statistics - in particular geographically weighted regression (GWR). GWR provides a local model of the variable or process the analyst is trying to understand by fitting a regression equation to every location in the dataset (in this counties or more appropriately regions). By applying spatial statistics, the analysis could account for both spatially autocorrelated regressors as well as potential omitted variables that are closely related to aspects of geographic space.

As well, the research pertaining to the benefits realized by producers participating in local and regional supply chains resulting from aspects of agglomeration externalities has been sporadic and poorly defined. Through the research presented here, I have attempted to define an analytical framework that can be employed for gaining a greater understanding of forces of agglomeration. Advances in Geographic Information Systems and in 
particular in spatial analysis and spatial statistics can facilitate our understanding of the potential benefits realized by producers at different stages in the industry lifecycle. As more and better spatially explicit data (like the data used in my spatial analysis) becomes available for more regions and over time, there will be more opportunities to relate specific land use phenomena to the structure and form of local and regional food systems. This line of inquiry holds particular promise for informing land use policy as different producer types benefit from different spatial structures. While the analysis I presented in chapter $\mathrm{V}$ is a good starting point, limitations in the sample size of my data constrained my ability to evaluate micro-scale clustering. It is these aspects of micro-scale clustering that may offer insights about the different scales at which firms cluster, and how different forces of agglomeration are realized at these different scales. The analysis would benefit from data specific to non-pecuniary externalities as well. Future data collection efforts should be both robust enough in sample size to ensure spatial representation as well as include pieces of information that can help assess distinct forces of agglomeration.

\section{5: CONCLUSION}

Through the research presented here I have explored aspects of local and regional food systems in the metropolitan region of Portland, OR and more broadly in the U.S. and Europe. My aim was to determine (1) how a "new food economy" is different than the more traditional, export-oriented agro-food industry, (2) if patterns specific to the spatial organization of actors (and in particular producers) can be recognized and (3) how these patterns may have implications for regional economic development. 
I explored these concepts through descriptive, qualitative and quantitative analyses, focusing on a key set of hypotheses:

Hypothesis 1: Local and regional food systems in the Portland region and other regions around North America and Europe can be differentiated from the export-oriented, global agro-food sector;

Hypothesis 1b: As a sector, local and regional food systems are indeed new relative to the export-oriented agro-food sector and; Hypothesis 1c: The new food economy is growing.

Hypothesis 2: The new food economy is subject to effects of agglomeration different than that of the global agro-food sector because it is a nascent industry.

Hypothesis 2b: We would expect this new food sector to be active in product innovations that are fostered by both "Jacobian" and "Porter" externalities (relative to the global food system that is vertically integrated, seeks out process innovations, cheap land and cheap labor) and hence;

Hypothesis 2c: We would expect this new food sector to be dominated by smaller actors clustered close together and close to the urban core. 
Hypothesis 3: Based on the new economic geography and the geography of knowledge literatures, urban and regional form matter because the distribution of producers, processors, distributors and consumers will affect the benefits realized from agglomeration economies.

There are several ways in which local and regional food systems can be differentiated from the export-oriented sector. However, these differences are dependent on whether you define the local and regional food system geographically or qualitatively. Depending on the qualitative or geographic definition, there can be a significant amount of overlap between the local and regional and export-oriented systems. Furthermore, depending on the definition, local and regional food systems represent a new economic sector that is indeed growing. There is insufficient evidence to indicate that the geographic definition of the system is growing whereas there seems to substantial growth specific to the qualitative definition and this system has spawned within the last 20 years.

My spatial analysis showed that there are differences in terms of the spatial structure (clustering) and distribution (proximity to the urban core) between producers who participate in the different systems. Local and regional producers tend to cluster closer together at smaller scales, are smaller in size and are found to be closer to the urban core than global producers. My qualitative research supported the finding that local and regional food producers do rely on being in close proximity to the urban core. I found that local and regional producers benefited extensively from agglomeration externalities 
stemming from the city. However, except for in two cases, producers rarely considered neighbors in farm location decisions. While they did benefit from close relations to neighbors, these benefits were realized whether the neighbor participated in local and regional supply chains or not. As such, the presence of a farm community was more important than neighbors who participated in similar supply chains. This indicates that land use laws like the one that established the UGB in the Portland Metro Region, while not directly benefiting small farms per se, do benefit farming communities more broadly which in turn can have indirect benefits to local and regional producers.

Additionally, information flows were essential for local and regional producers and depending on the supply chain in which they participated, local and regional producers accumulated knowledge in much different ways. In particular, producers who marketed their products exclusively through farmers' markets relied on the markets themselves as a primary source of information and were unlikely to benefit from pecuniary or nonpecuniary externalities from their neighbors. On the other hand, producers who marketed their products exclusively through CSA's tended to benefit from having close relationships with their neighbors. Notwithstanding, producers who participated in intermediated supply chains relied on more traditional sources of information (e.g. extension offices, ODA) but also benefited from their neighbors.

Finally, there are several theoretical reasons why local and regional food systems might contribute to regional economic development; however, the scale and extent of this 
impact is difficult to measure. Currently, there is little empirical research that accurately represents all of the potential benefits of local and regional food systems to regional economies. However there have been recent advances in modeling approaches that should shed light on some potential benefits, particularly as new data become available (e.g. 2012 Census of Agriculture).

To understand how local and regional food systems might contribute to regional economies, new approaches must break free of the theoretic confines of export-base. The purely geographic definition of local and regional foods is conceptually limited to the empirical frames of multipliers and import substitution. On the other hand, a qualitative definition of local and regional foods affords the opportunity for a richer exploration of regional economic development. The theoretical frames presented in Chapter II, when considered in aggregate constitute the underpinnings for how local and regional food systems might contribute to regional economies more broadly and aligns with what Markusen \& Schrock (2009) present as consumptive growth. They argue, a local consumption base can be a source of regional economic growth because: differences in regional tastes drive consumer spending in favor of goods and services that are locally produced; growth in local serving sectors may be amplified because the composition of inputs in these sectors may be more labor intensive and may create jobs filled by people whose propensity to spend locally is high and; innovations in local serving sectors may mature to the point of becoming exports and subsequently contribute to the export base. Perhaps most important however is that distinct local consumption-base offerings help to 
attract skilled workers, managers, entrepreneurs and retirees who bring human capital, companies and retirement incomes to the regional economy. It is this lens of endogenous growth that may prove helpful in eventually uncovering the potential contributions of local and regional foods to regional economies. 


\section{REFERENCES}

Allen, P., Fitzsimmons, M., Goodman, M. \& Warner, K. (2003). "Shifting Plates in the Agrifood Landscape: The Tectonics of Alternative Agrifood Initiatives in California." Journal of Rural Studies 19, no. 1. 61-75.

Anas, A., Arnott, R., Small, K., (1998). Urban spatial structure. Journal of Economic.Literature. 36, 1426-1464

Anselin, L., (2007). "Spatial Econometrics in RSUE: Retrospect and Prospect." Regional Science \& Urban Economics 37, no. 4: 450-456.

Anselin, L., (1998) Spatial econometrics: methods and models, Boston: Kluwer Academic.

Anselin, L. (1995). "Local indicators of spatial association - LISA". Geographical Analysis, 27, 93-115.

Anselin, L. \& Getis, A. (1992). Spatial statistical analysis and geographic information systems The Annals of Regional Science Vol 26(1), 19-3

Anselin L, Syabri I, Kho Y (2006). GeoDa: An Introduction to Spatial Data Analysis. Geographical Analysis, 38(1):5-22.

Anselin, L., Varga, A., \& Acs, Z. J. (2000). Geographic and sectoral characteristics of academic knowledge externalities. Papers in Regional Science, 79(4), 435-443.

Anselin, L., Varga, A., \& Acs, Z. (1997). Local geographic spillovers between university research and high technology innovations. Journal of urban economics, 42(3), 422448. 
Ahearn, M., \& Sterns, J. (2013). Direct-to-Consumer Sales of Farm Products: Producers and Supply Chains in the Southeast. Journal of Agricultural and Applied Economics, 45(03), pp. 497-508

Arrow, K. (1962), 'Economic Welfare and the Allocation of Resources for Invention', in R. Nelson (ed.), The Rate and Direction of Inventive Activity, Princeton, NJ, Princeton University Press.

Audretsch, B. (1998). Agglomeration and the location of innovative activity. Oxford Review of Economic Policy, 14(2), 18-29. doi:10.1093/oxrep/14.2.18

Bellows, A. \& Hamm, M. (2001) Local autonomy and sustainable development: Testing import substitution in localizing food systems. Agriculture and Human Values 18: $271-84$

Bertinelli, L., \& Decrop, J., (2005). Geographical Agglomeration: Ellison and Glaeser's index Applied to the Case of Belgian manufacturing Industry, Regional Studies 39(5): 567-583.

Bhatia, R., \& Jones, P. (2011). Supporting equitable food systems through food assistance at farmer's markets. The American Journal of Public Health, 101(5), 781.

Black, W. R. (1995). "Spatial interaction modeling using artificial neural networks", Journal of Transportation Geography. 3(3): 159-166.

Blay-Palmer, A. \& Donald, B. (2006) A tale of three tomatoes: the new food economies in greater Toronto. Economic Geography 82: 383-399. 
Bond, J. K., Thilmany, D., \& Bond, C. (2009). What influences consumer choice of fresh produce purchase location? Journal of Agricultural and Applied Economics, 41(1), $61-74$.

Born, B \& Purcell, M. (2006). Avoiding the local trap:: Scale and food systems in planning research. Journal of Planning Education and Research. 26 no. 2 195-207

Boys, K., \& Hughes, D. (2013). A Regional Economics-Based Research Agenda for Local Food Systems. Journal of Agriculture, Food Systems, and Community Development, 1-6.

Boyle, P., \& Flowerdew, R., (1997). Improving distance estimates between areal units in migration models, Geographical Analysis. 29(2): 94- 107.

Brown, L. (2013). ConAgra finalizes purchase of Ralcorp. St. Louis Post-Dispatch. January 29, 2013. Retrieved from: http://www.stltoday.com/business/local/conagrafinalizes-purchase-of-ralcorp/article_eeb2367d-78ec-58ea-aa6f-fa1626993552.html 6-13-2013

Brown, J. P., Goetz, S. J., Ahearn, M. C., \& Liang, C. -1. (2014). Linkages Between Community-Focused Agriculture, Farm Sales, and Regional Growth. Economic Development Quarterly, 28(1), 5-16.

Bruton, H. (1998). A Reconsideration of Import Substitution. Journal of Economic Literature. 36(2):903-936.

Christ, J.P. (2009). New Economic Geography Reloaded: Localized Knowledge Spillovers and the Geography of Innovation. FZID Discussion Papers. 01-2009 
City of Portland (2013). Portland Timeline: 1843 to 1901, City of Portland Auditor's Office, Accessed, 1-22-2014. http://www.portlandonline.com/auditor/index.cfm?c=26811\&a=11002 Chan, Y (2001). Location Theory and Decision Analysis. Thomson South-Western, New York, NY.

Christaller, W. (1966). Central Places in Southern Germany (C.W. Baskin, transl.). Englewood Cliffs, NJ: Prentice Hall.

Cliff, A.D., and Ord, J. K., 1981. Spatial Processes: Models and Applications. Pion, London. Duranton, Gilles and Overman, Henry G, 2002. "Testing for Localization Using Micro-Geographic Data," The Review of Economic Studies 72(4): 1077-1106 Cogan Owens Cogan (2012) Portland Regional Food System Economic Analysis. Western Sustainable Agriculture Research and Education. Retrieved from: http://mysare.sare.org/mySARE/assocfiles/954522App3\%20Food\%20System\%20Ec onomic\%20ProfileAug9.pdf (12-14-2013).

Combes, P.-P., \& Overman, H. G. (2004). Chapter 64 The spatial distribution of economic activities in the European Union. In J. Vernon Henderson and JacquesFrançois Thisse (Ed.), Handbook of Regional and Urban Economics (Vol. Volume 4, pp. 2845-2909). Elsevier.

Cross, R., Borgatti, S., \& Parker, A. (2001). Beyond answers: Dimensions of the advice network. Social Networks, 23(3), 215-235.

Daniels, T. (1999) When City and Country Collide: Managing Growth in the Metropolitan Fringe. Washington, DC: Island Press. 
Deller, S.C., \& Tsai, T.S.H.. (1999) An Examination of the Wage Curve: A Research Note. Journal of Regional Analysis and Policy. 28(2): 3-12.

Dimitri, C., Effland, A., Conkland, N. (2005). The 20 $0^{\text {th }}$ Century Transformation of U.S. Agriculture and Farm Policy USDA, ERS Information Bulletin 3.

Donald, B., Gertler, M., Gray, M., \& Lobao, L. (2010). Re-regionalizing the food system? Cambridge Journal of Regions, Economy and Society, 3(2), 171-175. doi:10.1093/cjres/rsq020

Duranton, G., \& Overman, H. G. (2008). Exploring the Detailed Location Patterns of U.k. Manufacturing Industries Using Microgeographic Data*. Journal of Regional Science, 48(1), 213-243.

Eigo, G., Engeman, R. H., \& Oregon Historical Society. (2002). A Market for the city: The history of Portland's public markets. Portland, OR: Oregon Historical Society. Elvin, D. (2008). An Analysis of Methods for Identifying Local Import Substitution Opportunities to Foster Sustainable Regional Economies. Masters Theses 141, University of Massachusetts.

Ericksen, P. J. (2008). Conceptualizing food systems for global environmental change research. Global Environmental Change, 18(1), 234-245.

Fearne, A., \& Hughes, D. (1999). Success factors in the fresh produce supply chain: insights from the UK. Supply Chain Management: An International Journal, 4(3), $120-131$.

Feenstra, G. (1997) Local food systems and sustainable communities. American Journal of Alternative Agriculture 12, 28-36. 
Feenstra, G., Lewis, C., Hinrichs, C., Gillespie, G., \& Hilchey, D. (2003). Entrepreneurial outcomes and enterprise size in U.S. retail farmers' markets. American Journal of Alternative Agriculture, 18, 46-55.

Fingleton, B., \& Lopez-Bazo, E. (2006). Empirical growth models with spatial effects. Papers in Regional Science, 85(2), 177-198.

Foltz, J. D., Jackson-Smith, D., \& Chen, L. (2002). Do purchasing patterns differ between large and small dairy farms? Econometric evidence from three Wisconsin communities. Agricultural and Resource Economics Review, 31(1), 28-38.

Foltz, J., \& Zeuli, K. (2005). The Role of Community and Farm Characteristics in Farm Input Purchasing Patterns. Review of Agricultural Economics, 27(4), 508-525.

Fotheringham, A.S. (1983). “A New Set of Spatial-Interaction Models: the theory of competing destinations", Environment and Planning A. Vol. 15. pp 15-36.

Fotheringham, A. Stewart and Chris Brundson. (1999). "Local Forms of Spatial Analysis", Geographical Analysis. 31(4): 340-355.

Friedmann, H. (2007). Scaling up: Bringing public institutions and food service corporations into the project for a local, sustainable food system in Ontario. Agriculture and Human Values, 24(3), 389-398.

Friedmann, H. (1993). The political economy of food: a global crisis. New Left Review, 29-29.

Food Institute (2013). Mergers and Acquisitions Report 2012: Despite Uncertain Times, Asset Swapping Continues. Food Institute. Retrieved from: 
http://www.foodprocessing.com/articles/2013/mergers-acquisitions-report/?start=1. $1-16-2014$

Fujita, M, Krugman, P., \& Venables, A. J. (1999), The Spatial Economy; Cities, Regions, and International Trade, Cambridge, MA, MIT Press.

Fujita, M., \& Thisse, J.F. (2001) Economics of Agglomeration: Cities, Industrial Location, and Regional Growth, Cambridge University Press, Cambridge, Gabeszewicz J.j., J.F. Thisse, M. Fujitta, U Schweizer, (1986) Location Theory (Fundamentals of Pure and Applied Ecomomics, Vol. 5). Harwood Publ. New York, NY.

Geary, R. C. (1954). The Contiguity Ratio and Statistical Mapping, The Incorporated Statistician 5 (3): 115-145.

Getis, A., \& Ord, J., (1992). The analysis of spatial association by use of distance statistics.Geographical Analysis, 24, 189-206.

Ghartey, E. E. (1993). Causal relationship between exports and economic growth: some empirical evidence in Taiwan, Japan and the US. Applied Economics, 25(9), 11451152.

Gibbon, P. (2003). Value-chain Governance, Public Regulation and Entry Barriers in the Global Fresh Fruit and Vegetable Chain into the EU. Development Policy Review, 21(5/6), 615 .

Gibson, J. R. (1985). Farming the frontier: The agricultural opening of the Oregon country, 1786-1846. Seattle: University of Washington Press. 
Glaeser, E. \& Ponzetto, G. (2008). Did the Death of Distance Hurt Detroit and Help New York? Harvard University. Harvard University WP-2007-08

Glaeser, E. L. \& Saiz, A. (2003). The Rise of the Skilled City. Harvard Institute of Economic Research. Discussion Paper Number 2025

Goodman, D. (2003). The quality 'turn' and alternative food practices: reflections and agenda. Journal of Rural Studies 19, 1-7.

Goodman, D. (2004). The Rural Europe Redux? Reflections on Alternative Agro-Food Networks and Paradigm Change. Sociologia Ruralis 44. 1, 3-16.

Graves, P.E. (1983) Migration with a Composite Amenity: The Role of Rents. Journal of Regional Science 23: 541-546.

Griliches, Z. (1979), Issues in assessing the contribution of R\&D to productivity growth, Bell Journal of Economics 10: 92-116.

Graff, T. \& Ashton, D., (1993). Spatial Diffusion of Wal-Mart: Contagious and Reverse Hierarchical Elements, Professional Geographer. 46(1): 19-29.

Guillain, Rachel and Le Gallo, Julie, (2007). "Agglomeration and dispersion of economic activities in Paris and its surroundings: An exploratory spatial data analysis," Regional Economics Applications Laboratory Discussion Paper 06-T-10

Hagerstrand, T. (1967). Innovation diffusion as a spatial process. Chicago: University of Chicago Press.

Halweil, B. (2004). Eat Here. Boston: W. W. Norton \& Company, Incorporated. Harvey, David (1989). The Condition of Post-Modernitity. Oxford University Press: Oxford, NY. 
Heffernan, W. \& Elder, S. (1987). Quality of life for farm families in metropolitan and nonmetropolitan counties. Pages 91-101IN W. Lockeretz (ed.), Sustaining agriculture near cities. Soil and Water Conservation Society, Ankeny, Iowa.

Hendrickson, M. \& Heffernan, W. (2002). Opening spaces through relocalization: locating potential resistance in the weaknesses of the global food system. Sociologia Ruralis 42, 347-69.

Hendrickson, M., Heffernan, W., Howard, P. \& Heffernan, J. (2001). Consolidation in food retailing and dairy. British Food Journal 103, 715-728.

Henneberry, S. R., Whitacre, B., \& Agustini, H. N. (2009). An evaluation of the economic impacts of Oklahoma farmers' markets. Journal of Food Distribution Research, 40, 64-78.

Henson, S., \& Reardon, T. (2005). Private agri-food standards: Implications for food policy and the agri-food system. Food policy, 30(3), 241-253.

Hesse, M., \& Rodrigue, J.-P. (2004). The transport geography of logistics and freight distribution. Journal of Transport Geography, 12(3), 171-184.

Hinrichs, C. (2003). The practice and politics of food system localization. Journal of Rural Studies 19, 33-45.

Hinrichs, C. (2000). Embeddedness and local food systems: notes on two types of direct agricultural market. Journal of Rural Studies 16, 295-303.

Hoehn, J.R., Berger, M. and Blomquist, C. (1987). A Hedonic Model of Interregional Wage, Rents, and Amenity Values. Journal of Regional Science 29(4): 605-620. 
Hughes, D. W., \& Isengildina-Massa, O. (2013). The impact of a buy local agriculture campaign on the South Carolina economy. Paper presented at the annual meeting of the Southern Regional Science Association, Washington, D.C.

Hughes, D. W., Brown, C., Miller, S., \& McConnell, T. (2008). Evaluating the economic impact of farmers' markets using an opportunity cost framework. Journal of Agricultural and Applied Economics, 40(1), 253-265.

Ikerd, J. (2005). Eating Local: A Matter of Integrity, presentation at The Eat Local Challenge kickoff event, Portland, OR, June 2, 2005.

Ilbery, B., \& Maye, D. (2005). Food supply chains and sustainability: evidence from specialist food producers in the Scottish/English borders. Land Use Policy, 22(4), $331-344$.

Ilbery, B., Watts, D., Simpson, S., Gilg, A., \& Little, J. (2006). Mapping local foods: Evidence from two English regions. British Food Journal, 108(3), 213-225.

Isard, W. (1956). Location and space-economy. Massachusetts Institute of Technology, Boston, MA.

Jacobs, J. (1969). The Economy of Cities, Random House, New York, NY.

Jun, M.-J. (2004). The effects of Portland's urban growth boundary on urban development patterns and commuting. Urban Studies, 41(7), 1333-1348.

Jung, W. S., \& Marshall, P. J. (1985). Exports, growth and causality in developing countries. Journal of development economics, 18(1), 1-12. 
Kim, K.-K., Marcouiller, D. W., \& Deller, S. C. (2005). Natural amenities and rural development: understanding spatial and distributional attributes. Growth and Change, 36(2), 273-297.

King, R., Hand, M., DiGiacomo, G., Clancy, K., Gomez, M., Hardesty, S., Lev, L., \& McLaughlin, E. (2010). Comparing the Structure, Size, and Performance of Local and Mainstream Food Supply Chains. Vol. 99, USDA, Economic Research Service.

Kline, J. \& Alig, R. (1999) Does land use planning slow the conversion of forest and farm lands, Growth and Change, 30, pp. 3-22.

Knapp, T. A. \& Graves, P.E. (1989). On the Role of Amenities in Models of Migration and Regional Development. Journal of Regional Science 29(1): 71-87.

Koc, M., \& Dahlberg, K. A. (1999). The restructuring of food systems: Trends, research, and policy issues. Agriculture and Human Values, 16(2), 109-116.

Lafourcade, Miren and Mion, Giordano (2007) Concentration, agglomeration and the size of plants. Regional science and urban economics, 37 (1). pp. 46-68.

Lindstrom, D. (1978). Economic Development in the Philadelphia Region, 1810-1850 (pp. 100-1). New York: Columbia University Press.

Lisansky, J. (1986). Farming in an urbanizing environment: agricultural land use conflicts and rights to farm, Human Organization, 45, 363-71.

Lockeretz, W., 1986. Urban consumers' attitudes towards locally grown produce. American Journal of Alternative Agriculture 1 (2), 83$\} 88$. 
Low, S. A., \& Vogel, S. (2011). Direct and intermediated marketing of local foods in the United States. ERR-128, U.S. Department of Agriculture, Economic Research Service,

Lowe, J.M. \& Sen, A. (1996). Gravity Model Applications in Health Planning: Analysis

Lucas, R. E.(1988). On the mechanics of economic development, Journal of Monetary

Economic, 22: 3-39.

Lummus, R. R., \& Vokurka, R. J. (1999). Defining supply chain management: a historical perspective and practical guidelines. Industrial Management \& Data Systems, 99(1), 11-17.

Lynch, L., \& Carpenter, J. (2003). Is there evidence of a critical mass in the Mid-Atlantic agriculture sector between 1949 and 1997?. Agricultural and Resource Economics Review, 32(1): 116-128.

Mangina, E., \& Vlachos, I. P. (2005). The changing role of information technology in food and beverage logistics management: beverage network optimisation using intelligent agent technology. Journal of Food Engineering, 70(3), 403-420.

Markusen, A., \& Schrock, G. (2009). Consumption-Driven Urban Development. Urban Geography, 3(4): pp 344-367.

Marsden, T., Banks, J., \& Bristow, G. (2000). Food supply chain approaches: exploring their role in rural development." Sociologia ruralis 40.4: 424-438.

Marsden, T.K. Murdoch, J. \& Morgan, K. (1999): Sustainable agriculture, food supply chains and regional development: editorial introduction. International Planning Studies 4, 295-301. 
Marshall, A. (1890). Principles of Economics. London: Macmillan.

Martinez, S. (2010). Local food systems; concepts, impacts, and issues. Economic Research Report No. (97) U.S. Department of Agriculture, Economic Research Service.

Metro (2010) County tax assessors tax lot spatial data, Regional Land Information System (RLIS).

Moran, P. A. P. (1950). "Notes on Continuous Stochastic Phenomena". Biometrika 37 (1): 17-23.

Morris, C., \& Buller, H. (2003). The local food sector: A preliminary assessment of its form and impact in Gloucestershire. British Food Journal, 105(8), 559-566.

Mottomley, P. A. and R. Fildes. (1998). The role of prices in models of innovation diffusion, Journal of Forecasting. Vol. 17. pp. 539-559. Sugiura, Y. 1993. "Spatial diffusion of Japanese electric power companies, 1887-1906: a discrete choice modeling”, Annals of Association of American Geographer. 83(4): 641-655.

Murdoch, J., Marsden, T., \& Banks, J., (2000). Quality, nature, and embeddedness: some theoretical considerations in the context of the food sector. Economic Geography 76 (2), 107-125.

Murnion, S. and R. G. Healey. (1998) Modeling distance decay effects in web server information flows, Geographical Analysis. 30(4): 285-303.

Nickel, S, J. Puerto, (2005), Location Theory: A Unified Approach, Springer, New York, NY. 
Nelson, A. C., \& Moore, T. (1993). Assessing urban growth management: The case of Portland, Oregon, the USA's largest urban growth boundary. Land Use Policy, 10(4), 293-302.

North, D. C.,(1956) Exports and Regional Economic Growth: A Reply. Journal of Political Economy, 64: 165.

North, D.C., (1955) Location Theory and Regional Economic Growth, Journal of Political Economy 63:243-258.

O’Hara, J., \& Pirog, R. (2013). Economic Impacts of Local Food Systems: Future Research Priorities. Journal of Agriculture, Food Systems, and Community Development, 1-8.

Openshaw S. (1984). The Modifiable Areal Unit Problem. GeoBooks, Norwich, UK Oregon Encyclopedia (2008). Oregon History and Culture, Portland Public Market Portland State University. Accessed: 2-12-2014. http://www.oregonencyclopedia.org/entry/view/portland_public_market/

Otto, D. \& Varner, T. (2005). Consumers, vendors, and the economic importance of Iowa farmers' markets: An economic impact survey analysis. Ames, Iowa: Iowa State University, Leopold Center for Sustainable Agriculture. Retrieved from http://www.leopold.iastate.edu/ 12-08-2013.

Pellegrini, G., Terribile, F., Tarola, O., Muccigrosso, T., \& Busillo, F. (2013). Measuring the effects of European Regional Policy on economic growth: A regression discontinuity approach. Papers in Regional Science, 92(1), 217-233. 
Pooler, James. (1993). “Structural Spatial Interaction”, Professional Geographer. 45(3): 297-305.

Porter, M. (1998). Clusters and the new economics of competition (Vol. 76, No. 6, pp. 77-90). Boston: Harvard Business Review.

Porter, M. (1990), The Comparative Advantage of Nations, New York, Free Press.

Regmi, A., \& Gehlhar, M. (2005). Processed food trade pressured by evolving global supply chains. Amber Waves, 3(1), 12-19.

Renting, H., Marsden, T.K. \& Banks, J. (2003). Understanding alternative food networks: exploring the role of short food supply chains in rural development. Environment and Planning A 35, 393-411.

Rey, S. J. (2006). Recent Advances in Software for Spatial Analysis in the Social Sciences. Geographical Analysis 38, no. 1: 1-4.

Rey, S. J. (2004). Spatial Analysis and Income Inequality. In Spatially Integrated Social Science eds. Goodchild, M. and D. Janelle, Oxford Press, New York, NY.

Rey, S.J. and L. Anselin (2007). PySal: A Python Library of Spatial Analytical Methods. The Review of Regional Studies Vol.37(1): 5-27

Romer, P. M. (1994), The Origins of Endogenous Growth, Journal of Economic Perspectives 8(1): 3-22.

Romer, P. M. (1986), Increasing returns and long-run growth, Journal of Political Economy 94(5): 1002-37.

Rosenthal, S. and W. Strange(2004), Chapter 49 Evidence on the nature and sources of agglomeration economies, In: J. Vernon Henderson and Jacques-Francois Thisse, 
Eds, Handbook of Regional and Urban Economics, Elsevier, Vol. 4, Cities and Geography: 2119-2171

Rosenthal, S., \& Strange, W., (2001). "The Determinants of Agglomeration,” Journal of Urban Economics 50: 191-229.

Ross, N. J., Anderson, M. D., Goldberg, J. P., Houser, R., \& Rogers, B. L. (1999). Trying and buying locally grown produce at the workplace: results of a marketing intervention. American Journal of Alternative Agriculture, 14(4), 171-179.

Ruttan, V.W. (1955). The impact of urban-industrial development on agriculture in the Tennessee Valley and the Southeast. Journal of Farm Economics, 37: 38-56.

Schultz, T.W. (1951.) A Framework for Land Economics-The Long View. Journal of Farm Economics 33 pp. 204-215.

Selfa, T \& Joan Qazi. (2005). Place, taste, or face to face? Understanding producerconsumer networks in "local" food systems in Washington State. Agriculture and Human Values. 22: 451-464

Senauer, B., \& Venturini, L. (2005). The globalization of food systems: A conceptual framework and empirical patterns. Food Industry Center, University of Minnesota. Retrieved from http://ageconsearch.umn.edu/bitstream/14304/1/tr05-01.pdf, 2-242013.

Sexton, R. J. (2000). Industrialization and consolidation in the US food sector: Implications for competition and welfare. American Journal of Agricultural Economics, 1087-1104. 
Sharma, S. C., Norris, M., \& Cheung, D. W. W. (1991). Exports and economic growth in industrialized countries. Applied Economics, 23(4), 697-708.

Sobal, J., Kettel Khan, L., \& Bisogni, C. (1998). A conceptual model of the food and nutrition system. Social Science \& Medicine, 47(7), 853-863.

Sonnino, R., \& Marsden, T. (2006). Beyond the divide: rethinking relationships between alternative and conventional food networks in Europe. Journal of Economic Geography, 6(2), 181-199.

Swenson, D. 2009. Investigating the Potential Economic Impacts of Local Foods for Southeast Iowa. Ames, IA: Leopold Center for Sustainable Agriculture.

Swenson, D. (2008). Estimating the production and market-value based impacts of nutritional goals in NE Iowa. Ames, IA: Leopold Center for Sustainable Agriculture.

Swenson D. (2006). The Economic Impacts of Increased Fruit and Vegetable Production and Consumption in Iowa: Phase II. Ames, Iowa. Regional Food Systems Working Group Leopold Center for Sustainable Agriculture, Iowa State University;. Retrieved from: http://www.leopold.iastate.edu/pubs/staff/files/health_0606.pdf. 3- 3-2013.

Tess, J. M. (1977). Uphill downhill Yamhill: The evolution of the Yamhill Historic District in Portland, Oregon. Portland, Or.

Thomson, S. (1997) Adaptive sampling in behavioural surveys, NIDA Research Monograph, 296-319

Tiebout, C. M. (1962). Community Economic Base Study. New York, NY: Committee for Economic Development. 
Tiebout, C.M. (1956) Exports and Regional Economic Growth, Journal of Political Economy 64:160-169.

Trobe, H. L. (2001). Farmers' markets: consuming local rural produce. Journal of Consumer Studies and Home Economics, 25(3), 181-192.

U.S. Bureau of Economic Analysis (2012), Regional Economic Accounts. Retrieved from https://www.bea.gov/iTable/index_regional.cfm . 11-28-2013.

U.S. Commerce Department, Census Bureau (2013) Annual Survey of Manufacturers. Current Industrial Reports. Retrieved from: http://www.census.gov/manufacturing/m3/ 8-19-2013

U.S. Commerce Department, Bureau of Census (2010). 2010 U.S. Census. Retrieved from http://quickfacts.census.gov/qfd/states/41000.html 7-16-2013.

USDA Agricultural Marketing Service. (2012). Farmers markets and local food marketing. Retrieved from http://www.ams.usda.gov/AMSv1.0/FarmersMarkets (February 11, 2014)

USDA Economic Research Service (2010) State Export Data: Total agricultural exports by State, last 5 fiscal years. Retrieved from: http://www.ers.usda.gov/Data/StateExports/. 4-9-2012

USDA Economic Research Service (2010). Oregon State fact sheet: Leading commodities by cash receipts. Accessed from: http://www.ers.usda.gov/statefacts/OR.HTM. 4-2-2012

USDA National Agricultural Statistics Service (2011). Oregon Agriculture: Facts and Figures. Retrieved from: 
http://www.nass.usda.gov/Statistics_by_State/Oregon/Publications/facts_and_figures/ facts_and_figures.pdf March 27, 2012.

USDA National Agricultural Statistics Service (2008). 2007 Census of Agriculture:

Volume 1, U.S. Summary and State Reports. Accessed from:

http://www.agcensus.usda.gov/Publications/2007/Full_Report/.3-30-2012

USDA National Agricultural Statistics Service (2008). USDA Census of Agriculture Historical Archive (1910-1987). Albert R. Mann Library, Cornell University. Retrieved from: http://agcensus.mannlib.cornell.edu/AgCensus/ . 3-30-2012

Valente, T. W. (1996). Social network thresholds in the diffusion of innovations. Social Networks, 18(1), 69-89. doi:10.1016/0378-8733(95)00256-1

Vogel, S., (2012). Multi-Enterprising Farm Households: The Importance of Their Alternative Business Ventures in the Rural Economy, U.S. Department of Agriculture, Economic Research Service., EIB-101

Von Thünen, J.H. 1966 (1826). Isolated State; an English edition of Der isolierte Staat. Translated by Carla M. Wartenberg. Pergamon Press, Oxford, New York.

Wagner, W.B. 1974. "A longitudinal study of retail gravitation between Columbus and Springfield, Ohio", Bulletin of Business Research, The Ohio State University. Vol. 49, No. 2.

Watts, D.C.H., Ilbery, B. \& Maye, D. (2005): Making reconnections in agro-food geography: alternative systems of food provision. Progress in Human Geography 29, $22-40$.

Weber, A.(1909) [translated by Friedrich, C., 1929]. Theory of the Location of Industries. 
Chicago: The University of Chicago Press, 1929.

Whaley, G. (2010). Oregon and the Collapse of Illahee: U.S. Empire and the

Transformation of an Indigenous World, 1792-1859. Chapel Hill: The University of North Carolina Press.

Winter, M. (2003). Embeddedness, the new food economy and defensive localism.

Journal of Rural Studies, 19(1), 23-32.

Wrigley, N., Coe, N. M., \& Currah, A. (2005). Globalizing retail: conceptualizing the distribution-based transnational corporation (TNC). Progress in Human Geography, 29(4), 437-457.

Ziobro, Paul. (2013) ConAgra CEO: Pieces in Place for Food Industry Consolidation. Euroinvester. Retrieved from http://www.euroinvestor.com/news/2013/02/19/conagra-ceo-pieces-in-place-forfood-industry-consolidation/12215330. 8-16-2013. 


\section{APPENDIX A: CLACKAMAS COUNTY AGRICULTURAL OPPORTUNITIES ASSESSMENT: PRODUCER SURVEY QUESTIONS}

Table A.1: Producer survey questions and response rate

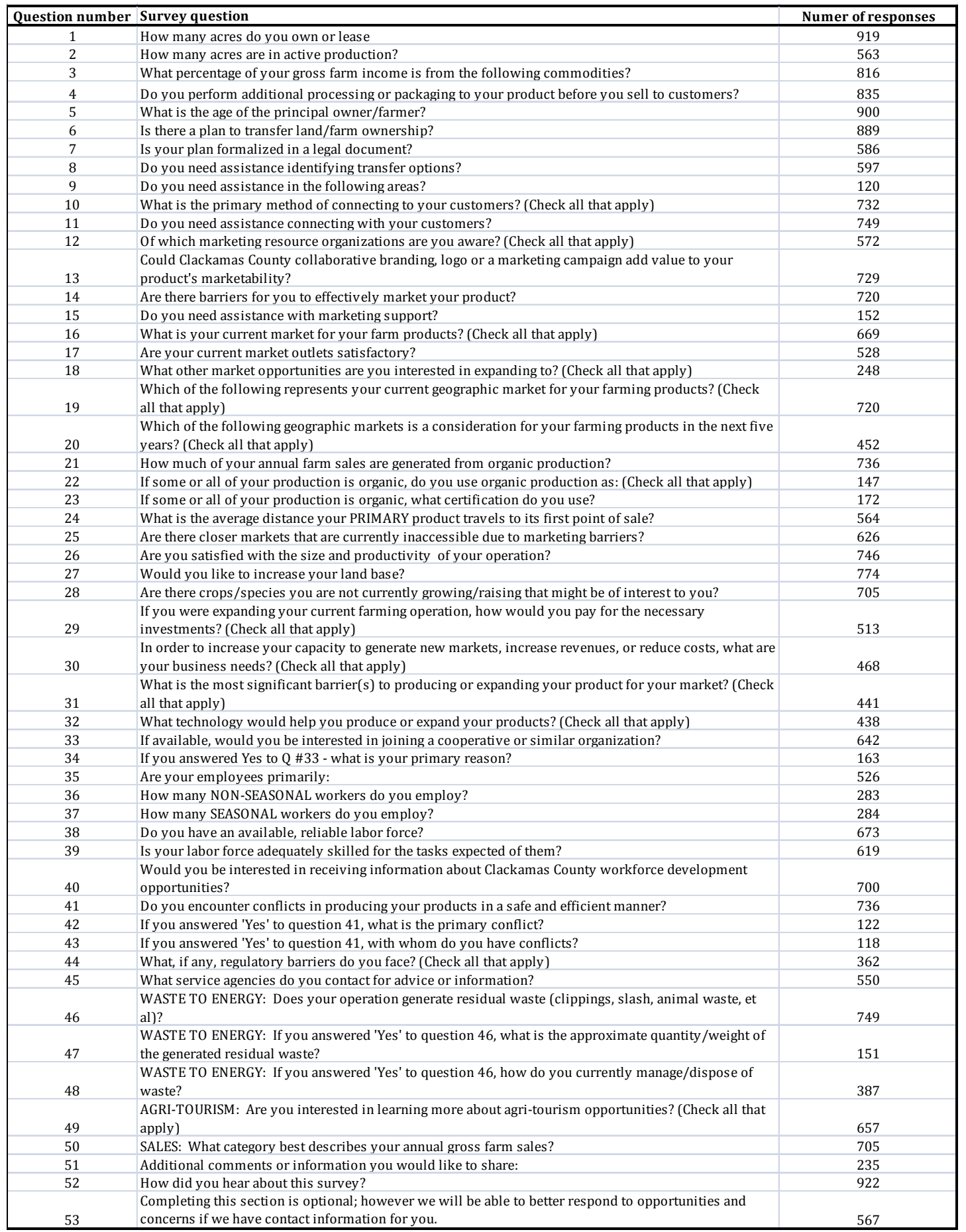




\section{APPENDIX B: CLACKAMAS COUNTY AGRICULTURAL OPPORTUNITIES ASSESSMENT: PROCESSOR / DISTRIBUTOR SURVEY QUESTIONS}

Table B.1: Processor / Distributor survey questions and response rate

\begin{tabular}{|c|c|c|}
\hline $\begin{array}{c}\text { Question } \\
\text { number }\end{array}$ & Survey question & $\begin{array}{l}\text { Number of } \\
\text { responses }\end{array}$ \\
\hline 1 & Contact information & 34 \\
\hline 2 & Which of the following best describes your business? & 33 \\
\hline 3 & Please categorize your company's manufacturing and processing operations. & 33 \\
\hline 4 & Which of the following is the primary market for your company? & 34 \\
\hline 5 & What is the ownership structure of your company? & 33 \\
\hline 6 & $\begin{array}{l}\text { What were your company's annual total production sales for the fiscal year ending in } \\
2010 \text { ? }\end{array}$ & 33 \\
\hline 7 & Which answer best describes your company's export activity? & 31 \\
\hline 8 & $\begin{array}{l}\text { What percent of your company's gross annual sales revenue is attributed to export } \\
\text { sales? }\end{array}$ & 16 \\
\hline 9 & What percent of your company's revenue is from the following market sectors? & 31 \\
\hline 10 & To which countries does your company export? & 12 \\
\hline 11 & To which countries do you want to export? & 9 \\
\hline 12 & How far do you ship your goods? & 30 \\
\hline 13 & $\begin{array}{l}\text { Which of the following best describes the food processing or distribution industry } \\
\text { sector your business operates? }\end{array}$ & 24 \\
\hline 14 & $\begin{array}{l}\text { What is the principal food processing activity of your establishment based on } \\
\text { proportion of annual total food sales? }\end{array}$ & 29 \\
\hline 15 & $\begin{array}{l}\text { From the list of food industry issues and trends defined below, please rate on how } \\
\text { they impact your company's bottom line performance. }\end{array}$ & 33 \\
\hline 16 & $\begin{array}{l}\text { How important do you believe a coordinated regional "brand" approach can be for the } \\
\text { agricultural industry? }\end{array}$ & 33 \\
\hline 17 & Where are your suppliers located? & 32 \\
\hline 18 & What, if any, challenges do you face using Clackamas County suppliers? & 20 \\
\hline 19 & $\begin{array}{l}\text { How many employees (including permanent, seasonal and casual, but excluding } \\
\text { contract employees) did your business employ during its last fiscal year ending in } \\
2010 \text { ? }\end{array}$ & 34 \\
\hline 20 & Do you have an available, reliable labor force? & 34 \\
\hline 21 & Is your labor force adequately skilled for the tasks expected of them? & 34 \\
\hline 22 & $\begin{array}{l}\text { Would you be interested in receiving information about Clackamas County workforce } \\
\text { development resources? }\end{array}$ & 34 \\
\hline
\end{tabular}




\section{APPENDIX C: SAMPLE QUESTIONS FOR OPEN ENDED INTERVIEWS WITH FOOD SYSTEM ACTORS}

\section{Questions for producers:}

This set of questions is meant as a starting point for discussion - The interviews are intended to be semi-structured meaning, I will allow derivations in my line of questioning. The primary purpose of the interviews is to gain an understanding of firm level characteristics in regards to sources of knowledge accumulation, types of innovations and system level interactions (e.g. markets, distribution channels etc.). As such my questions will focus on three general areas of interest: generally background information of the operator, market specific information, and aspects of innovation.

\section{Background}

- What is your background? (i.e. where were you raised, how long have you been farming, educational background, general interests).

- Why did you get involved with farming?

- What led you to look to local markets to market your food?

\section{Market specific questions}

- What is your primary geographic target for your products?

- Do you think markets for local products are increasing?

- Do you have a working definition (geographic scope) of local / regional?

- What are your primary outlets for your products?

- Why do you think your customers purchase your product (or other local food products) instead of products at large outlet grocery stores? 


\section{Innovation}

- How often do you experiment with new products?

- When you do experiment with new products, where do you come up with the idea of what types of products to experiment with?

- What is your main source of information regarding; distribution channels, products, best practices, and markets. 


\section{APPENDIX D: SUPPLEMENTAL ANALYSES TO SUPPORT DISSERTATION}

\section{D.1: TESTING FOR VIOLATIONS OF REGRESSION ASSUMPTIONS IN THE TIME SERIES ANALYSIS.}

I used time series data between 1949 and 2007 (every five years) derived from USDA historic censes of agriculture to observe trends in farmland related to urbanization (as expressed by population growth). With an unusually small sample size $(n=14)$ I was unable to use robust models (e.g. autoregressive integrated moving averages) typically used for time series analysis. I therefore applied an ordinary least squares (OLS) model paying close attention to violations of the assumptions of linear regression. Of special concern in time series analysis are violations of independence. Also known as serial correlation of the residuals, this is where there is some inherent trend in the dependent variable that is not accounted for in the specification. To test for serial correlation I used the Box-Pierce test. The Box-Pierce test examines the Null of independently distributed residuals. It is derived from the idea that the residuals of a correctly specified model are independently distributed. If the residuals are no, then they come from a miss-specified model. I performed the Box-Pierce test for both the model that evaluated the influence of population on the proportion of small farms as well as the model that tested the influence of the UGB on the proportion of small farms (when population was controlled for). The results were as follows: 
Effects of population on proportion of small farms.

Box-Pierce test

$\mathrm{X}$-squared $=2.7649, \mathrm{df}=1, \mathrm{p}$-value $=0.09635$

Effects of the UGB on proportion of small farms (when population was controlled for).

Box-Pierce test

$\mathrm{X}$-squared $=1.5235, \mathrm{df}=1, \mathrm{p}$-value $=0.2171$

The test was not significant for the latter model and only marginally significant for the former $(\mathrm{p}=.09635)$ indicating serial correlation was not a concern once the UGB was considered in the analysis.

\section{D.2: CORRELATION BETWEEN PARCEL SIZE AND DISTANCE TO THE URBAN CORE}

I summarized the mean distance value developed in section 5.4 for a sample of parcels throughout the Three County Region $(n=1,577)$. I also recorded which of these parcels were contained within the UGB. I specified an OLS regression model regressing parcel size on distance to the urban core and whether or not it was within the UGB. While only $21 \%$ of the variance was explained by these two variables, they were both highly significant. As expected, there was a positive relationship between parcel size and distance to the urban core, and a negative relationship between parcel size and the UGB 
(indicating parcel sizes were smaller inside the urban core). Table D.1 shows the regression coefficients from the analysis.

Table D.1: Parameter estimates for parcel size and distance relationship

\begin{tabular}{|r|r|r|r|}
\hline \multicolumn{1}{|l|}{ Residuals: } & & & \\
\hline Min 1Q & Median & 3Q & Max \\
\hline-94.84 & -3.22 & 7.43 & 571.38 \\
\hline
\end{tabular}

\begin{tabular}{|l|r|r|r|l|l|}
\hline & \multicolumn{1}{|l|}{ Estimate } & Std. Error & t value & $\operatorname{Pr}(>|t|)$ & \\
\hline (Intercept) & -22.672 & 6.4193 & -3.532 & 0.000425 & $* * *$ \\
\hline MEAN & 1.8191 & 0.1547 & 11.759 & $<2 \mathrm{e}-16$ & $* * *$ \\
\hline UGB_DUM & -15.3215 & 3.7078 & -4.132 & 0.0000378 & $* * *$ \\
\hline Residual standard error: 51.3 on 1574 degrees of freedom \\
Multiple R-squared: 0.2144, Adjusted R-squared: 0.2134 \\
F-statistic: 214.8 on 2 and 1574 DF, p-value: < 2.2e-16 \\
\hline
\end{tabular}




\section{APPENDIX E: EMPLOYMENT IN FOOD RELATED ESTABLISHMENTS IN THE THREE COUNTY REGION}

The U.S. Bureau of Economic Analysis (BEA) reports job growth by North American Industry Classification (NAICS) codes. It can be challenging to assess total employment within the food system using the standard industry codes reported by BEA because food business related employment must in some cases be estimated from aggregated categories. However, considering the BEA data is the only data available that allows for the assessment of trends in food related industries, I provide a brief summary of the data to describe employment within the food sector. I extracted the food related businesses from the retail trade, transportation and warehousing, farm support services, food service, wholesalers, farming and manufacturing NAICS codes. Table E.1 shows the NAICS codes and associated industry classifications used to summarize food system related employment in the Three County Region. 
Table E.1: NAICS codes used to determine food system employment

\begin{tabular}{|l|l|l|}
\hline Code & Industry & Sector \\
\hline 1111 & Oilseed and Grain Farming & Agriculture \\
\hline 1112 & Vegetable and Melon Farming & Agriculture \\
\hline 1113 & Fruit and Tree Nut Farming & Agriculture \\
\hline 112 & Animal Production and Aquaculture & Agriculture \\
\hline 311 & Food Manufacturing & Agriculture \\
\hline 4244 & Grocery and Related Product Merchant Wholesalers & Wholesale \\
\hline 4245 & Farm Product Raw Material Merchant Wholesalers & Wholesale \\
\hline 42491 & Farm Supplies Merchant Wholesalers & Wholesale \\
\hline 483211 & Inland Water Freight Transportation & Transportation \\
\hline 48411 & General Freight Trucking, Local & Transportation \\
\hline 48422 & Specialized Freight (except Used Goods) Trucking, & Transportation \\
\hline 49312 & Refrigerated Warehousing and Storage & Warehousing \\
\hline 49313 & Farm Product Warehousing and Storage & Warehousing \\
\hline 4451 & Grocery Stores & Retail \\
\hline 4452 & Specialty Food Stores & \\
\hline 7223 & Restaurants and Other Eating Places & \\
\hline 7225 & & Recial Food Services \\
\hline
\end{tabular}

In 2011 food related employment accounted for a total of 111,210 , or roughly $15.4 \%$ of total employment across 12,132 businesses (including 6,380 farms) for the Three County Region. The vast majority of these jobs were in food service related businesses $(57,002$ or roughly $51 \%$ ). Food retail and farm employment accounted for roughly $15 \%$ and $13 \%$ 
of total employment respectively. Table E. 2 shows the employment, payroll and number of businesses by industry.

Table E.2: Regional food system employment by sector

\begin{tabular}{|l|r|r|r|}
\hline Sector & \multicolumn{1}{|c|}{ Jobs } & Payroll (\$1,000) & \multicolumn{1}{|c|}{ Businesses } \\
\hline Farming & 14,530 & $235,000^{*}$ & 6,380 \\
\hline Food retail & 16,826 & 397,156 & 872 \\
\hline Freight trucking & 5,697 & 231,940 & 394 \\
\hline Warehousing & 3,524 & 168,912 & 110 \\
\hline Food service & 57,002 & na & 3,917 \\
\hline Wholesalers & 6,343 & 307,999 & 206 \\
\hline Food manufacturing & 7,145 & 289,503 & 211 \\
\hline Total & 111,069 & $1,395,510$ & 12,089 \\
\hline
\end{tabular}

*estimated from USDA NASS 2007 Census of Agriculture

The data demonstrate the importance of food outlets (food service and retail) for the system as a whole, but also highlight the importance of intermediaries. This shows how, if local food strategies are to be fostered, consideration of intermediated channels is of importance. The multiplier effects of intermediated local and regional products need to be accounted for in any analysis. While previous work has analyzed the multiplier effects of direct to market supply chains, these account for a very small proportion of the food economy. 
Furthermore, the portion of farm employment is important as many of these farms represent employment in the rural periphery. In 2011, farm employment accounted for a total of 14,530 jobs, roughly $1.3 \%$ of total jobs in the Three County Region. From 2001 to 2011, there was a net decrease in farm employment in terms of both net jobs and the share of total jobs. The Region lost 242 total jobs related to farm employment, a decrease of $4.4 \%$ over the 10 year period. This represents a $13.89 \%$ decrease had it grown at the same rate as its counterpart at the national level since 2001.

Much of the employment in the farm sector however is seasonal. Specific questions pertaining to seasonal employment were part of The Clackamas Producers' survey. The survey indicated that farmers and their families are the primary labor source for farming operations. $72 \%$ of respondents indicated their main source of labor is non-seasonal, local or family employees. Only $27 \%$ of respondents employed non-seasonal workers and $32 \%$ employed seasonal workers. The majority of those respondents that did report they employed seasonal or non-seasonal workers reported employing between 1 and 5 laborers.

According the USDA 2007 Census of Agriculture, in the Three County Region, a total of 1,902 farms employed seasonal or non-seasonal workers and a total payroll of just over $\$ 235$ million dollars. This constitutes only the fourth largest payroll of jobs by food sector (behind retail, wholesale and food manufacturing). This indicates jobs associated with on-farm work are lower paying than jobs in the other sectors. 


\section{APPENDIX F: AGRICULTURAL PRODUCER CHARACTERISTICS IN CLACKAMAS COUNTY}

In this section I present characteristics of food producers in the Portland Metro Region using data specific to Clackamas County agricultural producers. The data is from a survey conducted by Clackamas County in 2011. This dataset is used extensively throughout this dissertation and is described in detail in the following chapter.

I used the Clackamas County Agricultural Producers Survey (the Survey) for my analysis. While this survey can be considered representative for the County (see the data section in the next chapter), there are aspects of production in Clackamas County that are significantly different than the other two counties in the region (total agricultural output, livestock production, nursery stock and Christmas tree production). Regardless, the dataset offers a unique opportunity to highlight some of the differences between local and non-local food producers regardless of marketing channel here in the Portland area because it explicitly asked the question of whether products are sold locally.

For my analysis, I stratified the database according to a variety of segments to test measures of scale, locality, food production and economic efficiency. My primary analysis focused on differences between local and non-local producers however I also evaluated key characteristics between food producers and non-food producers as well as diversified producers and the scale of operations. 


\section{F.1: FOOD GROWERS AND NON-FOOD GROWERS}

Clackamas County is made up of a wide variety of agricultural producers and the Clackamas County Agricultural Producers' Survey (the Survey) included a sample of all agricultural producers in the County. Table F.1 shows total agricultural output by type for all three counties in the region as well as the food production rates. ${ }^{22}$ While Clackamas County is the most diverse in terms of total number of products in the State (OSU, 2012), their food production rate is roughly equivalent to Multnomah County ( $27 \%$ food v. non food compared to $26 \%$ for Multnomah County) and only slightly higher than Washington county (24\%). The food production rate for the three county region is $26.1 \%$ - a rate that has remained fairly consistent for the last two decades (USDA, NASS Census of Agriculture)

\footnotetext{
${ }^{22}$ Food production rate represents the proportion of total agricultural output that's associated with food products not including inputs to food production such as hay, silage or other feeds.
} 
Table F.1: Agricultural output for the Three County Region and food production rates*

\begin{tabular}{|l|c|c|c|c|}
\hline Product & Clackamas & Multnomah & Washington & Total \\
\hline Total value of ag products sold & 397,318 & 84,546 & 311,380 & 793,244 \\
\hline $\begin{array}{l}\text { Value of crops including nursery \& } \\
\text { greenhouse }\end{array}$ & 335,357 & 81,689 & 295,001 & 712,047 \\
\hline $\begin{array}{l}\text { value of livestock, poultry and their } \\
\text { products }\end{array}$ & 61,961 & 2,858 & 16,379 & 81,198 \\
\hline Grains, oilseeds, dry beans & 549 & 473 & 8,036 & 9,058 \\
\hline Vegetables, melons, potatoes & 19,212 & 11,774 & 6,874 & 37,860 \\
\hline Fruits, tree nuts and berries & 27,567 & 7,567 & 52,551 & 87,685 \\
\hline Nursery, greenhouse and sod & 227,114 & 60,177 & 199,317 & 486,608 \\
\hline Christmas trees & 46,898 & 217 & 3,213 & 50,328 \\
\hline Other crops and hay & 14,017 & 1,482 & 25,009 & 40,508 \\
\hline Poultry and eggs & 41,067 & 29 & 588 & 41,684 \\
\hline Cattle and calves & 7,985 & 852 & 3,559 & 12,396 \\
\hline Milk and other dairy products & 4,859 & 0 & 7,645 & 12,504 \\
\hline Hogs and pigs & 994 & 11 & 466 & 1,471 \\
\hline Sheep and goats & 689 & 51 & 96 & 836 \\
\hline Horses & 2,306 & 608 & 989 & 3,903 \\
\hline Aquaculture & 516 & 0 & 100 & 616 \\
\hline other animals and animal products & 3,546 & 255 & 2,937 & 6,738 \\
\hline Total food** & 103,438 & 20,757 & 79,915 & 204,110 \\
\hline Total non-food & 293,881 & 62,739 & 231,465 & 588,085 \\
\hline Food production ratio & $35.20 \%$ & $33.08 \%$ & $34.53 \%$ & $34.71 \%$ \\
\hline Food production ratio not including \\
grains & $34.95 \%$ & $32.09 \%$ & $30.01 \%$ & $32.66 \%$ \\
\hline
\end{tabular}

\footnotetext{
*2007 dollars

**Food production rate is the proportion of value for livestock and poultry products, fruits and nuts and vegetable, melons, potatoes and sweet potatoes relative to the total value of agricultural products Source: USDA NASS 2007 Census of Agriculture.
} 
While total value of products was not collected as part of the Survey (only proportion of value that any crop represented), I used the number of respondents, weighted by the proportion of the value of the crop grown times the acres under production to estimate the food production rate equivalent from the survey. Expressed as:

$$
R s=\frac{\sum_{n=1}^{r} \sum_{n=1}^{i} p_{i}{ }^{*} A_{r}}{\sum_{n=1}^{r} A_{r}}
$$

(equation F.1)

Where:

$\mathrm{R} s$ is the Food production rate derived from the survey

$\mathrm{P}$ is the proportion of each crop (c) for each respondent (r) and;

A is the total acres under production for each respondent.

Based on this calculation, the results exhibited similar food production rates for Clackamas County (33\%) as well as proportion of non-livestock and poultry product foods (i.e. vegetables, fruits and nuts and berries). Furthermore, I evaluated the number of respondents who were considered food growers. Respondents were allowed to indicate multiple crops for a single property (farm) and I considered a respondent a food grower based on whether the sum of food crops (in terms of proportion of value) constituted at least $15 \%$ of the total value of production for any given respondent. Of the food growers, livestock was the most common product identified in the Survey, representing the majority respondents: 170 or roughly $17 \%$ of all respondents. This closely mimics the 
proportion of the number of livestock producers for Clackamas County recorded in the 2007 Census of Agriculture (15.5\%) however is significantly higher than the proportion of livestock producers at the Three County scale (10\%). Table F.2 shows the number of respondents by agricultural crops based on number of respondents reporting either the majority of value from a given food crop as well as any value reported from that food crop.

Table F.2: Number of respondents from the Survey reporting by product type

\begin{tabular}{|l|c|c|}
\hline Product type & Mujority & Any \\
\hline & 26 & 54 \\
\hline Berry farmers & 170 & 264 \\
\hline Livestock & 7 & 73 \\
\hline Egg producers & 34 & 66 \\
\hline Fruit and nut producers & 27 & 65 \\
\hline Vegetable farmers & 264 & 522 \\
\hline Total & & \\
\hline
\end{tabular}

Food growers were found to be more likely to sell either some of their product or all of their products locally (54\% of food growers reported selling their entire product locally whereas only $39 \%$ of non-food growers reported selling all their products locally $\left(\chi^{2}(1)=35.47, \mathrm{p}<0.001\right)$. Food growers are also more likely to grow more than a single product category ( $30 \%$ relative to $\left.21 \%, \chi^{2}(1)=7.86 \mathrm{p}<0.01\right)$, and perceive fewer market barriers than non-food growers (only $21 \%$ of food growers stated they had significant 
barriers to market penetration whereas $26 \%$ of non-food growers perceived barriers to markets, $\left.\chi^{2}(1)=2.79, \mathrm{p}<0.1\right)$. However, food growers are no more likely to sell direct than non-food growers $\left(\chi^{2}(1)=0.198, \mathrm{p}>0.1\right) .^{23}$

${ }^{23}$ Many non-food production operations include production of hay that was sold directly to neighbors or operators of livestock or equestrian operations in close proximity, or Christmas tree operations through ucut sales. 